Sérgio Ferreira da Silva

\title{
Identificação de Torque de Carga em Motores de Indução Usando Abordagem Baseada em Sistemas Fuzzy
}

Dissertação apresentada à Escola de Engenharia de São Carlos da Universidade de São Paulo, sendo parte dos requisitos para obtenção do título de Mestre em Engenharia Elétrica.

Orientador: Prof. Dr. Ivan Nunes da Silva

São Carlos 

"Vede que ninguém dê a outrem mal com mal, mas segui sempre o bem, tanto uns para com os outros, como para com todos.”

Tessalonicenses 5,15 



\section{Agradecimentos}

A todos que colaboraram direta ou indiretamente na elaboração desse trabalho, o meu reconhecimento.

Gostaria de agradecer a todos os meus tutores e professores que me permitiram chegar até aqui, em especial ao Prof. Dr. Ivan Nunes da Silva pelos seus ensinamentos, pelas suas sugestões no decorrer do desenvolvimento deste trabalho e sobre tudo por me proporcionar a oportunidade de tê-lo como orientador.

À minha família pelo especial apoio que sempre me concederam, em especial a senhora Dilmacy Rodrigues Ferreira por ser minha luz em momentos de escuridão.

Aos colegas de laboratório, em especial ao Eng. ${ }^{\circ}$ Marcelo Suetake por todo o suporte que tem me fornecido.

Ao colega Prof. MSc. Alessandro Goedtel pelo apoio e conselhos acadêmicos que sempre está prontamente disposto a dar, pelas sugestões provenientes de sua vivência na área de máquinas elétricas e, incentivo na elaboração deste trabalho.

Meus agradecimentos também, e de forma geral, a EESC-USP que me acolheu como um de seus filhos. 



\section{SUMÁRIO}

Resumo

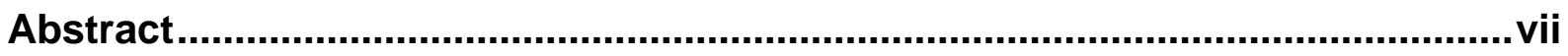

Lista de Siglas e Abreviaturas .......................................................................

Lista de Figuras..............................................................................................

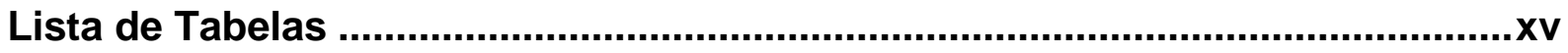

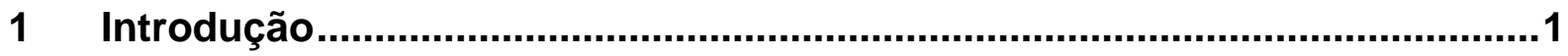

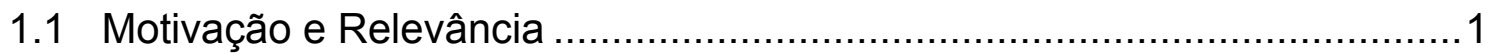

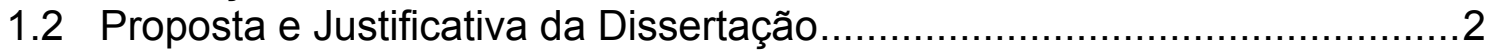

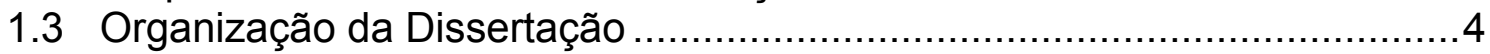

2 Aspectos da Modelagem do Motor de Indução …….......................................

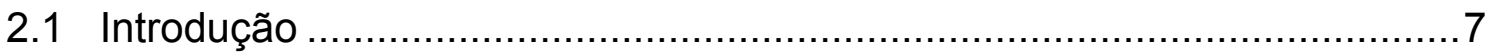

2.2 Princípios de Funcionamento do Motor de Indução ..................................

2.2.1 Efeito Pelicular................................................................11

2.3 Modelagem Matemática do Motor de Indução …...................................13

2.3.1 Transformações Lineares .......................................................21

2.3.2 Transformação Linear "qd0 ".................................................22

2.4 Classificação dos Principais Tipos de Cargas Acopladas ao Motor

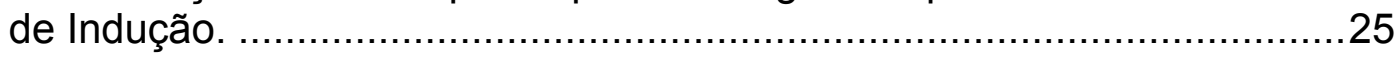

3 Aspectos de Sistemas de Inferência Fuzzy …............................................31

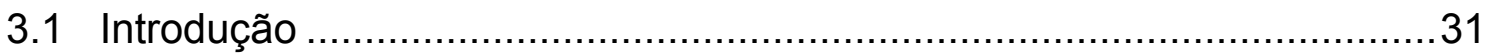

3.2 Constituição dos Sistemas de Inferência Fuzzy ....................................32

3.2.1 Sistema de Inferência no Modelo de Takagi-Sugeno .....................37

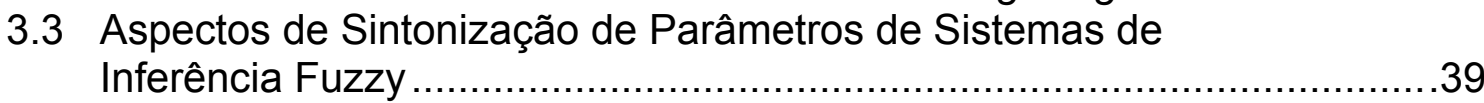

3.3.1 Características do ANFIS no Matlab .........................................41

3.4 Aplicações de Sistemas de Inferência Fuzzy em Motores de Indução......44

4 Metodologia Proposta Para Identificação de Torque de Carga Usando

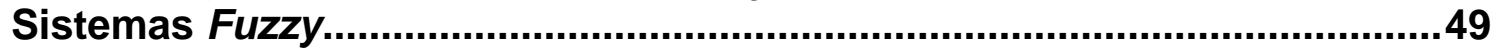

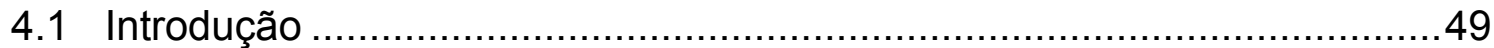

4.2 Descrição da Estratégia de Obtenção das Curvas de Torque

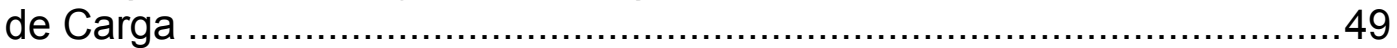

4.2.1 Parâmetros Elétricos e Mecânicos do Motor Simulado ...................50

4.2.2 Treinamento do Sistema ANFIS ...............................................51

4.3 Estrutura do Sistema Fuzzy Para Identificação do Torque de Carga .........57 


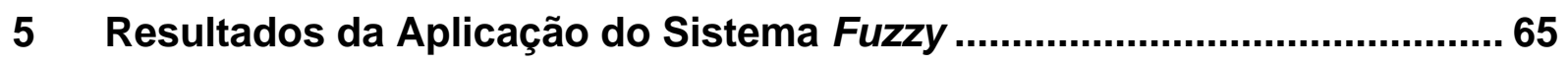

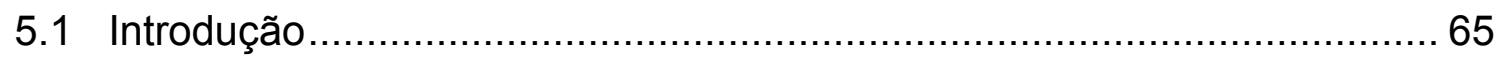

5.2 Resultados do Sistema Fuzzy na Identificação de Torque de

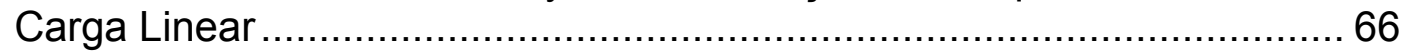

5.3 Resultados do Sistema Fuzzy na Identificação de Torque de

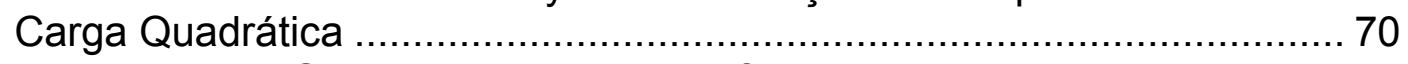

5.4 Resultados do Sistema Fuzzy na Identificação de Torque de Carga Inversa ........................................................................... 73

5.5 Comparação de Resultados Entre Estratégias Inteligentes........................ 77

6 Conclusões Gerais e Trabalhos Futuros .................................................. 81

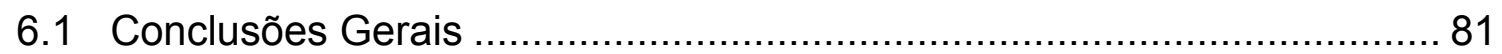

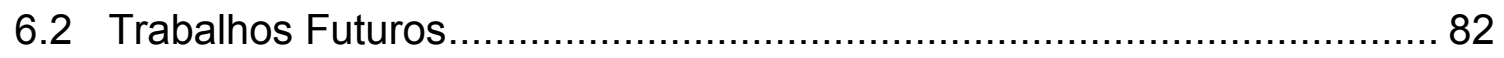

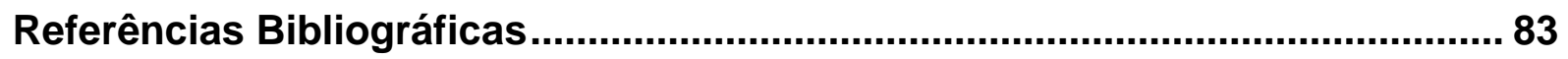

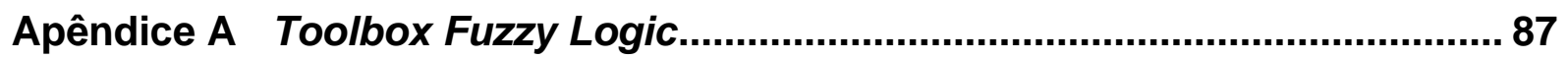

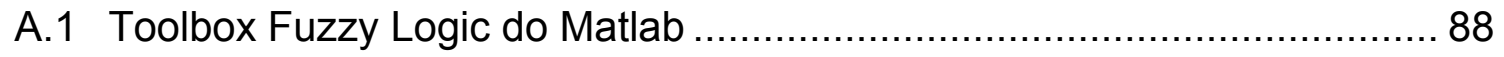

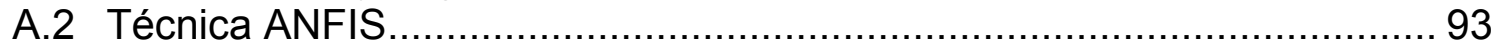

Apêndice B Modelo do MIT usado para as simulações....................................... 95 


\section{Resumo}

SILVA, S. F. D. (2007). Identificação de Torque de Carga em Motores de Indução Usando Abordagem Baseada em Sistemas Fuzzy. Dissertação (Mestrado) - Escola de Engenharia de São Carlos, Universidade de São Paulo, 2007.

Os motores de indução trifásicos são largamente usados em vários setores da indústria. O dimensionamento da potência adequada de um motor de indução ou assíncrono trifásico, em função do comportamento das cargas acopladas ao eixo, continua em alguns casos impreciso pela falta de conhecimento mais completo do comportamento das cargas. A proposta deste trabalho consiste na utilização de sistemas fuzzy como uma alternativa aos métodos tradicionais para levantamento do comportamento de carga e, em processos de controle, onde há a necessidade de conhecimento do comportamento do conjugado aplicado ao eixo do motor, enfocando diversos tipos de cargas encontrados em indústrias. Resultados de simulações são apresentados para validar a proposta deste trabalho.

Palavras chave: Motor de Indução, sistemas fuzzy, estimativa de torque de carga. 



\section{Abstract}

SILVA, S. F. D. (2007). Identification of Load Torque in Induction Motors Using Fuzzy System Approach. Dissertação (Mestrado) - Escola de Engenharia de São Carlos, Universidade de São Paulo, 2007.

The three phase induction motors are widely used in all industrial sectors. The selection procedure of the motor for a particular application is sometimes inaccurate due to the lack of complete knowledge about the load connected to its shaft. The proposal of this work consists of using fuzzy system as an alternative tool to the classical methods for extraction of the load behavior and, in control process, where knowledge of the torque behavior applied to the motor shaft are need, focusing several types of loads found in industries. Simulation results are presented to validate the proposal of this work.

Keywords: Induction Motor, fuzzy systems, load torque estimation. 



\section{Lista de Siglas e Abreviaturas}

$\begin{array}{ll}\text { AGP } & \text { Air-Gap Torque } \\ \text { ANFIS } & \text { Adaptive Neuro-Fuzzy Inference System } \\ \text { DTC } & \text { Direct Torque Control } \\ \text { EKF } & \text { Extended Kalman Filter } \\ \text { FIS } & \text { Fuzzy Inference System } \\ f_{m m} & \text { Força Magneto Motriz } \\ \text { FOC } & \text { Field Orientation Control } \\ \text { GUI } & \text { Ghaphical User Interface } \\ \text { MIT } & \text { Motor de Indução Trifásico } \\ \text { MRAS } & \text { Model Reference Adaptive System } \\ \text { RNA } & \text { Redes Neurais Artificiais }\end{array}$





\section{Lista de Figuras}

Figura 2.1 - Diagrama fasorial e senóides trifásicas..........................................11

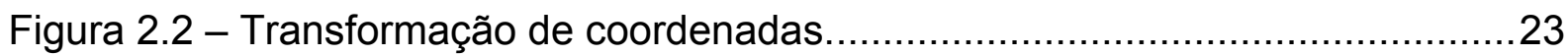

Figura 2.3 - Conjugado de Carga Constante....................................................2

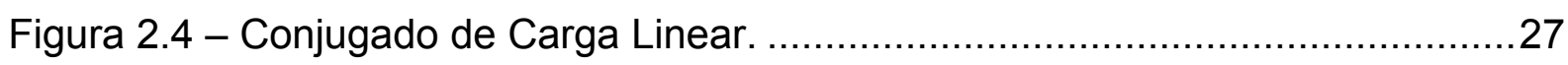

Figura 2.5 - Conjugado de Carga Quadrática..................................................28

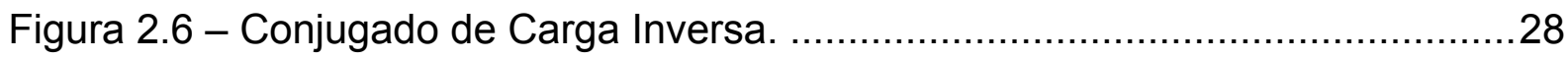

Figura 3.1 - Diagrama do processo de inferência fuzzy. .......................................32

Figura 3.2 - Função de pertinência Gaussiana.......................................................35

Figura 3.3 - Ilustração do método da média dos máximos. .....................................37

Figura 3.4 - Processos Internos ao modelo de Takagi-Sugeno.................................39

Figura 3.5 - Interface gráfica do ANFIS no Matlab. ..........................................42

Figura 3.6 - Configuração dos parâmetros de inicialização do sistema de

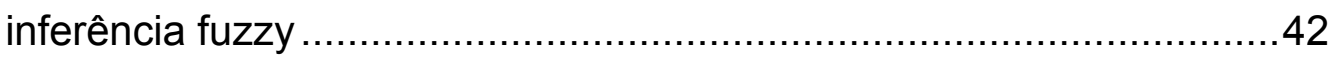

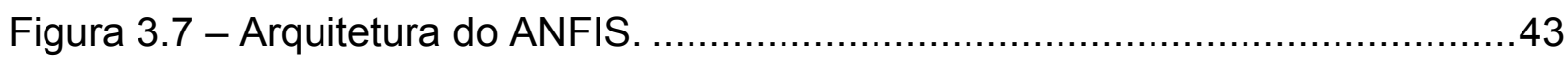

Figura 4.1 - Diagrama esquemático do sistema fuzzy .......................................50

Figura 4.2 - Análise das correntes do motor de indução. .........................................54

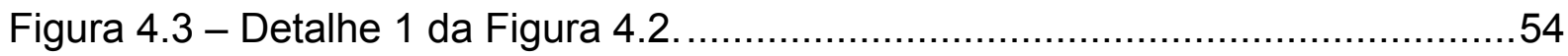

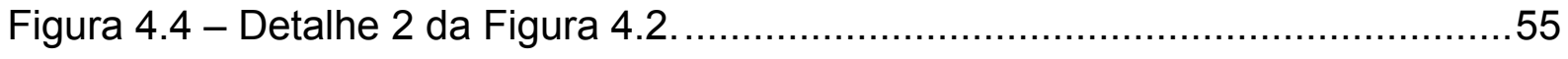

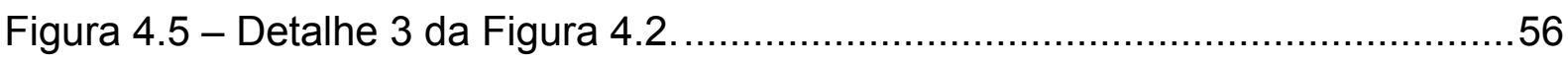

Figura 4.6 - Curva de conjugado para faixa de tensão de $\pm 10 \%$ da

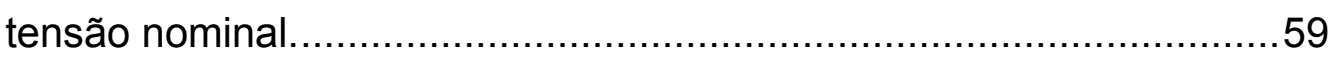

Figura 4.7 - Curva de torque para carga linear.................................................60

Figura 4.8 - Funções de pertinência para a tensão. ……........................................60 
Figura 4.9 - Funções de pertinência para a variável lingüística "corrente".

Figura 4.10 - Função de pertinência para variável lingüística "velocidade".

Figura 4.11 - Diagrama de blocos

Figura 5.1 - MIT submetido a conjugado resistente linear alimentado

com 202V.

Figura 5.2 - MIT submetido a conjugado resistente linear alimentado

com 220V.

Figura 5.3 - MIT submetido a conjugado resistente linear alimentado

com 238V. 68

Figura 5.4 - Erro relativo ponto-a-ponto entre conjugado estimado

e real/simulado.

Figura 5.5 - MIT submetido a conjugado resistente quadrático alimentado

com 205V. 70

Figura 5.6 - MIT submetido a conjugado resistente quadrático alimentado

com 220V. 71

Figura 5.7 - MIT submetido a conjugado resistente quadrático alimentado

com 238V. 72

Figura 5.8 - Erro relativo ponto-a-ponto referente à Figura 5.7. 72

Figura 5.9 - MIT submetido a conjugado resistente inverso alimentado

com $209 \mathrm{~V}$. 74

Figura 5.10 - MIT submetido a conjugado resistente inverso alimentado com $220 \mathrm{~V}$. 75

Figura 5.11 - MIT submetido a conjugado resistente inverso alimentado com $230 \mathrm{~V}$. 76

Figura 5.12 - Erro relativo ponto-a-ponto referente à Figura 5.11. 76 
Figura A.1 - Esquema dos componentes constituintes do toolbox Fuzzy Logic do Matlab. .88

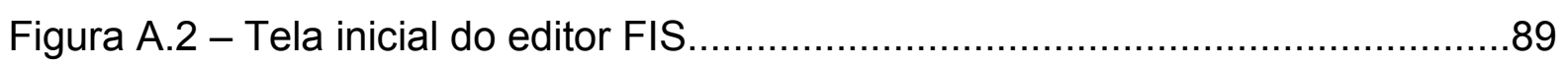

Figura A.3 - Tela inicial do editor das funções de pertinência...................................90

Figura A.4 - Editor de regras ilustrando regras de um sistema com três entradas. 91

Figura A.5 - Visualização das regras de um sistema proposto com três entradas. 91

Figura A.6 - Visualizador de superfícies. . 92 



\section{Lista de Tabelas}

TABELA 4.1 - Parâmetros do motor de indução trifásico e carga. 50

TABELA 4.2 - Funções matemáticas das cargas industriais. 51

TABELA 4.3 - Composição dos dados de treinamento agrupados por tensão.

TABELA 4.4 - Composição dos dados de treinamento agrupados por conjugado de carga. 57

TABELA 4.5 - Faixa de tensões de treinamento. 59

TABELA 4.6 - Universo de discurso para cada faixa de tensão. 61

TABELA 4.7 - Terminologia dos termos de pertinência. 61

TABELA 4.8 - Universo de discurso para as variáveis lingüísticas: velocidade e corrente. 63

TABELA 5.1 - Desempenho do estimador para conjugado linear. 69

TABELA 5.2 - Desempenho do estimador para conjugado quadrático. .73

TABELA 5.3 - Desempenho do estimador para conjugado inverso. 77

TABELA 5.4 - Comparação de resultados entre sistemas inteligentes para a carga linear.

TABELA 5.5 - Comparação de resultados entre sistemas inteligentes para a carga quadrática. 78

TABELA 5.6 - Comparação de resultados entre sistemas inteligentes para a carga inversa. 





\section{Introdução}

\subsection{Motivação e Relevância}

O setor industrial é responsável pelo consumo de quase metade do total de energia elétrica gerada. Dentro deste panorama, os motores elétricos são os principais responsáveis por mais da metade de toda a energia elétrica consumida [1].

Os motores de indução trifásicos (MIT) são largamente usados em vários setores da indústria. Eles têm sido os motores preferidos da indústria desde o princípio do uso da energia elétrica em corrente alternada. Tal destaque em relação aos outros motores foi alcançado em virtude de sua robustez, simplicidade e baixo custo, tanto operacional quanto de mercado.

A necessidade crescente de busca por processos mais econômicos na utilização racional e eficiente da energia elétrica tem implicado na realização de estudos detalhados para a otimização de todo o processo industrial, visando também, a necessidade pela conservação da energia elétrica. Dentro deste contexto, os motores elétricos se tornaram elementos indispensáveis na maioria dos processos que envolvem os setores produtivos, pois os mesmos se destacam como os principais elementos de conversão de energia elétrica em mecânica. Como conseqüência, essas máquinas elétricas vêm sofrendo constantes melhorias que atendem às necessidades emergentes dos processos produtivos, levando-se também em conta sua importância energética dentro do cenário industrial nacional. 
A medição do conjugado ou torque é de grande importância em muitas aplicações no meio industrial. A informação a respeito do conjugado de carga pode ser utilizada em malhas de controle, assim como em subsistemas de monitoramento e supervisão.

Assim, para a correta escolha do motor de indução e de seu acionamento em uma determinada aplicação, tornar-se-á necessário o conhecimento do comportamento da carga que será acionada pelo motor. Entretanto, o conjugado exigido pela carga do motor de indução desde a partida até o regime permanente é normalmente desconhecido pelo projetista.

\subsection{Proposta e Justificativa da Dissertação}

Este trabalho tem como proposta apresentar um método alternativo para a determinação do conjugado de carga exigido no eixo dos motores de indução trifásicos, utilizando para tanto um sistema de inferência fuzzy adaptativo.

Os motores de indução são os mais empregados em aplicações industriais que necessitam de máquinas elétricas rotativas, pois eles possuem um baixo custo e uma maior durabilidade. Entretanto, há a necessidade de uma ferramenta ou

metodologia simples que seja capaz de descrever de forma satisfatória o comportamento da carga, observando-se que tal aspecto tem se tornado fator limitante no momento da especificação de um motor e seu respectivo acionamento. O subdimensionamento de um motor implica em redução de sua vida útil, assim que, da mesma forma, o seu super-dimensionamento resulta em diminuição de fator de potência e perdas de rendimento, tendo então como conseqüência o aumento das perdas de energia elétrica [2]. 
As variáveis corrente, tensão, torque e velocidade angular são algumas das responsáveis por determinar o tipo de motor a ser utilizado em dada aplicação, assim como para o projeto de seu acionamento e seu controle de velocidade. Há então a necessidade do mapeamento ponto-a-ponto das curvas características de cada conjunto motor-carga para se determinar tais parâmetros, além da análise do comportamento dessas características quando da variação das condições de funcionamento.

A informação do conjugado de carga pode ser adquirida diretamente a partir de um sensor de torque no eixo do motor ou do uso de uma célula de carga que fornece uma informação proporcional ao torque ou conjugado eletromagnético. Mas esses métodos são invasivos e de difícil implementação em sistemas que já estão sendo operados.

Os modelos convencionais de máquinas ou processos acionados por motores elétricos apresentam resultados satisfatórios para determinadas situações, mas para o comportamento não-linear dos componentes envolvidos em tais sistemas, como por exemplo, a variação das resistências dos enrolamentos devido ao aumento de temperatura, os mesmos são normalmente bastante particularizados ou falhos [2]. Um modelo utilizando abordagem de sistemas fuzzy para mapear o comportamento dessas máquinas pode lidar satisfatoriamente com esses problemas caracterizados pelas não-linearidades das variáveis envolvidas no processo.

Em geral, as abordagens inteligentes têm sido aplicadas cada vez mais em sistemas complexos, onde o equacionamento convencional é um tanto falho para processos não-lineares que envolvam um sistema dinâmico, pois os mesmos em certos casos acabam sendo aproximados por sistemas lineares. Além disso, tais 
abordagens inteligentes estão, também, sendo cada vez mais utilizadas em várias aplicações devido ao incremento do poder computacional dos microprocessadores.

Neste trabalho, a estimativa de conjugado de carga de motores de indução pode contribuir para três finalidades principais. A primeira, e mais importante, é prover informações sobre a carga, permitindo então contribuir para o correto dimensionamento do motor frente a determinada aplicação. A segunda finalidade é prover dados relativos ao comportamento da carga no eixo de forma a determinar a eficiência e desempenho da conversão de energia [3]. Em terceiro lugar, a estimativa de conjugado aplicado nos eixos dos motores de indução é de fundamental importância para o desenvolvimento de técnicas eficientes que permitam o controle deles no regime transitório e permanente [3, 4].

Desta forma, esse trabalho tem como objetivo a proposição de um modelo computacional capaz de fornecer o comportamento do conjugado da carga, considerando diversas aplicações onde seu conhecimento se torna de grande importância, utilizando ainda para tanto somente variáveis primárias da máquina como tensão, corrente e velocidade.

\subsection{Organização da Dissertação}

A presente dissertação se desenvolve em 6 capítulos, conforme descritos na seqüência.

No Capítulo 2 são apresentados os aspectos da modelagem do motor de indução, abordando os seguintes pontos: os princípios de funcionamento, a modelagem matemática do motor de indução utilizado para as simulações 
necessárias ao processo de aquisição dos dados e, por fim, a classificação dos principais tipos de cargas acopladas ao motor.

No Capítulo 3, tem-se uma descrição da constituição dos sistemas de inferência fuzzy, dos aspectos de sintonização de seus parâmetros, assim como aplicações de sistemas fuzzy em motores de indução.

No Capítulo 4, mostra-se a metodologia proposta para a identificação de torque de carga usando sistemas fuzzy.

No Capítulo 5, apresentam-se os resultados obtidos pela aplicação da metodologia proposta para as cargas estudadas.

Finalmente, no Capítulo 6, as conclusões gerais deste trabalho são tecidas e propostas para trabalhos futuros são também apresentadas. 



\section{Aspectos da Modelagem do Motor de Indução}

Neste capítulo serão apresentados os aspectos da modelagem do motor de indução, pois através deste, serão realizadas as simulações necessárias para o desenvolvimento do trabalho. Assim, o respectivo modelo matemático torna-se de suma importância para o entendimento de seu funcionamento.

\subsection{Introdução}

A fim de possibilitar o estudo e o desenvolvimento do trabalho aplicado a um motor de indução, analisando sua estrutura, características, vantagens e desvantagens, é necessário, primeiramente, conhecer os modelos matemáticos envolvidos nesse sistema.

Desta forma, neste capítulo são apresentados os modelos matemáticos que serão empregados no decorrer do trabalho, assim como as devidas transformações de coordenadas pertinentes. A geração dos dados para a inferência do sistema fuzzy será adquirida através do modelo matemático apresentado, sendo portanto este de grande importância para o trabalho. Já o modelo de estimação de torque de carga será apresentado no Capítulo 3, juntamente com o sistema de inferência fuzzy, de forma a facilitar o seu entendimento.

Os modelos aqui apresentados não serão desenvolvidos de forma detalhada por serem facilmente encontrados na literatura como, por exemplo, em [5-7]. No 
entanto, uma explanação será realizada com o objetivo de compreender de forma clara as simplificações envolvidas em tais modelos.

\subsection{Princípios de Funcionamento do Motor de Indução}

Há dois tipos de motores de indução que são diferenciados pelo tipo de rotor utilizado. O motor com rotor bobinado ou rotor enrolado é comumente chamado de motores de anéis [8, 9]. Este rotor tem seu enrolamento polifásico construídos de forma similar ao do estator, com o mesmo número de pólos. Através de escovas de carvão apoiadas sobre anéis coletores isolados montados sobre o eixo do motor, tem-se o acesso aos terminais do enrolamento do rotor [7, 8].

Enquanto que o outro tipo de motor é conhecido como motores "gaiola de esquilo" [8], sendo que estes são ao mais comuns e mais utilizados. O rotor em gaiola consiste de barras paralelas e condutoras, curto-circuitadas em cada extremidade por anéis condutores, sendo que essas barras são fixadas no ferro do rotor $[7,9]$. O motor com rotor de gaiola possui outras variações, além desta que é denominada de rotor de gaiola simples. As outras variações são o rotor de gaiola dupla e o rotor de gaiola de barras profundas [10]. Os motores de gaiola de esquilo utilizam o efeito pelicular (Seção 2.2.1).

O rotor de gaiola dupla consiste de duas gaiolas concêntricas. Uma externa que é construída de tal forma que se tenha uma resistência elevada de modo a permitir um bom conjugado de partida; enquanto que a gaiola interna é constituída para se ter uma resistência baixa de modo que se garanta um bom rendimento em funcionamento nominal. $\mathrm{O}$ benefício que se obtém da utilização de motores deste tipo, consiste de aumento do conjugado de partida e também uma ligeira diminuição 
do valor da corrente de partida, sendo que no momento da partida funcionará essencialmente a gaiola externa, enquanto que a gaiola interna funcionará em situação de regime.

O rotor de gaiola de barras profundas é semelhante ao de gaiola simples (ambos são denominados de gaiola de esquilo), embora as barras que constituem o seu enrolamento possuem uma considerável profundidade. Suas características de arranque são análogas ao do rotor de gaiola dupla [10].

No motor de indução a excitação dos enrolamentos do estator e rotor são feitos da seguinte forma: diretamente no estator, pois a corrente alternada é fornecida diretamente ao estator, enquanto que no rotor as correntes são induzidas pela ação de transformador do enrolamento do estator [7]. Assim sendo, quando excitado por uma fonte polifásica simétrica, o enrolamento produzirá um campo magnético no entreferro, sendo esse o princípio de funcionamento do motor de indução. Esse campo magnético girará com velocidade síncrona determinada pelo número de pólos magnéticos do motor e pela freqüência elétrica da rede conforme a Equação (2.1) [7, 8].

$$
\omega_{s}=120 \frac{f_{s}}{P}(\mathrm{rpm})
$$

em que: $\omega_{s}$ é a velocidade síncrona, $f_{s}$ é a freqüência elétrica e $P$ é número de pólos.

Para ter tensões induzidas e fazer com que o motor funcione, deve-se então haver movimento relativo entre velocidade do campo girante e a velocidade do rotor, sendo o mesmo denominado escorregamento. Por isso, o motor de indução é caracterizado como assíncrono. O escorregamento é expresso como um percentual da velocidade síncrona de acordo com a Equação (2.2). 


$$
S=\frac{\omega_{e m}-\omega_{r m}}{\omega_{e m}} 100
$$

em que:

s é o escorregamento.

$\omega_{e m}$ é a velocidade síncrona em rad/s.

$\omega_{r m}$ é a velocidade angular do rotor em rad/s.

A alimentação trifásica (senoidal) do enrolamento do estator de um motor de indução faz com que circulem correntes, igualmente senoidais, pelas bobinas atrasadas em relação às senoides de tensão. Em conseqüência a esse atraso que é gerado pela reatância indutiva do estator à circulação de corrente, ocorre-se à criação de um campo magnético para cada uma das correntes circulantes, sendo que os mesmos estão defasados de 120 graus elétricos em relação ao outro e suas amplitudes variam conforme a amplitude da tensão aplicada ao enrolamento.

Fazendo-se a composição vetorial dos três campos magnéticos gerados, obtém-se um vetor campo magnético resultante que gira a uma velocidade $\omega_{e}\left(=2 \pi f_{e}\right)$ no diagrama fasorial, sendo essa velocidade definida como velocidade angular da força magnetomotriz $\left(f_{m m}\right)$, onde o termo $f_{e}$ é a freqüência de excitação da rede de alimentação [9]. A Figura 2.1 ilustra o diagrama fasorial correspondente e as senóides de correntes trifásicas no tempo. 

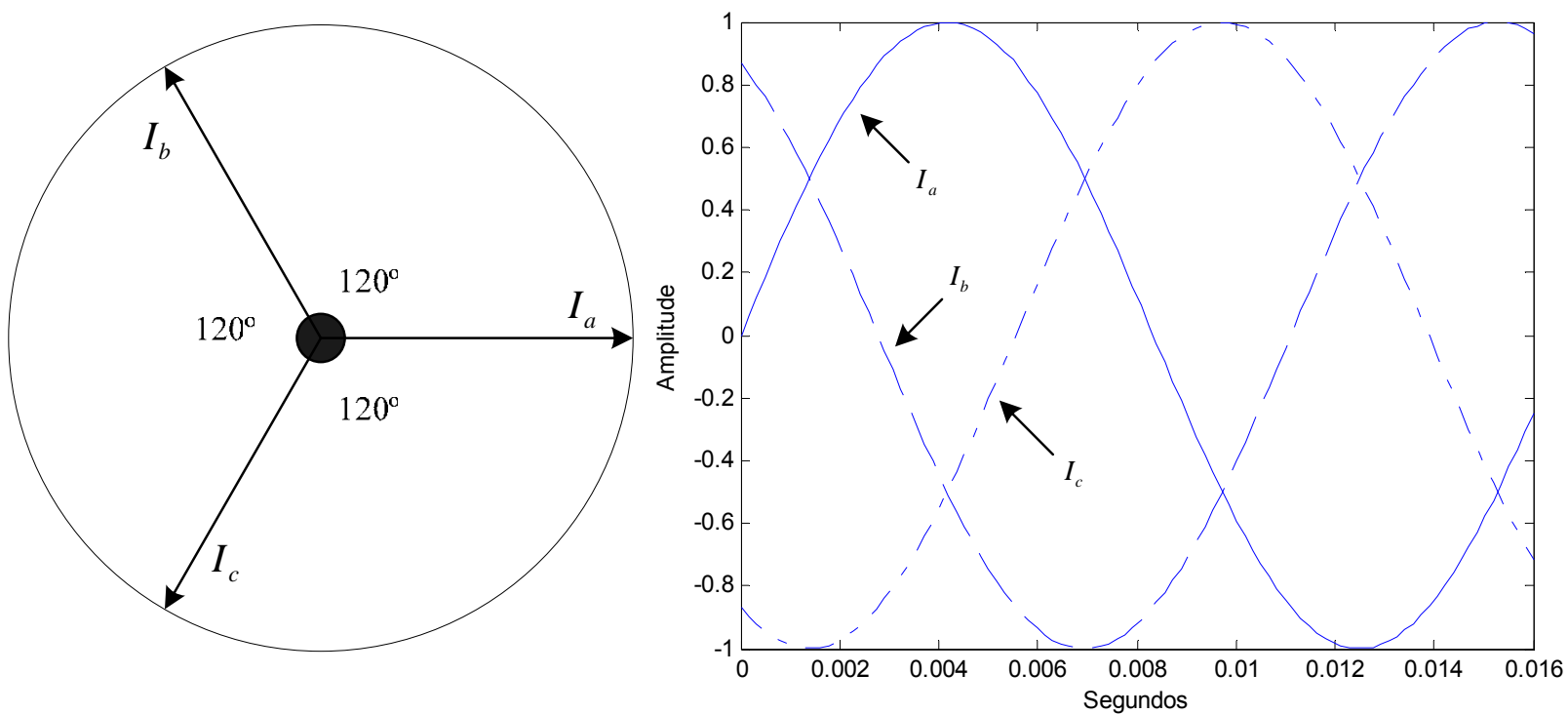

Figura 2.1 - Diagrama fasorial e senóides trifásicas.

Assim, à medida que o campo girante faz seu caminho ao longo do estator, são então induzidas tensões nos enrolamentos do rotor em curto circuito. As correntes elevadas que circulam, produzidas pelas tensões induzidas, geram um campo magnético resultante que tende a se opor ao campo magnético produzido pelo enrolamento do estator, originando, desta forma, o conjugado eletromagnético [2].

\subsubsection{Efeito Pelicular}

O efeito pelicular é responsável pela variação da densidade de corrente no rotor devido à variação de freqüência da corrente induzida no rotor.

Considerando um rotor de gaiola com barras profundas, se o ferro do rotor tivesse permeabilidade infinita, todas as linhas de fluxo disperso se fechariam em caminhos embaixo da ranhura. Devido ao fato da camada no fundo ser mais concatenada com fluxo disperso, a indutância de dispersão da camada mais 
profunda é maior em corrente contínua que a camada no topo. Como as camadas estão eletricamente em paralelo, conseqüentemente, em corrente alternada, a corrente nas camadas superiores de baixa reatância será maior do que nas camadas baixas de alta reatância, assim como a corrente será forçada contra o topo da ranhura, a corrente nas camadas superiores se adiantará à corrente nas camadas baixas $[7,11]$.

A distribuição não uniforme da corrente resulta em um aumento na resistência efetiva e, em menor escala, num decréscimo da indutância de dispersão efetiva na barra. Como a distorção na distribuição de corrente depende de um efeito indutivo, a resistência efetiva é função da freqüência. Da mesma forma, é também uma função da profundidade da barra, permeabilidade e resistividade do material da barra $[7,12]$.

Assim, um rotor de gaiola com barras profundas pode ser projetado para ter uma resistência efetiva à freqüência estator, rotor parado, várias vezes maior do que sua resistência em corrente contínua. Deste modo, conforme o motor acelera a freqüência do rotor decresce e, portanto, a resistência efetiva do rotor decresce aproximando-se de seu valor em corrente contínua com escorregamento pequeno [7].

Conforme aqui explanado, a variação de freqüência da corrente induzida no rotor tem efeito direto sobre a resistência do rotor e na reatância indutiva do rotor cujo valor tem relação direta com a freqüência a qual está submetida. De forma aplicável a qualquer circuito indutivo, tem-se:

$$
X_{L}=2 \cdot \pi \cdot f \cdot L
$$

em que:

$X_{L}$ é a reatância indutiva em $\mathrm{Ohm}$. 
$f$ é a freqüência de alimentação da indutância em Hertz.

$L$ é a indutância em Henry.

A freqüência das correntes do rotor é igual à das correntes de estator ficando a corrente concentrada na parte superior da barra, isso na partida. Desta forma, produz um acréscimo no valor da resistência da barra e, devido à distribuição do fluxo, uma diminuição na reatância de dispersão.

A medida que o rotor gira e atinge a velocidade nominal, a corrente na barra tem uma distribuição praticamente uniforme. Desta forma, há uma alteração dos valores de resistência em relação aos valores na partida.

Para considerar o comportamento físico do motor de indução na simulação é necessária a inclusão de um fator de correção na resistência e na reatância em função da freqüência das correntes do rotor, a qual está relacionada com o escorregamento do rotor. Um modelo matemático capaz de levar em consideração os efeitos da freqüência nos valores de resistência e reatância foi desenvolvido em $[13,14]$

\subsection{Modelagem Matemática do Motor de Indução}

O equacionamento matemático do motor de indução foi desenvolvido adotando algumas hipóteses com objetivo de simplificar o modelo de forma que a simulação seja viabilizada, pois sem as mesmas, essa modelagem seria extremamente complexa [5]. Cabe salientar que tais hipóteses são facilmente encontradas na literatura [5, 7, 9] por possuir resultados próximos das situações práticas. A seguir são apresentadas as considerações utilizadas: 
- entreferro uniforme (rotor e estator cilíndricos);

- circuito magnético linear;

- as fases do enrolamento do estator são idênticas e são enroladas de modo a se obter uma onda de $f_{m m}$ senoidal espacial, estabelecida pela aplicação de correntes balanceadas;

- no rotor, as fases do enrolamento (motor de anéis), ou as barras da gaiola (gaiola de esquilo), são arranjadas para se obter onda de $f_{m m}$ espacial com o mesmo número de pólos do estator. Para tanto, despreza-se a saturação no circuito magnético, a variação das resistências dos enrolamentos por efeito pelicular (skin) e de temperatura, e as harmônicas das ondas de $f_{m m}$.

- as indutâncias mútuas entre cada bobina do estator e do rotor são funções harmônicas do deslocamento angular $(\theta)$ definido entre 0 eixo magnético de uma bobina de fase do rotor à correspondente do estator, apresentando valor máximo para dois conjuntos de mútuas.

Com base nessas hipóteses, pode-se aplicar o princípio da superposição. Assim, tem-se para o fluxo total do motor $\Phi_{\text {total }}$ a expressão da equação (2.4).

$$
\Phi_{\text {total }}=\Phi_{r}+\Phi_{e}
$$

em que:

$$
\begin{aligned}
& \Phi_{r}=\Phi_{r 1}+\Phi_{r 2}+\Phi_{r 3} \\
& \Phi_{e}=\Phi_{e 1}+\Phi_{e 2}+\Phi_{e 3}
\end{aligned}
$$


sendo que $\Phi_{r}$ representa o fluxo do rotor e $\Phi_{e}$ o fluxo do estator. Em que, $\Phi_{r 1}, \Phi_{r 2}, \Phi_{r 3}$ ilustra as três fases da máquina para o rotor e, $\Phi_{e 1}, \Phi_{e 2}, \Phi_{e 3}$ as três fases para o estator.

As equações de tensão do rotor são dadas por:

$$
\begin{aligned}
& V_{j r}=i_{j r} R_{r}+\frac{d \Phi_{j r}}{d t} \\
& V_{j e}=i_{j e} R_{e}+\frac{d \Phi_{j e}}{d t}
\end{aligned}
$$

em que:

j representa qualquer uma das fases do estator ou do rotor.

$R$ é a resistência do rotor ou estator em Ohms (Ohm).

$V$ é a tensão do rotor ou do estator em Volt .

$\Phi$ representa o fluxo para qualquer uma das fases do estator ou rotor em Weber.

i é a corrente para qualquer uma das fazes do estator ou do rotor em Ampère.

Como está sendo considerado que os enrolamentos do estator e rotor são iguais e possuem uma mesma resistência, então as indutâncias próprias tanto do estator como do rotor são iguais. Deste mesmo princípio, as indutâncias mútuas tanto do estator e rotor são constantes. Assim, para as indutâncias próprias do motor de indução, tem-se:

$$
\begin{aligned}
& L_{e}=L_{e 1}=L_{e 2}=L_{e 3} \\
& L_{r}=L_{r 1}=L_{r 2}=L_{r 3}
\end{aligned}
$$


sendo que $L_{e}$ representa as indutâncias do estator, enquanto que $L_{r}$ as do rotor. Já as indutâncias mútuas são dadas por:

$$
\begin{aligned}
& M_{e}=M_{e 13}=M_{e 23}=M_{e 12} \\
& M_{r}=M_{r 13}=M_{r 23}=M_{r 12}
\end{aligned}
$$

onde $M_{e}$ representa as indutâncias mútuas entre as fases do estator e $M_{r}$ as do rotor. Para as resistências, tem-se $R_{e}$ como resistência do estator e $R_{r}$ do rotor.

Além das indutâncias próprias e mútuas do estator e rotor, têm-se as indutâncias entre as fases do estator e as do rotor. Essas indutâncias são funções senoidais do deslocamento angular $\theta[5]$.

Assim, para essas indutâncias, tem-se a expressão em notação matricial da equação (2.9).

$$
M_{e r}(\theta)^{T}=m_{e r}\left[\begin{array}{lll}
\cos \theta & \cos \left(\theta+\frac{2 \pi}{3}\right) & \cos \left(\theta-\frac{2 \pi}{3}\right) \\
\cos \left(\theta-\frac{2 \pi}{3}\right) & \cos \theta & \cos \left(\theta+\frac{2 \pi}{3}\right) \\
\cos \left(\theta+\frac{2 \pi}{3}\right) & \cos \left(\theta-\frac{2 \pi}{3}\right) & \cos \theta
\end{array}\right]=M_{r e}(\theta)(2.9)
$$

onde $M_{e r}$ representa as indutâncias mútuas das fases do estator em relação ao rotor, enquanto que $M_{r e}$ representa as do rotor em relação ao estator. O parâmetro $m_{e r}$ representa a amplitude das indutâncias mútuas das fases do estator em relação ao rotor.

Definindo as indutâncias próprias de rotor e estator em formato matricial, tem-se a equação (2.10). 


$$
L_{e e}=\left[\begin{array}{lll}
L_{e} & M_{e} & M_{e} \\
M_{e} & L_{e} & M_{e} \\
M_{e} & M_{e} & L_{e}
\end{array}\right]
$$

e,

$$
L_{r r}=\left[\begin{array}{ccc}
L_{r} & M_{r} & M_{r} \\
M_{r} & L_{r} & M_{r} \\
M_{r} & M_{r} & L_{r}
\end{array}\right]
$$

onde $L_{e e}$ representa a matriz das indutâncias próprias do estator e $L_{r r}$ do rotor.

Para as correntes serão adotadas as $i_{e}$ (correntes do estator) e $i_{r}$ (correntes do rotor), conforme a Equação (2.12).

$$
\begin{aligned}
& i_{e}=\left[\begin{array}{l}
i_{e 1} \\
i_{\mathrm{e} 2} \\
i_{\mathrm{e} 3}
\end{array}\right] \\
& i_{r}=\left[\begin{array}{l}
i_{r 1} \\
i_{r 2} \\
i_{r 3}
\end{array}\right]
\end{aligned}
$$

Desta forma, para os fluxos do estator e rotor, tem-se a equação (2.13):

$$
\begin{aligned}
& \Phi_{e}=L_{e e} i_{e}+M_{r e}(\theta) i_{r} \\
& \Phi_{r}=L_{r r} i_{r}+M_{e r}(\theta) i_{e}
\end{aligned}
$$

Para a obtenção das equações das tensões do motor com base na Equação (2.6), considerando tanto o estator como o rotor, as equações dos fluxos devem ser 
desenvolvidas (Equação (2.13)). Deste modo, derivando a Equação (2.13) em relação ao tempo, tem-se a equação (2.14):

$$
\begin{aligned}
& \frac{d \Phi_{e}}{d t}=L_{e e} \frac{d i_{e}}{d t}+M_{e r}(\theta) \frac{d i_{r}}{d t}+\frac{\partial M_{e r}(\theta)}{\partial \theta} i_{r} \frac{d \theta}{d t} \\
& \frac{d \Phi_{r}}{d t}=L_{r r} \frac{d i_{r}}{d t}+M_{r e}(\theta) \frac{d i_{e}}{d t}+\frac{\partial L_{r e}(\theta)}{\partial \theta} i_{e} \frac{d \theta}{d t}
\end{aligned}
$$

Assim, substituindo as Equações (2.14) em (2.6), obtêm-se as equações das tensões do estator dada em (2.15), e do rotor em (2.16).

$$
\begin{aligned}
& V_{e}=R_{e} i_{e}+L_{e e} \frac{d i_{e}}{d t}+M_{e r}(\theta) \frac{d i_{r}}{d t}+\frac{\partial M_{e r}(\theta)}{\partial \theta} i_{r} \frac{d \theta}{d t} \\
& V_{r}=R_{r} i_{r}+L_{r r} \frac{d i_{r}}{d t}+M_{r e}(\theta) \frac{d i_{e}}{d t}+\frac{\partial M_{r e}(\theta)}{\partial \theta} i_{e} \frac{d \theta}{d t}
\end{aligned}
$$

em que:

$$
R_{e}=\left[\begin{array}{ccc}
R_{e} & 0 & 0 \\
0 & R_{e} & 0 \\
0 & 0 & R_{e}
\end{array}\right]
$$

e,

$$
R_{r}=\left[\begin{array}{ccc}
R_{r} & 0 & 0 \\
0 & R_{r} & 0 \\
0 & 0 & R_{r}
\end{array}\right]
$$


Para a modelagem matemática do torque eletromagnético, deve-se levar em consideração a transferência de potência nos seis enrolamentos (três no estator e três no rotor). Assim, considerando a equação (2.19):

$$
[L(\theta)]_{6 \times 6}=\left[\begin{array}{cc}
{\left[L_{e e}\right]_{3 \times 3}} & {\left[M_{r e}(\theta)\right]_{3 \times 3}} \\
{\left[M_{e r}(\theta)\right]_{3 \times 3}} & {\left[L_{r r}\right]_{3 \times 3}}
\end{array}\right]
$$

para o equacionamento do torque, obtém-se a equação (2.20):

$$
T=\frac{1}{2}[i]_{1 \times 6}^{T}\left\{\frac{d}{d \theta}[L(\theta)]\right\}[i]_{6 \times 1}
$$

em que:

$$
[i]=\left[\begin{array}{c}
i_{e 1} \\
i_{e 2} \\
i_{e 3} \\
-- \\
i_{r 1} \\
i_{r 2} \\
i_{r 3}
\end{array}\right]
$$

Desenvolvendo-se a derivada em relação a $\theta$ na Equação (2.19), tem-se:

$$
\frac{d}{d \theta}[L(\theta)]_{6 \times 6}=\left[\begin{array}{cc}
{[0]} & \frac{d}{d \theta}\left[M_{r e}(\theta)\right] \\
\frac{d}{d \theta}\left[M_{e r}(\theta)\right] & {[0]}
\end{array}\right]
$$

Mas: 


$$
\left[M_{e r}(\theta)\right]=\left[M_{e r}(\theta)\right]^{T}
$$

Logo, tem-se:

$$
T=\frac{1}{2}\left[\left[i_{e}\right]^{T} \mid\left[i_{r}\right]^{T}\right]\left[\begin{array}{cc}
{[0]} & \frac{d}{d t}\left[M_{e r}(\theta)\right]^{T} \\
\frac{d}{d \theta}\left[M_{e r}(\theta)\right] & {[0]}
\end{array}\right]\left[\begin{array}{l}
{\left[i_{e}\right]} \\
-- \\
{\left[i_{r}\right]}
\end{array}\right]
$$

que pode ser escrito como:

$$
T=\frac{1}{2}\left\{\left[i_{r}\right]^{T} \frac{d}{d \theta}\left[M_{e r}(\theta)\right]^{T} \quad\left[\quad\left[i_{e}\right]^{T} \frac{d}{d \theta}\left[M_{e r}(\theta)\right]\right\}\left[\begin{array}{c}
{\left[i_{e}\right]} \\
-- \\
{\left[i_{r}\right]}
\end{array}\right]\right.
$$

Para simplificar todo o equacionamento do torque é preciso usar algumas propriedades advindas da álgebra linear sobre matrizes. Desta forma, consideram-se algumas propriedades matriciais, tais como as seguintes:

$$
[A]^{T}[B]^{T}=[B][A]
$$

sendo que:

$$
[C]=\left[[C]^{T}\right]^{T} \text { e }[A]^{T}[B]^{T} C=[B][A][C]
$$

então:

$$
[A]^{T}[B]^{T}\left[[C]^{T}\right]^{T}=[C]^{T}[A]^{T}[B]^{T}=[C]^{T}[B][A]
$$


Assim, com base nessas propriedades, a equação do torque dada em (2.25) pode ser escrita da seguinte forma:

$$
T=\left[i_{e}\right]^{T}\left\{\frac{d}{d \theta}\left[M_{e r}(\theta)\right]\right\}\left[i_{r}\right]
$$

Portanto, através desse processo de modelamento matemático, chegou-se às equações de tensão (Equações (2.15) e (2.16)) e torque (Equação (2.29)) do motor de indução.

\subsubsection{Transformações Lineares}

As equações matemáticas aqui modeladas para o motor de indução trifásico são não-lineares para o torque, pois nela há o produto de correntes, e lineares a coeficientes variantes no tempo para o motor, sendo estas tão difíceis de analisar quanto as não-lineares. Desta forma, foram desenvolvidas técnicas baseadas em transformações lineares com o objetivo de estabelecer modelos mais simples a partir do modelo original aqui estabelecido $[5,12,14]$.

Estas equações são acopladas devido às indutâncias mútuas entre os enrolamentos, assim, à medida que o rotor gira, tais termos acoplados variam com o tempo; desta forma, essas transformações lineares facilitam o cálculo da solução transitória, transformando as equações diferenciais variantes no tempo em equações de indutâncias constantes [5, 7]. Entre essas transformações lineares, as mais conhecidas são de Clark (“ $\alpha \beta 0$ ”) e a de Park (“qd0 ”). 


\subsubsection{Transformação Linear " $q d 0$ "}

A transformação " $q d 0$ " consiste em simplificar as equações da máquina introduzindo um conjunto de variáveis hipotéticas, transformando assim numa máquina bifásica com enrolamentos estatóricos fixos e enrolamentos rotóricos pseudo-estacionários [5]. A possibilidade de reproduzir o fluxo magnético no entreferro, bem como a distribuição de correntes no estator e rotor no sistema de coordenadas adotado como referência, tem o mesmo efeito do sistema de coordenadas original. Uma variável representada por uma relação biunívoca entre as variáveis dos dois sistemas de referência é expressa por:

$$
\gamma_{q d 0}=c^{-1} \gamma_{a b c}
$$

em que $C$ é a relação entre as variáveis dos dois sistemas de coordenadas. A Figura 2.2 mostra graficamente a ação de transformação onde $a_{e}, b_{e}$ e $c_{e}$ são os eixos de coordenadas referenciadas ao estator e $a_{r}, b_{r}$ e $c_{r}$ os eixos de coordenadas referenciados ao rotor. 


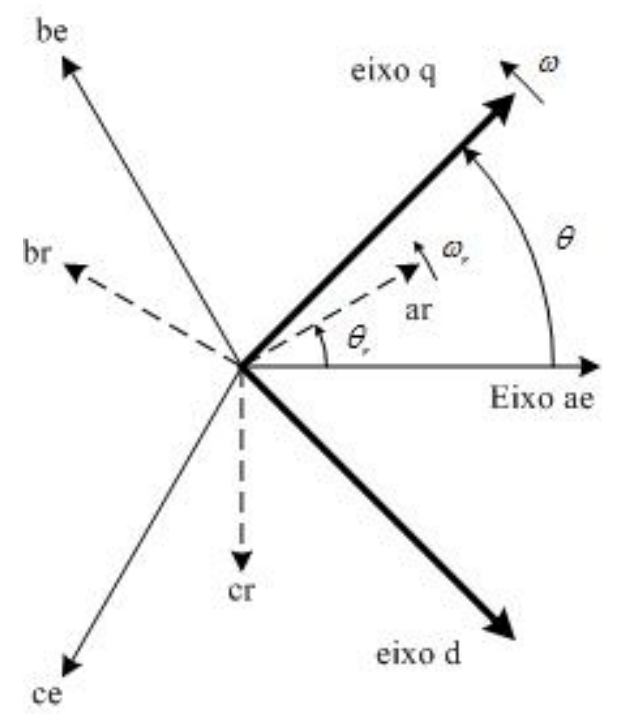

Figura 2.2 - Transformação de coordenadas.

A equação de transformação do sistema original " $a b c$ ", para "qd0" é descrita pela Equação (2.31).

$$
\left[\begin{array}{l}
\gamma_{q} \\
\gamma_{d} \\
\gamma_{0}
\end{array}\right]=\left[C_{q d 0}(\theta)\right]\left[\begin{array}{l}
\gamma_{a} \\
\gamma_{b} \\
\gamma_{c}
\end{array}\right]
$$

em que $\gamma$ pode representar a tensão, corrente ou fluxo eletromagnético de cada fase. A matriz transformação $\left[C_{q d 0}(\theta)\right]$ é dada por:

$$
\left[C_{q d 0}(\theta)\right]=\frac{2}{3}\left[\begin{array}{ccc}
\cos \theta & \cos \left(\theta-\frac{2 \pi}{3}\right) & \cos \left(\theta+\frac{2 \pi}{3}\right) \\
\sin \theta & \sin \left(\theta-\frac{2 \pi}{3}\right) & \sin \left(\theta+\frac{2 \pi}{3}\right) \\
\frac{1}{2} & \frac{1}{2} & \frac{1}{2}
\end{array}\right]
$$

e a matriz de transformação inversa $\left[C_{q d 0}(\theta)\right]^{-1}$ é expressa por: 


$$
\left[C_{q d 0}(\theta)\right]^{-1}=\left[\begin{array}{lrr}
\cos (\theta) & \sin (\theta) & 1 \\
\cos \left(\theta-\frac{2 \pi}{3}\right) & \sin \left(\theta-\frac{2 \pi}{3}\right) & 1 \\
\cos \left(\theta+\frac{2 \pi}{3}\right) & \sin \left(\theta+\frac{2 \pi}{3}\right) & 1
\end{array}\right]
$$

O sistema de coordenadas " $q d 0$ " é usualmente selecionado tomando-se por base a conveniência ou compatibilidade com a representação de outros componentes como descrito em [9]. Alem do mais, estas transformações reduzem a importância dos coeficientes variantes no tempo, como os encontrados nas equações que definem o motor da máquina.

Na análise do MIT há dois sistemas de referência, a saber: estacionário e o síncrono. De acordo com [9], para estudos de regime transitório é usualmente mais conveniente o uso de sistemas de coordenadas fixo, tanto para a simulação do MIT como do sistema de controle e acionamento, enquanto que estudos em regime permanente o referencial síncrono é o mais recomendado.

Este trabalho tem o interesse em simular a máquina do instante da partida ao regime permanente. Desta forma utiliza-se o sistema de coordenadas fixo para simulação. As equações são deduzidas para o sistema de coordenadas síncrono, que gira a uma velocidade $\omega=\omega_{e}$, como ilustrado na Figura 2.2. Fazendo $\omega$ igual a zero, obtém-se o sistema de coordenadas fixo. Esse modelo é genérico para simular tanto o regime transitório como permanente da máquina.

Como mencionado anteriormente, esta seção tem apenas o objetivo de demonstrar o modelamento matemático de forma resumida, visando promover o entendimento de como as simulações do motor de indução para as cargas em 
estudo serão implementadas. O detalhamento da transformação "qd0" pode ser encontrado em $[2,5]$.

A partir destas equações modeladas, pode-se simular o comportamento do motor de indução trifásico. Como mencionado anteriormente o objetivo deste trabalho é simular o comportamento do motor desde a partida até ao seu regime permanente, sendo este período extremamente curto, assim não serão consideradas variações térmicas, o efeito pelicular e a saturação da máquina. Deste modo, a consideração dessas variáveis fica como proposta para trabalhos futuros.

Para o motor, considera-se que as três fases que alimentam o motor são equilibradas e senoidais, estando ausentes de distorções harmônicas. A freqüência é de $60 \mathrm{~Hz}$, conforme o padrão brasileiro.

As cargas que serão aplicadas ao eixo do MIT através de simulação computacional são divididas conforme será apresentado na Seção 2.4 desse capítulo.

No Apêndice B é apresentado o modelo desenvolvido no simulink/matlab utilizado para a simulação da máquina aqui equacionada.

\subsection{Classificação dos Principais Tipos de Cargas Acopladas ao Motor de Indução}

Em [15] é afirmado que uma carga mecânica requer uma determinada potência. De certa forma, isso equivale a afirmar que tal carga necessita de um determinado conjugado a uma dada velocidade de rotação. Ou seja, para um sistema dotado de movimento de rotação, tem-se:

$$
P=C \cdot \omega
$$


em que:
$P$ é a potência desenvolvida $(\mathrm{kW})$.
C é o conjugado desenvolvido (Nm).
$\omega$ é a velocidade angular do movimento ( $\mathrm{rad} / \mathrm{s})$.

De acordo com [15], as cargas mecânicas podem ser divididas em seis grandes grupos em função de suas características de conjugado versus velocidade:

- Carga Constante;

- Carga Linear;

- Carga Quadrática;

- Carga Inversa;

- Cargas que não solicitam conjugado;

- Conjugado não uniforme.

As cargas constantes são praticamente independentes da rotação; assim, elas apresentam pouca ou nenhuma variação de conjugado resistente exigido do motor. Desta forma, o seu valor com o aumento da velocidade permanece constante. Como exemplos desse tipo de carga, têm-se: guinchos, guindastes, transportadores de correias sob carga constante [15]. A Figura 2.3 ilustra o comportamento dessa carga. 


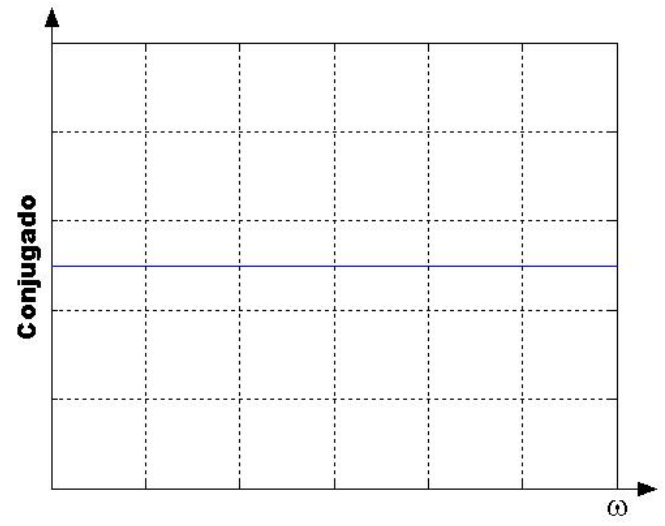

Figura 2.3 - Conjugado de Carga Constante.

As cargas lineares são aquelas que variam linearmente com a rotação (Figura 2.4), sendo que tal tipo de carga é encontrado em diversas aplicações como moinhos de rolos, bombas de pistão, serras para madeiras [15].

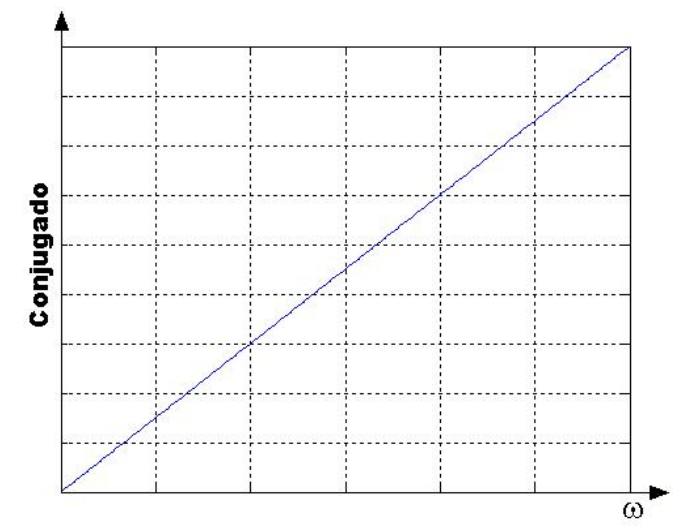

Figura 2.4 - Conjugado de Carga Linear.

As cargas quadráticas são cargas que variam com o quadrado da rotação e são encontradas em aplicações como ventiladores, centrífugas, exaustores [15]. O seu comportamento pode ser ilustrado de acordo com a Figura 2.5. 


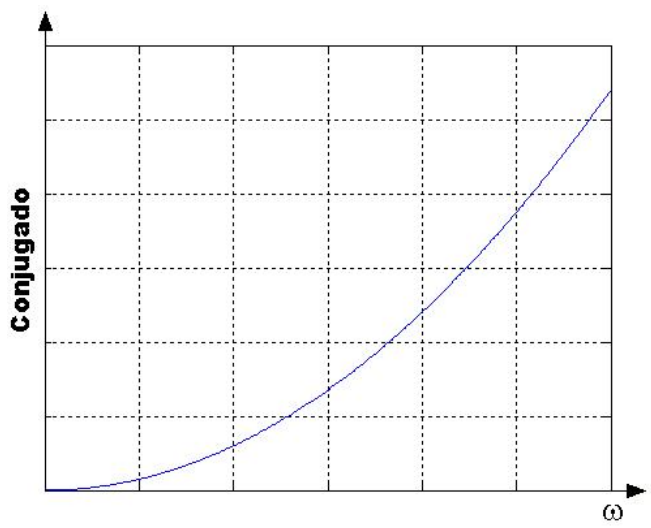

Figura 2.5 - Conjugado de Carga Quadrática.

A carga cujo conjugado varia inversamente com a rotação, resultando em potência constante, ou seja, diminuindo com o aumento da velocidade, é denominada de carga inversa. As cargas inversas são encontradas em aplicações como máquinas operatrizes ( fresadoras e mandriladoras [15]). Seu comportamento pode ser observado conforme mostra a Figura 2.6.

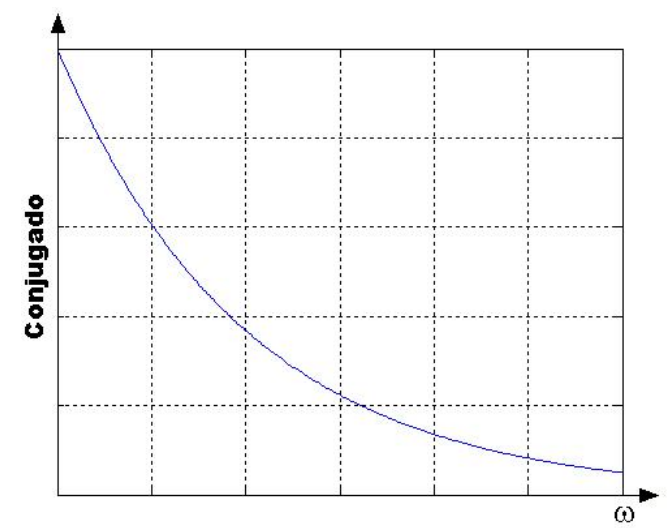

Figura 2.6 - Conjugado de Carga Inversa.

As cargas que não solicitam conjugados também são denominadas de volantes e tem como propósito liberar a maior parte da energia cinética armazenada visando suprir picos de demanda de energia por parte da máquina acionada. Desta forma, o motor atua como repositor de energia cinética entre dois picos consecutivos de demanda, vencendo apenas o conjugado resistente originado por atritos. $O$ 
volante é constituído normalmente de ferro fundido, alinhado e balanceado de forma a não produzir vibração no eixo do motor [2]. Como exemplo desse tipo de carga, têm-se as prensas de perfuração e estampagem profundas, sendo ambas não hidráulicas [15].

Para o conjugado de carga que varia de maneira não uniforme com a rotação não se tem uma função matemática que descreva de forma satisfatória seu comportamento. De acordo com [15], tem-se como exemplo desse tipo carga, fornos rotativos de grandes porte. 



\section{Aspectos de Sistemas de Inferência Fuzzy}

\subsection{Introdução}

A lógica fuzzy foi desenvolvida por L. A. Zadeh em 1965 para representar o conhecimento incerto ou impreciso. Consiste em meios aproximados mais efetivos de descrever o comportamento de sistemas que são muito complexos, mal definidos ou não simples de se analisar matematicamente $[16,17] .$.

O sistema fuzzy permite trabalhar com indecisões vindas do raciocínio humano, pois muitas das tomadas de decisões humanas são abstratas, de tal forma que a lógica clássica não consegue inferí-lo de forma apropriada no modelo computacional.

A teoria de conjuntos fuzzy e os conceitos de lógica fuzzy podem ser utilizados para traduzir em termos matemáticos a informação imprecisa expressa por um conjunto de regras lingüísticas.

A aplicação do sistema de inferência fuzzy se tem mostrado eficiente em diversas áreas, tais como controle, classificação e reconhecimento de padrões, visão computacional e otimização.

Há diversos trabalhos e livros disponíveis na literatura sobre os sistemas fuzzy, detalhando de forma consistente a teoria de conjuntos fuzzy, os conceitos de lógica fuzzy juntamente com o processo de inferência fuzzy e várias aplicações que envolvem esse sistema [18-21]. Desta forma, neste capítulo serão abordados apenas alguns conceitos necessários para que se tenha, de forma objetiva, a compreensão do sistema de inferência fuzzy adotada para o desenvolvimento deste mesmo. 


\subsection{Constituição dos Sistemas de Inferência Fuzzy}

Para o entendimento dos sistemas fuzzy, torna-se necessário um breve conhecimento sobre os princípios de conjuntos fuzzy, desde o processo de fuzzificação, passando pela inferência fuzzy e indo até o processo de defuzzificação do sistema fuzzy.

Os sistemas de inferência fuzzy permitem o mapeamento do conhecimento a respeito de um processo através de regras fuzzy do tipo "Se - Então". De posse dessas regras, pode-se determinar o comportamento das variáveis de saída do sistema, isso por intermédio do processo de inferência. Desta forma, o sistema de inferência fuzzy permite o tratamento de informações incertas ou imprecisas, representadas por uma família de conjuntos fuzzy. Assim, a inferência fuzzy oferece uma forma sistemática para a modelagem de processos cujas informações são fornecidas de forma qualitativa.

O processo de inferência fuzzy pode ser dividido em três etapas: etapa de fuzzificação; regras e inferências; e defuzzificação, como mostra a Figura 3.1.

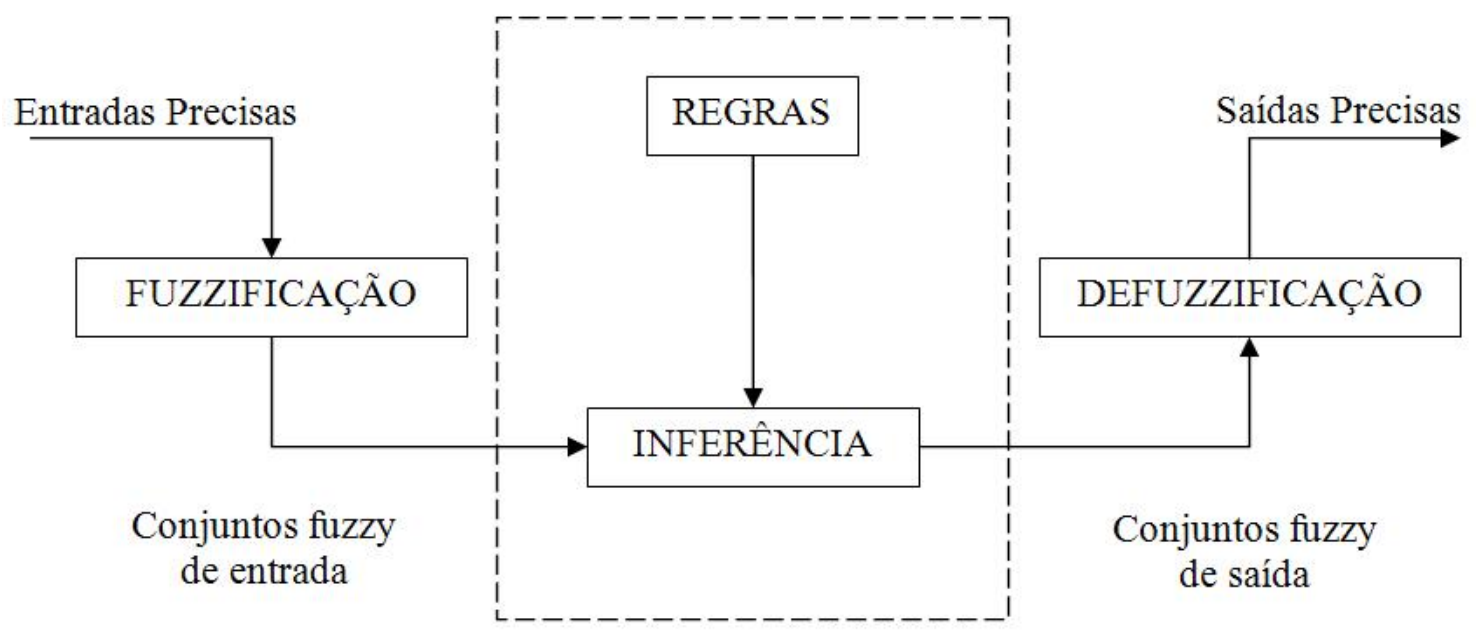

Figura 3.1 - Diagrama do processo de inferência fuzzy.

A seguir, será explicada a funcionalidade de cada bloco do diagrama da Figura 3.1: 
Fuzzificação: Nessa etapa as entradas não fuzzy ou precisas são apresentadas ao sistema por intermédio de medições ou observações de dados, os quais são considerados como sendo o conjunto de dados de entrada do sistema. Deste modo, é necessário efetuar um mapeamento desses dados de entrada para o conjunto fuzzy, de tal forma, que o sistema possa identificar a quais variáveis lingüísticas esses dados pertencem e o quanto os mesmos são pertinentes a essas variáveis. Nesta fase também ocorre à ativação das regras fuzzy relevantes para um dado sistema.

Regras: As regras podem ser fornecidas por especialistas, com base em seu conhecimento a respeito do processo que se deseja analisar, em forma de sentenças lingüísticas, e se constituem em um aspecto fundamental no desempenho de um sistema de inferência fuzzy. Desta forma, o sistema de inferência fuzzy terá um desempenho confiável e satisfatório, somente se, as regras expressarem o comportamento do sistema de forma fiel e consistente. Entretanto, a extração de um conjunto de regras advindas do conhecimento desses especialistas pode não ser uma tarefa fácil, por mais que os mesmos conheçam profundamente o problema que se deseja analisar. Portanto, existem outras alternativas ao uso do conhecimento dos especialistas para a definição da base de regras, tais como os métodos de extração de regras a partir de dados numéricos. Esses métodos são particularmente úteis em aplicações onde haja disponível um conjunto de dados numéricos que refletem o comportamento entrada/saída do sistema.

Inferência: No processo de inferência ocorrem as operações com os conjuntos fuzzy. Um aspecto importante é a definição dos conjuntos fuzzy correspondentes às variáveis de entrada e às de saída, pois o desempenho do sistema de inferência dependerá do número de conjuntos e de sua forma adotada. É 
possível efetuar uma sintonia manual das funções de pertinências dos conjuntos, mas é mais comum empregarem-se métodos automáticos. A integração entre sistemas de inferências fuzzy e redes neurais artificiais tem se mostrado adequada para a sintonização das funções de pertinências, assim como para a geração automática de regras.

Defuzzificação: Após o processo de Inferência, tem-se o processo de defuzzificação que, de posse do conjunto fuzzy de saída adquirido através do processo de inferência, é responsável pela interpretação dessa informação para saídas precisas (dados não fuzzy). Isto se faz necessário, já que, em aplicações práticas são requeridos valores não fuzzy.

Na lógica clássica, modelo de Aristotéles, uma dada variável é ou não pertencente a uma classe; desta forma, na teoria dos conjuntos pertencente a este modelo, a sua função de inclusão indica se um determinado elemento, de forma total, pertence ou não a um dado conjunto. Já em relação aos conjuntos fuzzy, um objeto pode pertencer a mais de um conjunto ao mesmo tempo, ou seja, os objetos podem pertencer parcialmente a um certo conjunto, deixando a função de inclusão flexibilizada.

Portanto, cada objeto tem um grau de pertinência em relação a um dado conjunto fuzzy, sendo este definido por uma função chamada de função de pertinência, ou seja:

$$
\mu_{A}(x): X \rightarrow[0,1] ; x \in X
$$

onde $\mu_{A}(x)$ retorna o grau de pertinência do objeto $x$, pertencente ao universo de discurso $X$, em relação ao conjunto fuzzy $A$, sendo que o grau de pertinência é um 
valor normalizado pertencente (localizado) entre 0 (zero) e 1 (um), onde tais valores limites indicam exclusão ou inclusão totais ao conjunto.

Os principais tipos de função de pertinência são as triangulares, trapezoidais, gaussianas e sigmóides. A função gaussiana, a qual é utilizada neste trabalho, é definida pela equação (3.2):

$$
\mu_{A}(x)=e^{-K(x-m)^{2}}, \operatorname{com} K>1
$$

no qual $m$ é o centro da gaussiana e $K$ é uma constante que define sua excentricidade.

Na Figura 3.2 é apresentada uma ilustração de uma função de pertinência do tipo gaussiana.

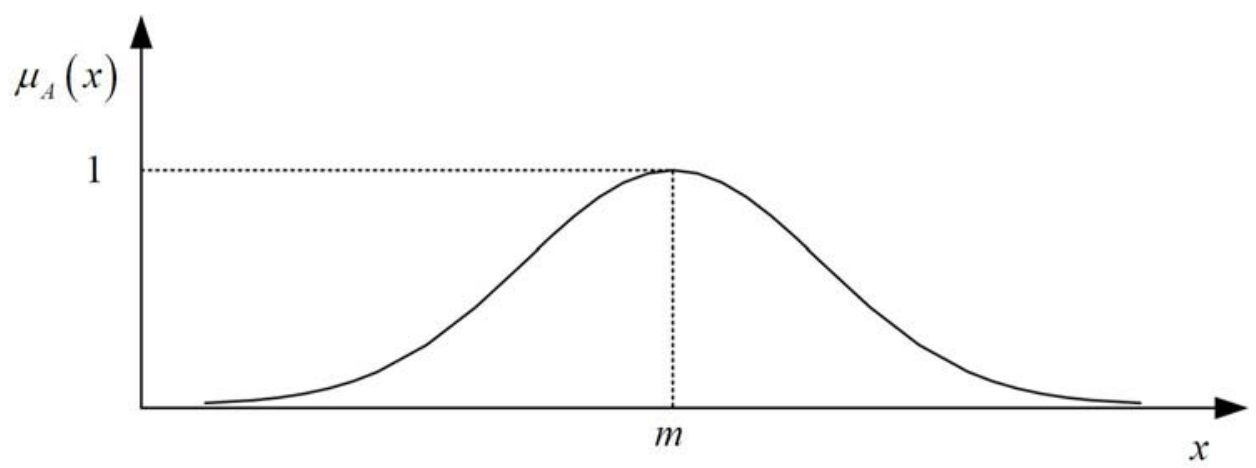

Figura 3.2 - Função de pertinência Gaussiana.

O processo de inferência se caracteriza sobre tudo na geração das regras fuzzy, no ajuste e nas definições dos conjuntos fuzzy correspondentes às variáveis de entradas e saídas, pois o desempenho do sistema de inferência dependerá do número de conjuntos e de sua forma geométrica (função de pertinência) adotados.

No processo de geração das regras, estas podem ser fornecidas por especialistas, em forma de sentenças lingüísticas, como mencionado anteriormente. 
Elas assumem um aspecto fundamental no desempenho do sistema de inferência fuzzy, pois a partir dessas se pode determinar, por intermédio do processo de inferência, o comportamento das variáveis de saídas do sistema. Entretanto, a extração de um conjunto de regras, do tipo "se - então", provenientes de um especialista, pode não ser uma tarefa fácil por mais que os mesmos conheçam profundamente o problema abordado. Assim, uma outra alternativa empregada, ao invés do uso de especialistas para a definição do conjunto de regras, é a utilização de métodos mais automáticos de extração de regras.

Tanto as regras como a sintonia das funções de pertinências dos conjuntos podem ser feitas de forma manual, mas são comumente utilizados métodos automáticos para ambos. A integração entre sistemas de inferências fuzzy e redes neurais artificiais tem se mostrado adequada para essa finalidade. O ANFIS (Adaptive Neuro-Fuzzy Inference System) é uma dessas abordagens, e foi utilizada nesse trabalho para a sintonia das funções de pertinência. Ele será abordado com maiores detalhes na Seção 3.3.

Dentro do sistema de inferência fuzzy, tem-se o processo de implicação fuzzy que consiste na geração da região de saída fuzzy dada uma entrada também fuzzy, ou seja, representa a implicação dos resultados obtidos dos conjuntos de entrada no conjunto de saída. Assim, com esse resultado é possível obter um valor numérico não-fuzzy do sistema fuzzy por intermédio do processo de defuzzificação. Dentre os operadores de implicação, têm-se Mandani, Zadeh, Aritmético, entre outros [19].

Existem também diversos métodos de defuzzificação, destacando-se entre eles o método do centro de área, método da média dos máximos (Equação (3.3)) e método do primeiro máximo [19]. No primeiro método, a saída é determinada 
extraindo-se o valor do universo de discurso que corresponda ao centro de área da região fuzzy de saída. No segundo, a saída precisa é obtida tomando-se a média entre os dois elementos extremos no universo de discurso e que correspondem aos maiores valores da função de pertinência de saída, ou seja:

$$
M_{M A X}=\sum_{k=1}^{M} \frac{V_{k}}{M}
$$

sendo que $V_{k}$ são os valores de $C^{\prime}$ (região fuzzy de saída) que contém graus de pertinência máximos e $M$ é a quantidade destes elementos. Uma ilustração envolvendo o método da média dos máximos é apresentada na Figura 3.3.

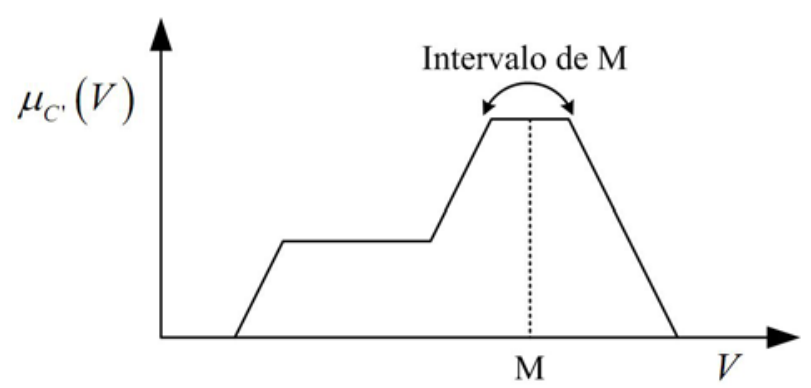

Figura 3.3 - Ilustração do método da média dos máximos.

\subsubsection{Sistema de Inferência no Modelo de Takagi-Sugeno}

Devido ao fato de que no sistema ANFIS (Seção 3.3) se utiliza o modelo de inferência de Takagi-Sugeno, realizar-se-á então aqui uma explanação visando um melhor entendimento do sistema ANFIS adotado nesse trabalho para a criação das regras e ajuste das funções de pertinências.

O modelo de Takagi-Sugeno, assim como outros modelos de inferência, consiste em obter todas as contribuições individuais advindas de cada uma das 
regras ativadas, sendo que a função de pertinência de saída do método de TakagiSugeno pode ser tanto uma função linear como uma função constante.

Portanto, para a inferência de Takagi-Sugeno, deve-se primeiramente fuzzificar todas as entradas, encontrar todas as regras ativadas, determinar os valores individuais das saídas vindas das funções de saídas de Takagi-Sugeno. Assim, de posse desses valores, realiza-se então uma ponderação entre os mesmos a fim de produzir uma resposta final.

No modelo de Takagi-Sugeno uma regra de inferência $R_{i}$ é dada da seguinte forma:

$$
\begin{aligned}
& R_{i} \text { : Se Entrada } 1 \text { é } x_{1} \text { e Entrada } 2 \text { é } x_{2} \\
& \text { Então Saída é } y_{i}=a_{i} \cdot x_{1}+b_{i} \cdot x_{2}+c_{i}
\end{aligned}
$$

sendo que o resultado final é obtido pela média ponderada de todos os resultados de saída, considerando os graus de pertinência de cada regra $R_{i}$ ativada, conforme a Equação (3.4).

$$
y=\frac{\sum_{i=1}^{N} \mu_{i} \cdot y_{i}}{\sum_{i=1}^{N} \mu_{i}}
$$

em que $y$ é a saída final, $N$ representa o total de regras ativadas, e $\mu_{i}$ é o grau de pertinência em relação à contribuição de cada regra ativada.

A ilustração seguinte (Figura 3.4) mostra os procedimentos internos associados ao modelo de Takagi-Sugeno quando aplicado a um sistema que possui 
duas variáveis como dado de entradas: temperatura, com domínio variando de 800 a $1200{ }^{\circ} \mathrm{C}$; e volume, tendo domínio variando de 20 a $80 \mathrm{~m}^{3}$ de água. A variável de saída é a pressão, tendo seu domínio variando de 4 a 12 atm. Uma particularidade do método de Takagi-Sugeno é a exigência de se ter apenas uma variável de saída. Entretanto, caso o sistema a ser modelado tiver mais que uma saída, basta-se então implementar um modelo de Takagi-Sugeno para cada uma delas.

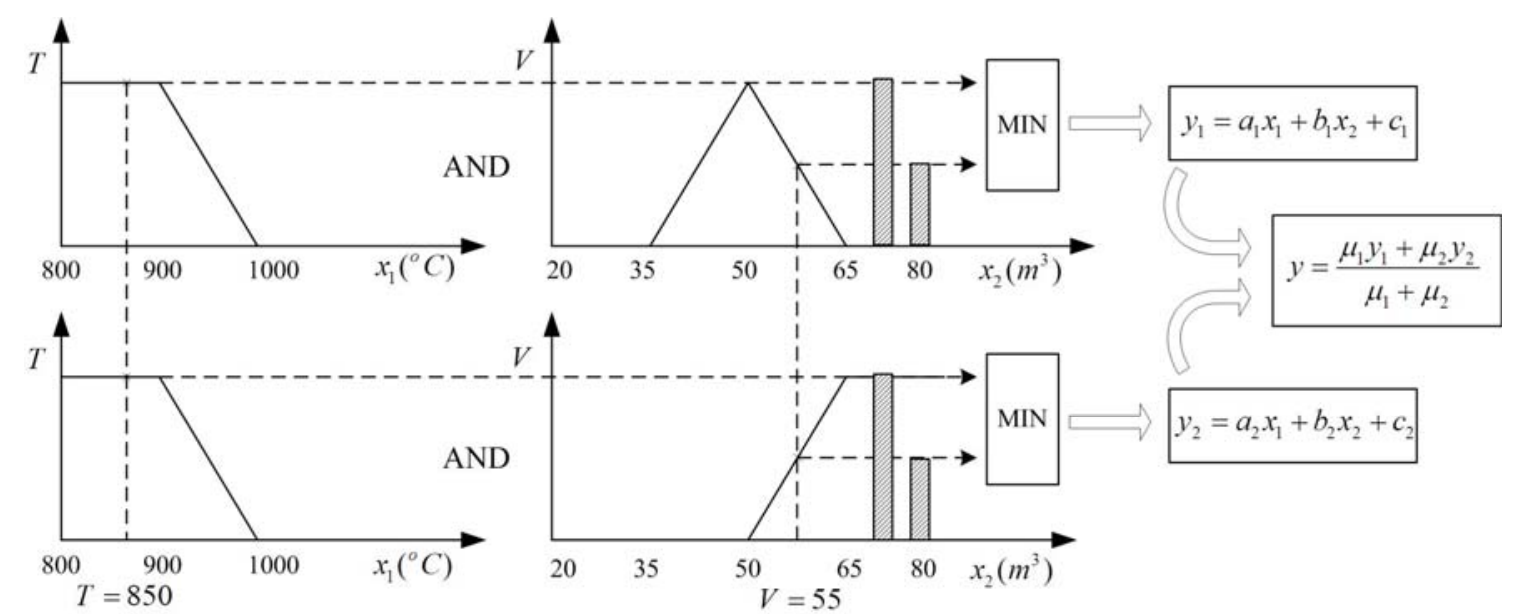

Figura 3.4 - Processos Internos ao modelo de Takagi-Sugeno.

\subsection{Aspectos de Sintonização de Parâmetros de Sistemas de Inferência Fuzzy}

O sistema de inferência fuzzy consiste em mapear as características de entrada através de funções de pertinências, que juntamente com as regras fuzzy resultarão em uma implicação. Essas implicações são agregadas proporcionando uma função de pertinência resultante, na qual pode ser determinado o valor preciso (não-fuzzy) da saída ou a decisão associada à saída do sistema.

Para tanto, há necessidade de se ter o conhecimento específico e detalhado dos processos envolvidos, de tal forma que o sistema seja implementado com as funções de pertinências adequadas e com as regras fuzzy coerentes ao problema 
em questão, proporcionando então uma confiabilidade e uma eficiência na obtenção das respostas esperadas (conhecimento extraído de um especialista).

Alternativamente, ao invés de extrair as características do processo por intermédio do conhecimento de um especialista visando ajustes dos parâmetros das funções de pertinência, um sistema de inferência neuro-fuzzy adaptativo pode ser capaz de extraí-los automaticamente, pois em determinadas ocasiões, a identificação detalhada dos processos, objetivando extrair as características da função de pertinência a ser utilizada, nem sempre é uma tarefa fácil.

O Adaptive Neuro-Fuzzy Inference System (ANFIS) ou sistema de inferência neuro-fuzzy adaptativo é baseado em técnicas de aprendizagem implementadas em redes neurais artificiais [22]. Através das informações contidas no conjunto de dados, torna-se possível ajustar os parâmetros da função de pertinência de tal forma que permite ao sistema de inferência fuzzy o mapeamento adequado do relacionamento entrada-saída do conjunto de dados. Para ressaltar, o ANFIS é baseado no modelo de inferência de Takagi-Sugeno como mencionado anteriormente.

$\mathrm{Na}$ literatura, encontram-se vários trabalhos que utilizam o ANFIS em diversas áreas. Em [23] o ANFIS é utilizado para a estimação dos parâmetros de um motor de indução, sendo obtido resultados satisfatórios. Em [24] é proposto um novo método para a identificação de sistemas não-lineares utilizando ANFIS. Por intermédio de simulações, o artigo menciona que o ANFIS se mostrou bastante eficiente na identificação de sistemas não-lineares. Em [25] é apresentado um sistema de controle de torque de um motor de indução utilizando ANFIS. De acordo com os seus resultados, o controle de torque neuro-fuzzy obteve melhores respostas frente ao controle de torque convencional. 
Portanto, para os ajustes de sintonização dos parâmetros dos sistemas de inferência fuzzy deste trabalho, adotar-se-á o ANFIS, sendo que o mesmo já se encontra também implementado no toolbox (Fuzzy Logic) do Matlab

\subsubsection{Características do ANFIS no Matlab}

O Matlab possui um componente ANFIS que permite ajustar as funções de pertinência e gerar as regras fuzzy. Desta forma, nesta seção será apresentado um breve estudo da utilização do ANFIS implementado pelo Matlab.

O Matlab possui uma interface gráfica para o ANFIS, sendo a mesma acessada através do comando anfisedit digitada na janela de comandos. A Figura 3.5 mostra a interface de configuração dos parâmetros que deverão ser inseridos para que o sistema faça a inferência.

Primeiramente, deve-se tratar os dados que serão utilizados no processo de aprendizagem do sistema, sendo que tais dados devem estar contidos em uma matriz. Como exemplo, se forem utilizadas duas entradas, a matriz deverá conter três colunas, sendo a última contendo os dados de saída. Essa matriz é carregada pela ferramenta apertando-se o botão load data, apresentado na Figura 3.5.

Após o carregamento dos dados, deve-se configurar alguns parâmetros para a inicialização do sistema de inferência fuzzy. Assim, em Generate FIS (ao pressionar esse botão aparecerá a Figura 3.6), deve-se parametrizar o ANFIS. Utilizou-se neste trabalho a opção grid partition, que consiste em agrupar os dados representativos do problema a ser mapeado em classes que contenham algum nível de similaridade. Portanto, os parâmetros necessários a serem definidos consistem na definição do número de funções de pertinências, no tipo de função de pertinência 
que será aplicada, bem como o tipo de função de saída a ser empregado no sistema. A Figura 3.6 mostra a janela na qual são configuradas essas informações iniciais.

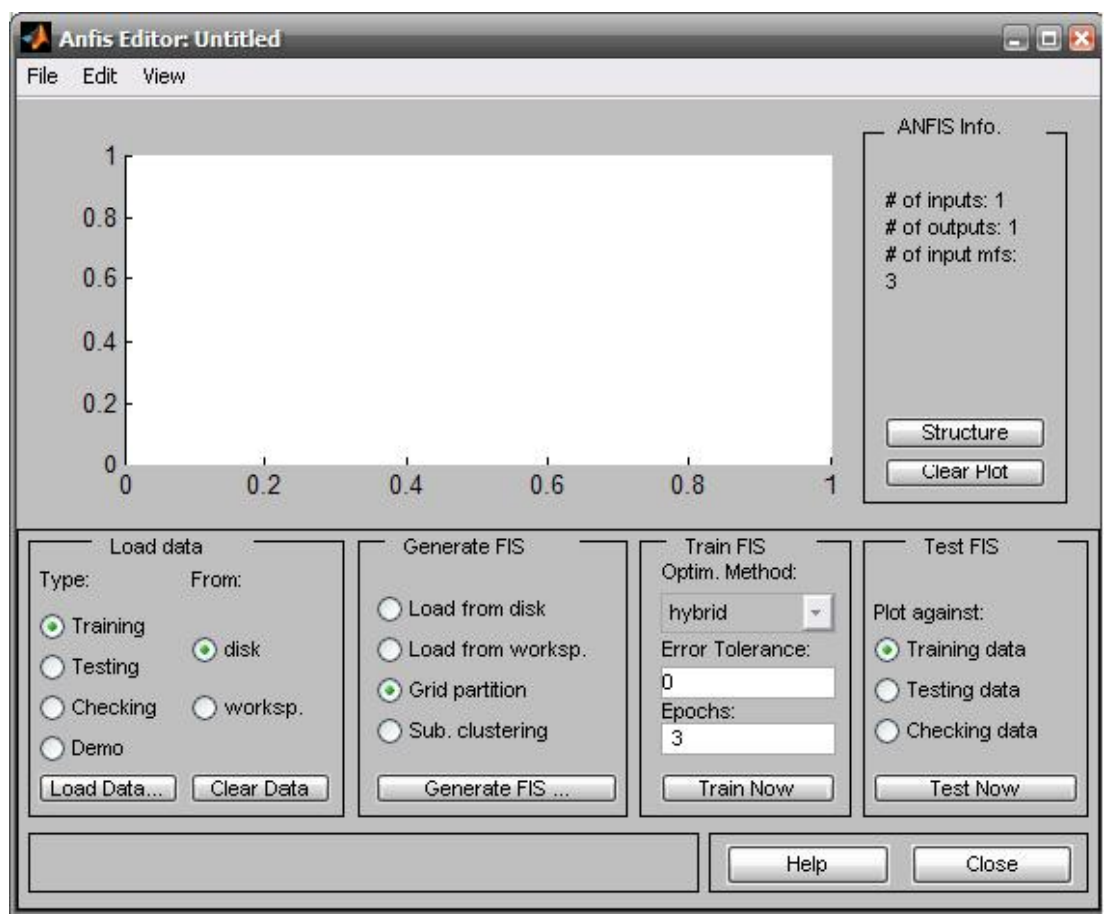

Figura 3.5 - Interface gráfica do ANFIS no Matlab.

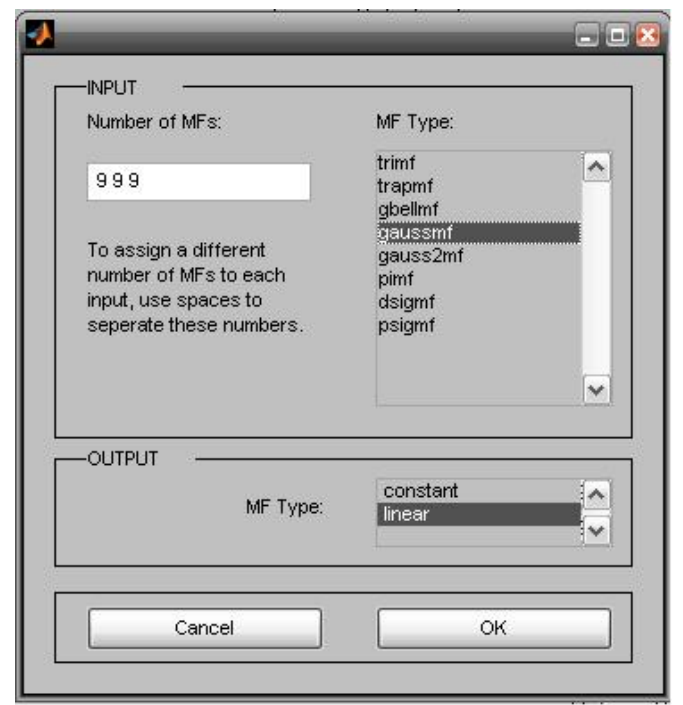

Figura 3.6 - Configuração dos parâmetros de inicialização do sistema de inferência fuzzy

Após a definição dos parâmetros de inicialização do sistema fuzzy (número de funções de pertinência para cada entrada, tipo de função de pertinência, e tipo de 
função de saída), ajusta-se o número de épocas desejadas para que o algoritmo de treinamento seja executado, além do erro mínimo que se deseja alcançar. O algoritmo é finalizado quando algum desses parâmetros for alcançado, pois ambos são considerados como critério de parada para o treinamento.

O ANFIS emprega o algoritmo de treinamento backpropagation ou, o método híbrido (combinação da estimação de mínimos quadrados com backpropagation) para estimar os parâmetros da função de pertinência [22]. Desta forma, o toolbox fornece a opção de escolher qual treinamento se deseja utilizar. Nesse trabalho foi utilizado o treinamento pelo método híbrido.

Após as configurações necessárias, faz-se o treinamento do sistema que retornará os ajustes das funções de pertinência juntamente com as regras. A Figura 3.7 ilustra a arquitetura do ANFIS, onde se pode perceber que as duas primeiras camadas não são amplamente conectadas. Na configuração das ligações entre estas duas camadas estão implicitamente caracterizados os antecessores das regras.

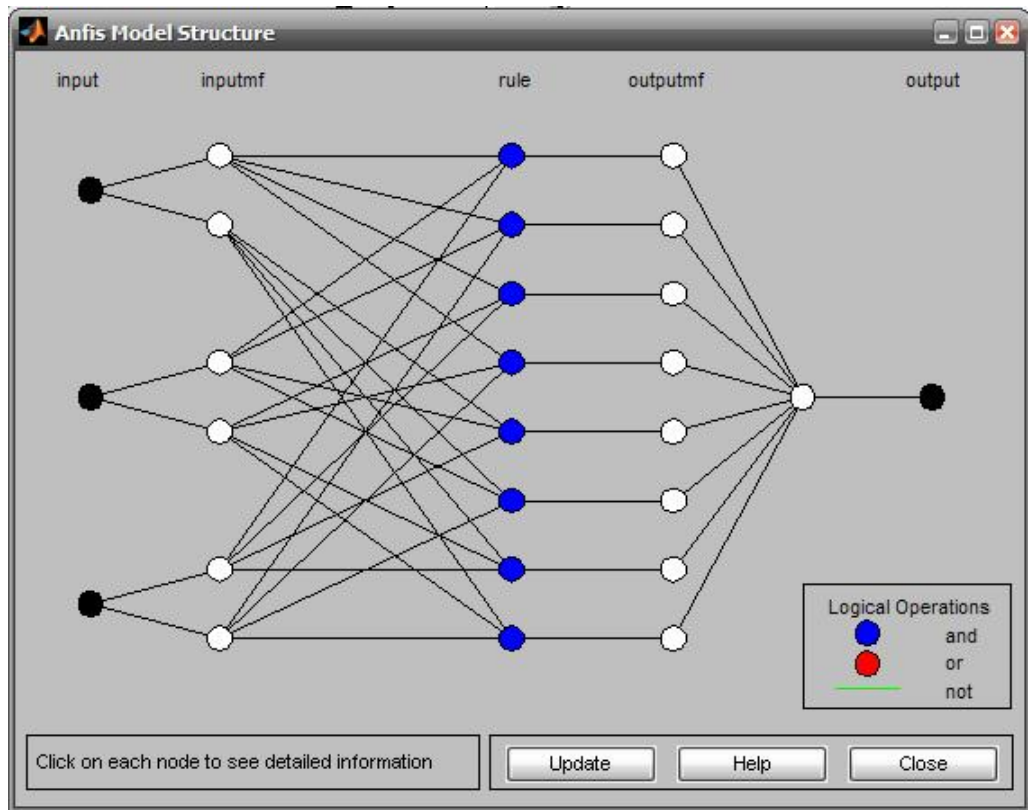

Figura 3.7 - Arquitetura do ANFIS. 
Devido ao fato de se utilizar em sua estrutura o modelo de inferência de Takagi-Sugeno, o ANFIS possui algumas limitações de aplicação, tal como a exigência de se ter apenas uma variável de saída. A mesma deve ser obtida utilizando-se a defuzzificação pela média ponderada dos pesos [22]. Todas as funções de pertinências de saída devem ser do mesmo tipo, ou seja, linear ou constante. Maiores detalhes da técnica ANFIS usada no Matlab é apresentada no Apêndice A.

\subsection{Aplicações de Sistemas de Inferência Fuzzy em Motores de Indução}

Os estudos feitos em lógica fuzzy mostraram que a mesma é um excelente aproximador universal $[26,27]$, pois os sistemas fuzzy são utilizados em diversas aplicações, entre elas, estão aquelas relacionadas às máquinas elétricas. Neste tópico serão citadas algumas referências sobre aplicação de sistemas de inferência fuzzy, direcionando para a estimativa de torque de carga em motores de indução trifásicos.

$\mathrm{Na}$ literatura, muitas aplicações para a modelagem de processos relacionadas ao MIT utilizando sistemas fuzzy podem ser encontradas [28], embora as aplicações para estimação de seus parâmetros possam ser consideradas relativamente novas $[29,30]$.

A medição do torque é de grande importância em aplicações industriais. As principais técnicas para medida do torque utilizam torquímetros girantes ou células de carga. Os torquímetros girantes são acoplados entre o eixo da máquina e do motor e medem conjugado de carga. As células de carga, por sua vez, medem 
conjugado eletromagnético. Mas, tais métodos são invasivos e de difícil implementação em sistemas que já estão sendo operados [31].

Em [28], apresenta-se um método para estimação de torque on-line do MIT, onde o sistema fuzzy é baseado em cinco entradas: o valor da temperatura do enrolamento do estator, as medidas estacionárias das componentes qd das correntes do estator, e estimação das componentes qd do fluxo do rotor. Em tal artigo, o desempenho do estimador baseado em lógica fuzzy obteve melhores resultados do que os estimadores clássicos (baseados no produto vetorial entre corrente do estator e fluxos). Embora o desempenho do estimador fosse demonstrada com controlador vetorial indireto, ele pode também ser estendido a outros tipos de sistemas.

O ajuste da velocidade baseado em controles vetoriais e controle direto do torque tem conquistado grande popularidade em aplicações de alto desempenho [32]. Os medidores de sinais dessas variáveis, como sensor de fluxo, velocidade e torque são caros, então o controle de MIT por sensorless tem recebido bastante atenção [33].

Alguns estimadores usam um simples modelo com parâmetros constantes do motor. Porém, a variação dos parâmetros do motor de indução ao longo de sua operação vem demonstrando ser uma das mais importantes fontes de erros dos controladores de alto desempenho (exemplo: resistência do estator e rotor), os quais são usados em técnicas de controle direto de torque e controle vetorial.

A variação da temperatura gerada na máquina ao longo do seu regime de operação produz alteração significativa dos parâmetros do modelo. Logo, quando são utilizados estimadores baseados nos modelos da máquina, como observadores de Luenberger, Modelo de Referência Adaptativo ( MRAS - MODEL REFERENCE 
ADAPTIVE SYSTEM ) e filtro de Kalman, há um desvio entre o valor estimado e o valor real da variável estimada; a saber: fluxo eletromagnético, torque e velocidade.

Este desvio ocasiona a deterioração do algoritmo de controle o qual foi sintonizado para a situação de início de operação (a frio) ou em regime permanente (a quente). Os sistemas fuzzy, por sua vez, não dependem do modelo e dos parâmetros da máquina. Então, torna-se possível mapear a relação entrada/saída de uma determinada variável considerando a dinâmica da máquina em estudo, seja em regime transitório ou em regime permanente.

$\mathrm{Na}$ técnica de controle direto de torque (DTC - DIRECT TORQUE CONTROL) é requerido o conhecimento da amplitude e posicionamento angular do fluxo a ser controlado, adicionando informações relacionadas com a velocidade angular em aplicações de controle de velocidades. No entanto, o não conhecimento do torque de carga e as incertezas relacionadas às resistência do estator/rotor por causa das condições de operação constitui o maior desafio para o desempenho de um sistema, conforme relatado na referência [34]. Há diversos trabalhos na área envolvendo o estudo do DTC, assim como o FOC (FIELD ORIENTATION CONTROL). Em [35] é proposto um método que não se enquadra em nenhuma dessas duas categorias, mas se aproxima mais do FOC.

Alguns estimadores de torque de carga têm também sido implementados baseados em filtros de Kalman e método recursivo dos mínimos quadrados [36].

Para o controle vetorial de alto desempenho sensorless, torna-se essencial saber as variações de temperatura e freqüência do estator, do rotor e do torque de carga. Entretanto, a resistência do estator pode ser obtida pela medição da temperatura do estator. Há dificuldades físicas em determinar a resistência do rotor em um MIT de gaiola de esquilo. Assim, a estimação da resistência do rotor e torque 
de carga são temas relevantes de pesquisa. Em [34], o torque de carga foi considerado como uma constante no algoritmo para considerar o atrito viscoso, obtendo-se um melhoramento do desempenho do estimador por intermédio do método de EKF (EXTENDED KALMAN FILTER).

O método de controle sensorless para MIT é usado não somente para onde os sensores não podem ser instalados por causa do seu ambiente, mas também para alcançar precisão de controle de sistemas de uso geral. Em [37], utiliza-se um modelo matemático que depende dos parâmetros atuais do motor para simular o MIT. A variação de ambos, torque e velocidade, com a corrente do estator são computados com diferentes valores de freqüência. Cada um deles (torque e velocidade) são simulados com o auxilio de uma regressão polinomial (fitting methods) de sexta ordem, na qual os coeficientes da corrente do estator varia com a alteração da freqüência, sendo que cada um desses coeficientes são simulados por uma equação polinomial de oitava ordem em função da freqüência. Portanto, o torque e velocidade podem ser calculados pela medição digital de ambas, corrente e freqüência, sem a necessidade de um sensor. Por causa da alta ordem das equações polinomiais esse método tem também suas limitações.

Em [38] é realizada uma pesquisa referente aos métodos de estimação, no qual são listados alguns algoritmos, ou combinações de diferentes algoritmos para estimações, tal como o método AGT ( AIR GAP TORQUE ) proposto em [39]. Este método considera as perdas associadas entre as tensões e corrente. No entanto, é necessário um teste sem-carga, sendo que a principal ressalva é o elevado nível invasivo. Outro método é o Shaft Torque Method, abordado em [40], sendo esse também bastante invasivo. 
Em [41] é projetado e implementado um controlador adaptativo de velocidade que estima o torque de carga para um MIT utilizando técnicas de processamento paralelo. Esse torque é obtido através de um observador de conjugado de carga baseado em mínimos quadrados de primeira ordem de tal forma que consiga descobrir qualquer mudança lenta ou súbita de perturbação de torque. Os autores concluem que há uma melhoria significativa quando utilizado um estimador de conjugado de carga.

Em [42] é proposto um estimador de torque e velocidade, mas somente para baixas freqüências. Já em [31] é proposta uma abordagem pouca invasiva, pois necessita apenas da medição da corrente e da tensão elétrica para a sua computação. A aplicabilidade é assegurada para sistemas com dinâmica lenta como, por exemplo, sistemas de elevação artificial de petróleo do tipo cavidades progressivas.

Assim, conforme pode ser testemunhado, há diversos estudos envolvendo a estimativa do conjugado de carga, pois a sua importância para os processos que utilizam os motores de indução é bem elevada. Portanto, este trabalho vem contribuir com mais uma metodologia para a estimativa do torque por intermédio dos sistemas fuzzy. 


\section{Metodologia Proposta Para Identificação de Torque de Carga Usando Sistemas Fuzzy}

\subsection{Introdução}

Neste capítulo serão descritas as considerações e metodologias empregadas com a finalidade de se implementar um sistema de inferência fuzzy que seja capaz de estimar com eficiência o conjugado de carga aplicado ao eixo de um motor de indução trifásico a partir dos dados simulados, os quais são referentes às tensões, correntes e velocidades do motor em questão.

Toda a modelagem do motor de indução utilizada neste trabalho foi desenvolvido usando as ferramentas computacionais do Matlab/Simulink [9], onde foram analisadas as cargas lineares que são encontradas em serras de madeiras, bombas de pistão; as cargas quadráticas que são aquelas que variam com o quadrado da rotação e são encontradas em aplicações como ventiladores e centrífugas. As cargas inversas são também analisadas no decorrer deste capítulo.

\subsection{Descrição da Estratégia de Obtenção das Curvas de Torque de Carga}

Nesta seção será apresentada a estratégia adotada para a obtenção das curvas de torque de carga, especificando assim os parâmetros da máquina simulada para a metodologia de treinamento do ANFIS. O diagrama da Figura 4.1 ilustra o sistema fuzzy adotado, onde são utilizados como dados de entrada as tensões, correntes e velocidade, e obtendo como saída a curva do conjugado da carga. 


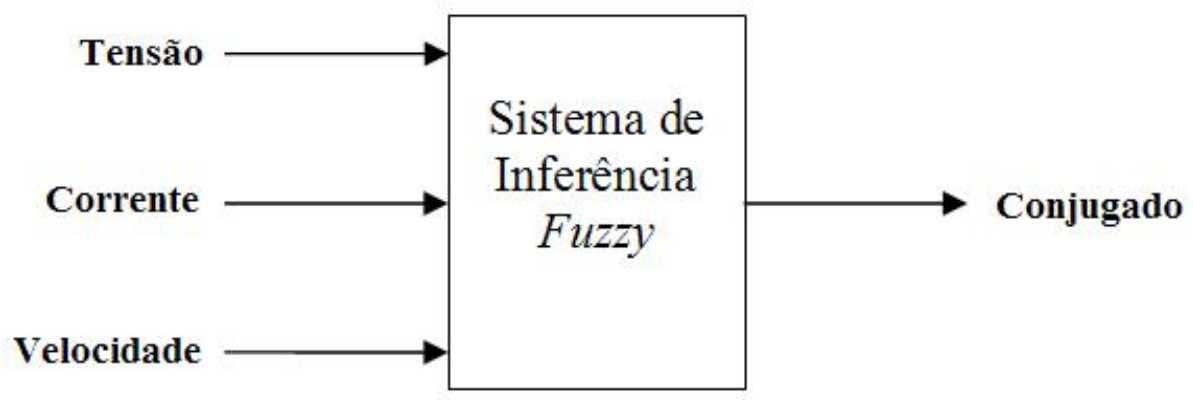

Figura 4.1 - Diagrama esquemático do sistema fuzzy.

\subsubsection{Parâmetros Elétricos e Mecânicos do Motor Simulado}

Os parâmetros elétricos e mecânicos do motor serão usados para simular o modelo matemático equacionado no Capítulo 2 utilizando a ferramenta Matlab/Simulink. Os dados mostrados na TABELA 4.1 foram fornecidos por um fabricante de motores elétricos (WEG - Catálogo Geral de Motores Elétricos).

TABELA 4.1 - Parâmetros do motor de indução trifásico e carga.

\begin{tabular}{|c|c|}
\hline \multicolumn{2}{|c|}{ Motor Linha Standard - IV Pólos $-60 \mathrm{~Hz}-220 / 380 \mathrm{~V}$} \\
\hline Potência (1 CV) & $745,69(\mathrm{~W})$ \\
\hline Resistência do Estator na Partida & $10,17(\Omega)$ \\
\hline Resistência do Estator em Regime & $12,40(\Omega)$ \\
\hline Resistência do Rotor na Partida & $5,80(\Omega)$ \\
\hline Resistência do Rotor em Regime & $6,95(\Omega)$ \\
\hline Indutância do Estator na Partida & $1,77 \times 10^{-2}(\mathrm{H})$ \\
\hline Indutância do Estator no Regime & $2,05 \times 10^{-2}(\mathrm{H})$ \\
\hline Indutância do Rotor na Partida & $1,10 \times 10^{-2}(\mathrm{H})$ \\
\hline Indutância do Rotor no Regime & $4,84 \times 10^{-2}(\mathrm{H})$ \\
\hline Indutância de Magnetização na Partida & $0,606(\mathrm{H})$ \\
\hline Indutância de Magnetização no Regime & $0,546(\mathrm{H})$ \\
\hline Momento de Inércia do Rotor & $2,71 \times 10^{-3}\left(\mathrm{Kg} \cdot \mathrm{m}^{2}\right)$ \\
\hline Velocidade Síncrona Mecânica & $188,49 \mathrm{rad} / \mathrm{s}(1800 \mathrm{rpm})$ \\
\hline Escorregamento Nominal & $3,8 \%$ \\
\hline Torque Nominal & $4,1 \mathrm{Nm}$ \\
\hline Classe & $\mathrm{N}$ \\
\hline Conjugado Máximo & $11,89 \mathrm{Nm}$ \\
\hline Conjugado de Partida & $10,25 \mathrm{Nm}$ \\
\hline
\end{tabular}

Neste trabalho, optou-se em usar um motor de $1 \mathrm{cv}$ alimentado em $220 \mathrm{~V}$, pois o mesmo pode ser encontrado com freqüência em aplicações industriais. 
Para a geração dos dados utilizados tanto para o treinamento do sistema de inferência fuzzy como para sua validação são usadas funções matemáticas que representam o comportamento da carga em questão. Como neste trabalho serão abordadas apenas as cargas lineares, quadráticas e inversas, a Tabela 4.2 descreve suas funções matemáticas.

TABELA 4.2 - Funções matemáticas das cargas industriais.

\begin{tabular}{|c|c|}
\hline Linear & $f(\omega)=T(\omega)=K+a \cdot \omega$ \\
\hline Quadrática & $f(\omega)=T(\omega)=K+a \cdot \omega^{2}$ \\
\hline Inversa & $f(\omega)=T(\omega)=a \cdot \varepsilon^{-b \omega}+K$ \\
\hline
\end{tabular}

A constante $K$ está relacionada com o conjugado inicial, isto é, para $\omega_{t=0+}$, considerando as cargas quadráticas e lineares. Em relação à carga inversa, tal constante representa o valor do conjugado de carga para o regime permanente, ou seja, para $\omega_{t=\infty}$. No qual a variável $\omega$ está em rad/s.

\subsubsection{Treinamento do Sistema ANFIS}

Para o treinamento do ANFIS foram utilizados os dados de simulação gerados pelo modelo matemático apresentado no Capítulo 2. Tal treinamento utiliza como dados de entrada apenas o conhecimento da tensão eficaz, da corrente eficaz e da velocidade no eixo visando estimar o torque de carga aplicado ao motor. Portanto, a variável de saída é o próprio torque de carga em questão. Assim, por intermédio desses dados de treinamento, utilizou-se o modelo ANFIS para ajustar os parâmetros das funções de pertinência usadas pelo sistema fuzzy. 
A ferramenta computacional, referente ao sistema de inferência neuro-fuzzy adaptativo oferecido pelo programa Matlab (anfisedit), consiste da configuração de três parâmetros, no qual esses são responsáveis pela sintonização do sistema fuzzy de forma adequada. Portanto, o desempenho do sistema é influenciado pela forma que se apresentam os dados, pela metodologia de geração do sistema de inferência e pelo algoritmo de treinamento utilizado.

Assim, no fornecimento dos dados de treinamento ao ANFIS, é preciso fazer uma análise dos dados de entrada para que o sistema possa ajustar as funções de pertinências e as regras de forma confiável e consistente. Desta forma, foi feita uma análise nesses dados de entrada, investigando-se o comportamento de cada variável separadamente.

Em relação à implementação do sistema de inferência fuzzy, após serem definidos os parâmetros necessários para a confecção do sistema e, posteriormente, o treinamento efetuado de forma coerente com a base de dados, é preciso verificar se o sistema está sendo capaz de realizar o mapeamento adequado da estimativa do conjugado de torque de carga. Além disso, é relevante que o sistema tenha habilidade para generalizar, ou seja, estimar os conjugados de torque de carga para casos em que os dados não pertençam ao conjunto de treinamento. Para isso, é necessário simular o sistema de inferência com dados de testes de validação e avaliar o seu desempenho.

Inicialmente os dados de treinamento foram agrupados por valor de tensão como mostra a TABELA 4.3. 
TABELA 4.3 - Composição dos dados de treinamento agrupados por tensão.

\begin{tabular}{|c|c|}
\hline Tensão(Volts) & Conjugado de Carga (Nm) \\
\hline 200 & 1 \\
\hline 200 & 3 \\
\hline 200 & 6 \\
\hline 201 & 2 \\
\hline 201 & 4 \\
\hline 202 & 3 \\
\hline 202 & 5 \\
\hline 203 & 1 \\
\hline 203 & 6 \\
\hline 204 & 2 \\
\hline 204 & 5 \\
\hline 205 & 1 \\
\hline 205 & 4 \\
\hline
\end{tabular}

Utilizada essa configuração dos dados para o treinamento do ANFIS, observou-se que na validação da metodologia não foram obtidos resultados satisfatórios para a estimativa do torque, pois o sistema não conseguia estimar de forma coerente a parte transitória das curvas. Neste caso, o sistema fuzzy conseguia estimar apenas o período de partida e o de regime.

Desta forma, efetuou-se uma análise nas variáveis de entrada e, observando o comportamento da corrente, percebeu-se que o problema mencionado anteriormente estava na forma como os dados estavam sendo apresentados para o treinamento do ANFIS. A Figura 4.2, Figura 4.3, Figura 4.4 e Figura 4.5, ilustram esse comportamento que afeta de forma direta a eficiência do sistema fuzzy. 


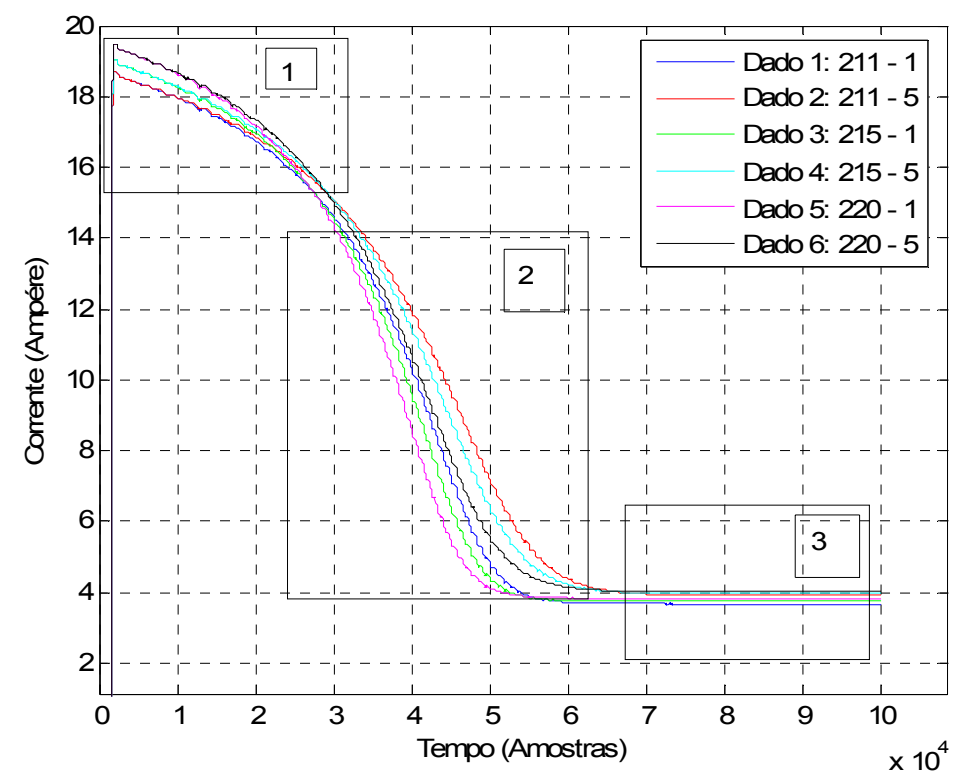

Figura 4.2 - Análise das correntes do motor de indução.

A Figura 4.2 ilustra o comportamento das correntes de uma carga linear, sendo que o Dado 1 representa uma curva de conjugado de torque de $1 \mathrm{Nm}$ para uma tensão de 211 Volts. Os demais dados estão ilustrados na legenda da Figura 4.2. Para melhor demonstrar tal comportamento, realizou-se um detalhamento da Figura 4.2, a qual foi dividida em 3 outras imagens.

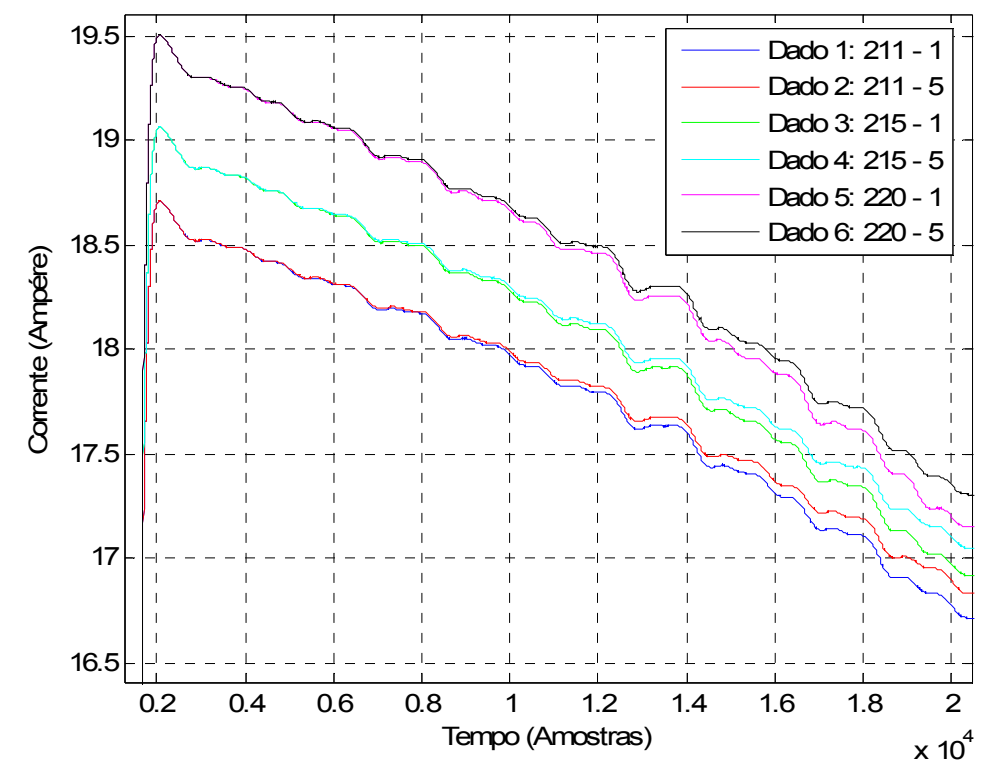

Figura 4.3-Detalhe 1 da Figura 4.2. 
A Figura 4.3 ilustra o comportamento da corrente quanto à partida da máquina. A curva ilustrada pelo Dado 1 mostra o comportamento da corrente para uma tensão de 211 Volts com conjugado de carga de $1 \mathrm{Nm}$. Os demais dados estão ilustrados pela legenda da figura em questão. Desta forma, verifica-se que no período de partida do motor as correntes são agrupadas pela tensão, assim os Dados 1 e 2 ficam próximos, da mesma forma que os Dados 3 e 4 e os Dados 5 e 6. Estes ficam juntos apesar de terem um conjugado de torque diferente. Tal comportamento é observado para todas as tensões, qualquer que seja o valor do conjugado.

A Figura 4.4 mostra o detalhe 2 da Figura 4.2, marcada com o retângulo 2. Esse detalhe ilustra o comportamento da corrente durante o transitório.

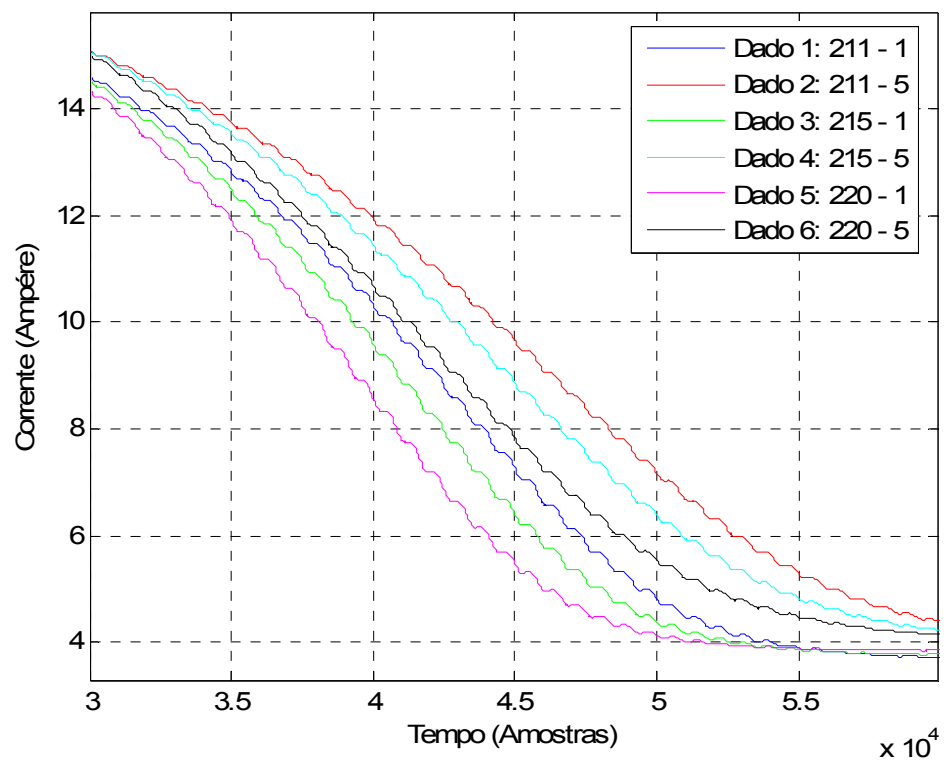

Figura 4.4 - Detalhe 2 da Figura 4.2.

No transitório, a corrente passa a se agrupar pelo conjugado. Na Figura 4.3 foi observado que os Dados 1 e 2 estavam mais próximos um do outro em relação aos demais dados, enquanto que na Figura 4.4, isso não acontece mais. Na Figura 4.4 observa-se que o Dado 1 está mais próximo dos Dados 3 e 5, pois estes têm os 
mesmos conjugados de carga do que anteriormente; enquanto que, da mesma forma, o Dado 2 se encontra agrupado com os Dados 4 e 6.

E por fim, a Figura 4.5 mostra o detalhe 3 da Figura 4.2 para 0 comportamento da corrente quando a máquina se encontra em regime.

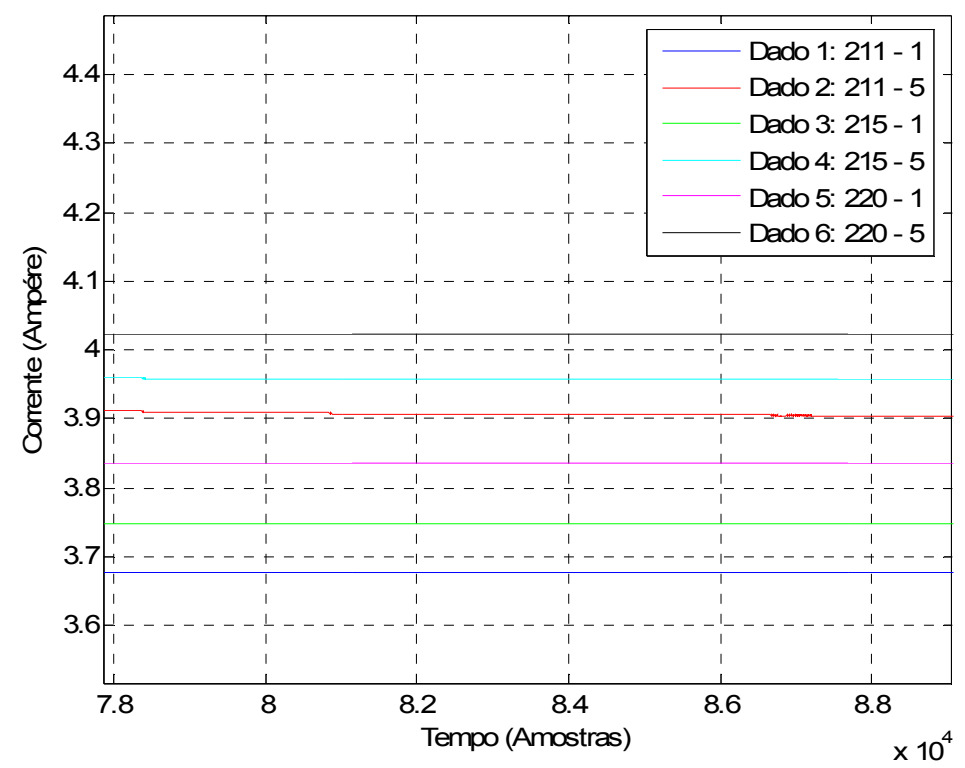

Figura 4.5 - Detalhe 3 da Figura 4.2.

Observa-se que durante o regime a corrente continua agrupada pelo conjugado, sendo que tal agrupamento teve início no transitório da máquina.

De acordo com a Figura 4.2 e os seus detalhes apresentados nas Figura 4.3, Figura 4.4 e Figura 4.5, observa-se que as correntes para cada conjugado se agrupam na partida por valores de tensões, enquanto que no transitório e em regime elas se agrupam por valor de conjugado. Desta forma, optou-se por agrupar os dados de treinamento não mais por tensão, e sim por conjugado de carga, como ilustra a TABELA 4.4. A partir desta abordagem se obteve resultados satisfatórios como será apresentado no Capítulo 5. 
TABELA 4.4 - Composição dos dados de treinamento agrupados por conjugado de carga.

\begin{tabular}{|c|c|}
\hline Tensão (Volts) & Conjugado de carga (Nm) \\
\hline 200 & 1 \\
\hline 203 & 1 \\
\hline 205 & 1 \\
\hline 201 & 2 \\
\hline 204 & 2 \\
\hline 200 & 3 \\
\hline 203 & 3 \\
\hline 201 & 4 \\
\hline 205 & 4 \\
\hline 202 & 5 \\
\hline 204 & 5 \\
\hline 200 & 6 \\
\hline 203 & 6 \\
\hline
\end{tabular}

\subsection{Estrutura do Sistema Fuzzy Para Identificação do Torque de Carga}

Com o intuito de se determinar o sistema de inferência fuzzy mais eficiente, vários sistemas foram implementados, com diversas variações, de tal forma que seja possível comparar o desempenho entre os mesmos. Desta maneira, foram implementados sistemas de inferências variando-se a forma de apresentação dos dados e o algoritmo de treinamento utilizado no ANFIS. Com a finalidade de se obter o menor erro, o parâmetro associado ao erro de tolerância foi configurado como sendo zero e, para todos os sistemas considerados, o número de épocas de treinamento foi ajustado para 5. Com um número de épocas maior, observa-se que a diminuição do erro é muito pequena, podendo ser até desprezível quando se leva em conta o custo computacional e o tempo de treinamento.

Após a realização dos treinamentos de cada um dos sistemas fuzzy propostos, os mesmos são validados com os dados de testes. Em seguida, calculase os valores de erro relativo médio e o desvio padrão para que se possa ser 
realizada uma comparação entre as diversas configurações propostas aos sistemas fuzzy, tendo a finalidade de se encontrar o mais eficiente.

Portanto, para cada variável de entrada, utiliza-se nove funções de pertinência, sendo que as mesmas são do tipo gaussiana. Desse modo, gera-se 729 regras para o sistema fuzzy. É valido salientar que desse total de regras geradas, pode ser que nem todas delas possam ser ativadas ou usadas ao mesmo tempo.

Como mencionado anteriormente, foram geradas várias configurações do sistema fuzzy, variando-se o número de funções para cada variável de entrada. Inicialmente, utilizou-se três funções de pertinência para cada entrada, e foi aumentando gradativamente esse número até se obter a melhor configuração, a qual foi obtida com nove funções de pertinência para cada entrada. Também foi variado o tipo de função de pertinência, sendo que inicialmente foram adotadas as funções triangulares, mas se observou que os melhores resultados eram obtidos através das funções do tipo gaussianas.

Neste trabalho, a faixa de tensão é dividida em faixas discretas, abrangendo uma variação de $\pm 10 \%$. Consegue-se, desta forma, atingir dois objetivos, ou seja, simular pequenas variações de tensão no motor devido à alta corrente de partida e dividir a estrutura fuzzy em vários sistemas fuzzy menores, implicando então numa maior modularidade na estrutura computacional.

A norma NBR7094:1996 [43], especifica que um motor deve ser capaz de desempenhar sua função principal continuamente numa faixa de tensão que varie $\pm 10 \%$ da tensão nominal. Considerando a alimentação do motor em $220 \mathrm{~V}$, a faixa de tensão abordada na simulação compreende 200 V a 240 V, conforme é mostrado na TABELA 4.5. É de fundamental importância considerar esta variação na 
alimentação, pois o conjugado entregue a carga tem uma relação quadrática com a tensão de alimentação [7].

TABELA 4.5 - Faixa de tensões de treinamento.

\begin{tabular}{|c|c|}
\hline $\begin{array}{c}\text { Faixa de Tensão } \\
\text { (Volt) }\end{array}$ & Variação \\
\hline 200 & $200-210$ \\
\hline 211 & $211-220$ \\
\hline 221 & $221-230$ \\
\hline 231 & $231-240$ \\
\hline
\end{tabular}

A Figura 4.6 ilustra a variação de conjugado na faixa de tensão estudada e, a Figura 4.7 apresenta o mapeamento para a carga do tipo linear. Há, desta forma, o mapeamento de uma região de conjugado limitada pela curva 1 e pela curva 66 . Dentro dessa região de mapeamento o sistema fuzzy deve fazer estimativas de torque.

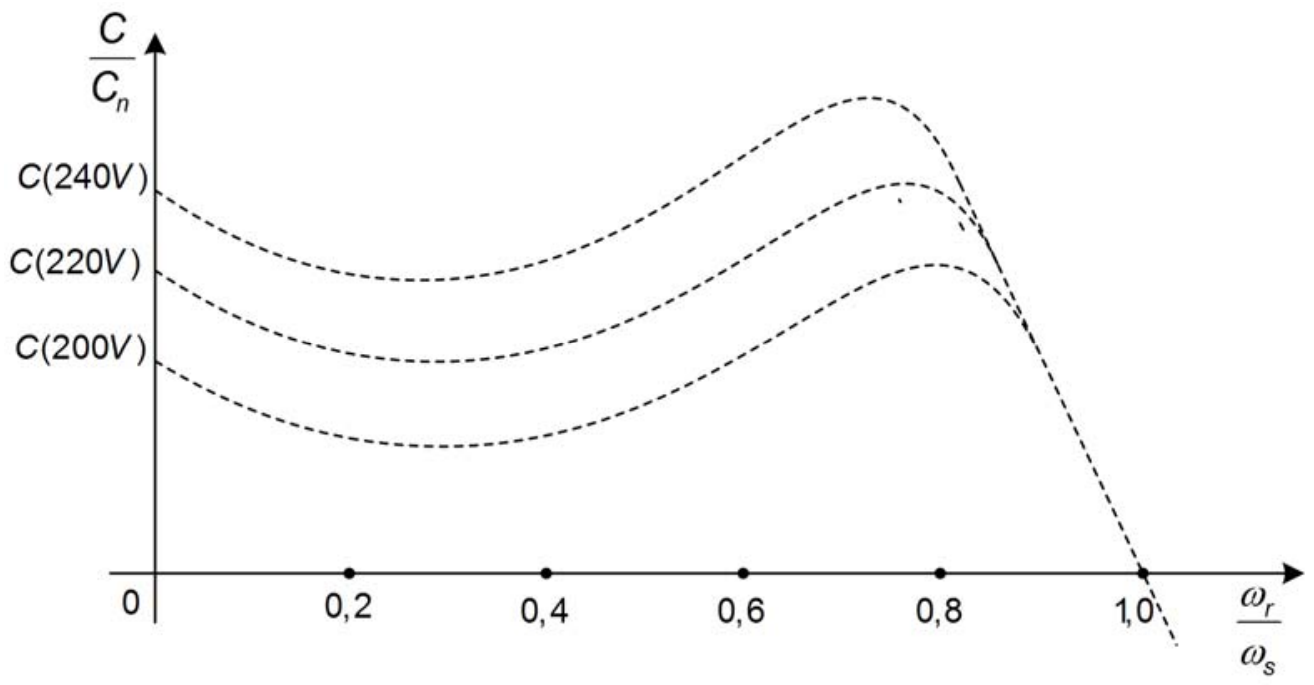

Figura 4.6 - Curva de conjugado para faixa de tensão de $\pm 10 \%$ da tensão nominal. 


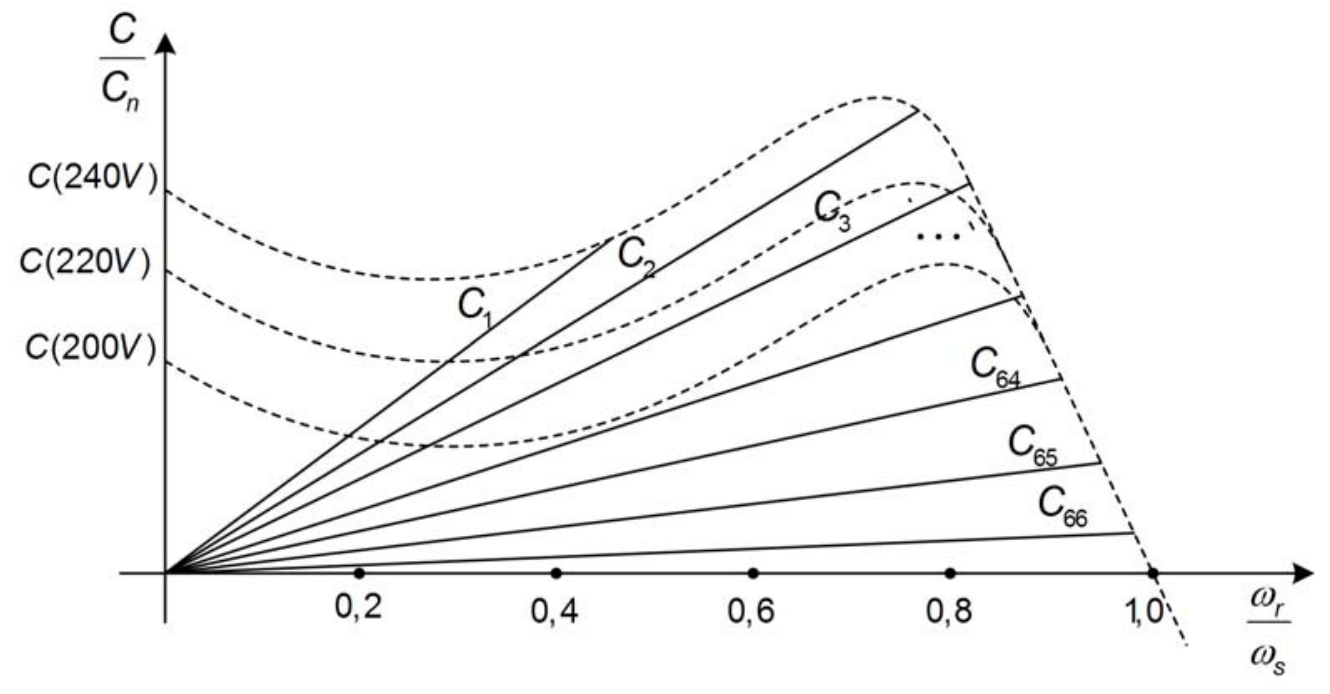

Figura 4.7 - Curva de torque para carga linear.

É valido salientar que o mapeamento produz valores diferentes de torque partida e regime permanente - para cada curva, dependendo do valor de tensão usado na alimentação do motor, conforme interseção das curvas de mapeamento e conjugado do motor.

Para cada faixa de tensão foi gerado um sistema fuzzy. Assim, para cada carga se tem um total de 4 sistemas fuzzy. A Figura 4.8 ilustra as funções de pertinência para a tensão que corresponde às faixas de tensões entre $200-210 \mathrm{~V}$. Tais ajustes foram fornecidos pelo sistema ANFIS, sendo que o universo de discurso para esse sistema fuzzy em questão varia de 0(zero) a 210 Volts.

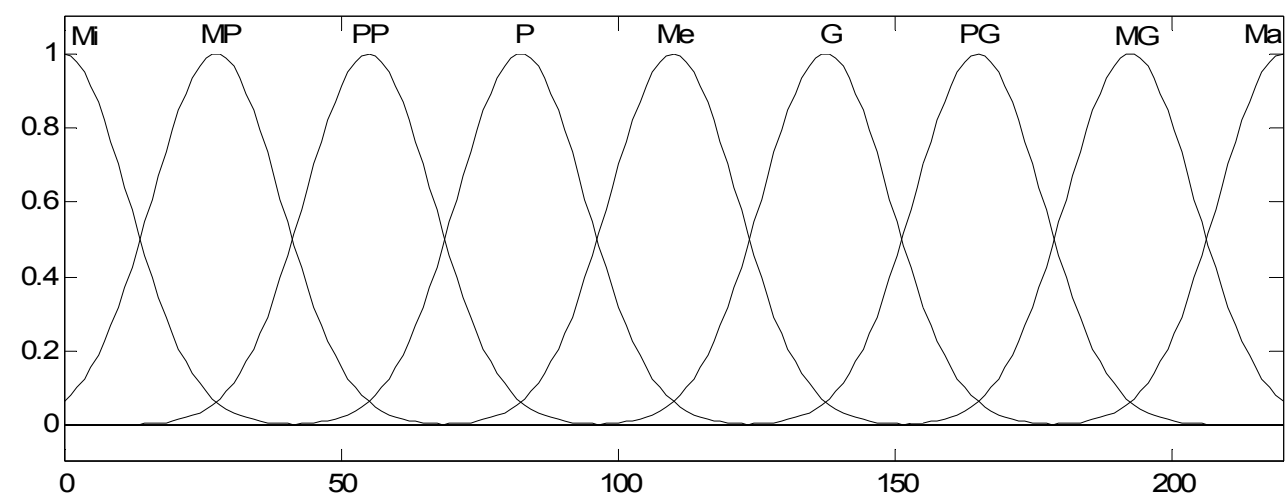

Figura 4.8 - Funções de pertinência para a tensão. 
De forma análoga, as funções de pertinência para as demais faixas de tensões são as mesmas, a única diferença é o universo de discurso para cada faixa. A TABELA 4.6 ilustra tais universos de discurso para todas as faixas de tensões.

TABELA 4.6 - Universo de discurso para cada faixa de tensão.

\begin{tabular}{|c|c|}
\hline Faixa de Tensão & Universo de Discurso \\
\hline 200 & $0-210$ \\
\hline 211 & $0-220$ \\
\hline 221 & $0-230$ \\
\hline 231 & $0-240$ \\
\hline
\end{tabular}

A TABELA 4.7 representa o significado da terminologia adotada para cada função de pertinência e para todas as variáveis lingüísticas (tensão, corrente e velocidade), ou seja, ilustra o conjunto de termos que será utilizado para expressar o comportamento de cada variável para o sistema de inferência fuzzy aqui adotado.

TABELA 4.7 - Terminologia dos termos de pertinência
\begin{tabular}{|c|c|}
\hline Símbolo & Significado \\
& Mínima \\
\hline Mi & Muito pequena \\
\hline MP & Pouco pequena \\
\hline PP & Pequena \\
\hline Pe & Média \\
\hline G & Grande \\
\hline PG & Pouco grande \\
\hline MG & Muito grande \\
\hline Ma & Máxima \\
\hline
\end{tabular}

A Figura 4.9 mostra as funções de pertinências para as correntes, sendo que as mesmas correspondem igualmente para todos os outros sistemas, ou seja, para todas as faixas de tensões de forma genérica, pois o que diferencia uma faixa de tensão para a outra é o universo de discurso associado à variável lingüística, "corrente", considerando este caso. 


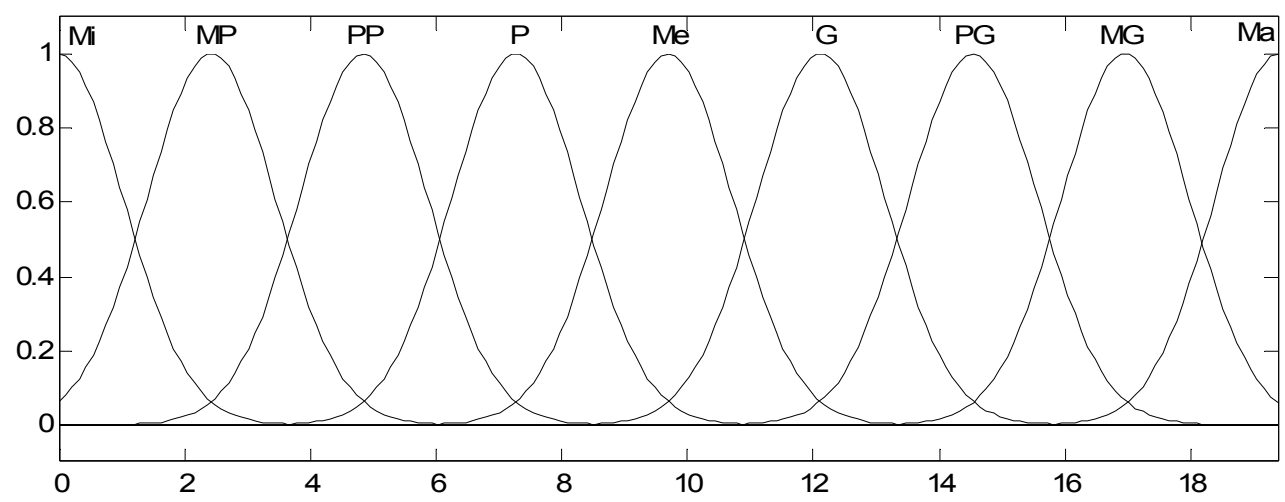

Figura 4.9 - Funções de pertinência para a variável lingüística "corrente".

A Figura 4.9 ilustra as funções de pertinência da corrente para uma carga linear, correspondendo à faixa de tensão de 211-220 V, sendo que o seu universo de discurso varia de 0 a 19,38 Ampére.

A Figura 4.10 mostra as funções de pertinências da velocidade, sendo que as mesmas correspondem igualmente para todos os outros sistemas, ou seja, para todas as faixas de tensões de forma genérica, pois, como mencionado anteriormente, o que diferencia uma faixa de tensão para a outra é o universo de discurso associado à variável lingüística, "velocidade”, considerando este caso.

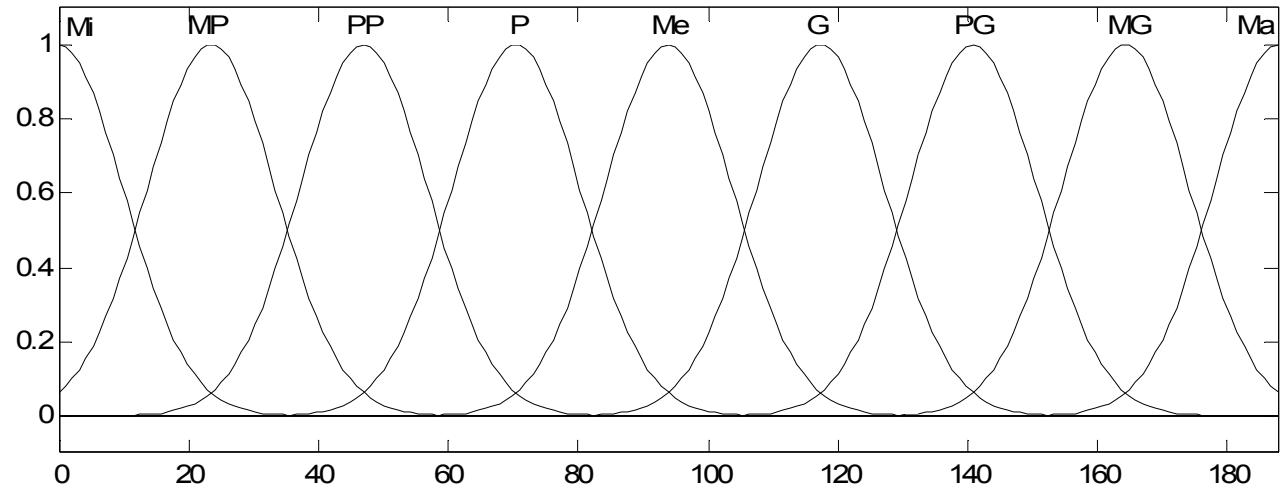

Figura 4.10 - Função de pertinência para variável lingüística "velocidade".

A Figura 4.10 ilustra as funções de pertinência da velocidade para uma carga linear, correspondendo à faixa de tensão de $211-220 \mathrm{~V}$, sendo que o seu universo de discurso varia de 0 a $188 \mathrm{rad} / \mathrm{s}$. 
A TABELA 4.8 ilustra os universos de discursos para as variáveis lingüísticas corrente e velocidade, sendo que tais universos para essas variáveis são os mesmos tanto para as cargas quadráticas como para as lineares e inversas.

TABELA 4.8 - Universo de discurso para as variáveis lingüísticas: velocidade e corrente.

\begin{tabular}{|c|c|c|}
\hline \multirow{2}{*}{ Faixa de Tensão } & \multicolumn{2}{|c|}{ Universo de Discurso } \\
\cline { 2 - 3 } & Velocidade & Corrente \\
\hline $200-210$ & $0-187,6$ & $0-18,07$ \\
\hline $211-220$ & $0-187,7$ & $0-19,38$ \\
\hline $221-230$ & $0-187,8$ & $0-20,25$ \\
\hline $231-240$ & $0-187,8$ & $0-21,12$ \\
\hline
\end{tabular}

A Figura 4.11, ilustra a metodologia aplicada na forma de diagrama de blocos.

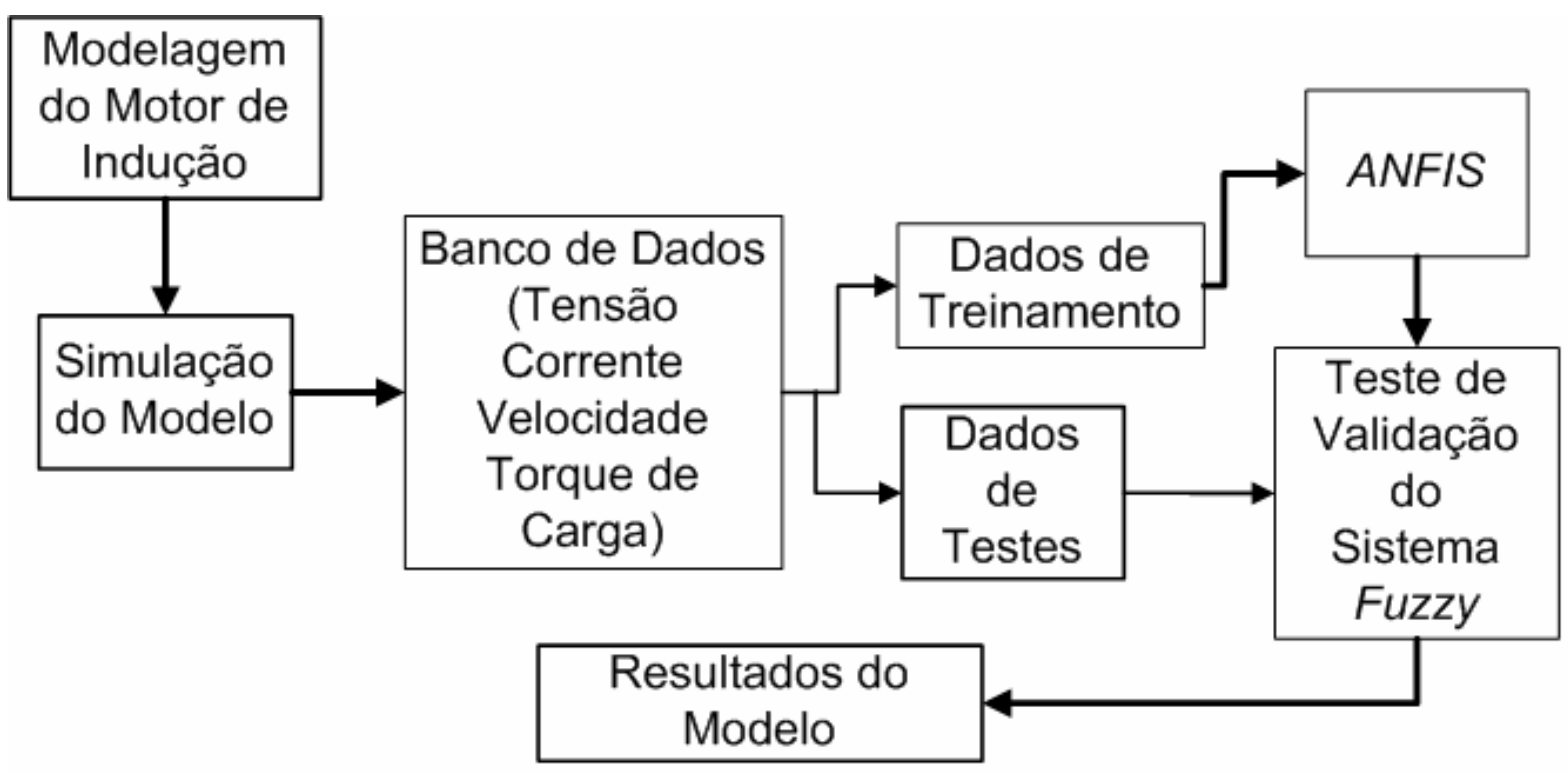

Figura 4.11 - Diagrama de blocos. 



\section{Resultados da Aplicação do Sistema Fuzzy}

\subsection{Introdução}

Os resultados de simulação são apresentados nesse capítulo para ilustrar a abordagem proposta e testar a eficiência da metodologia.

Conforme descrito no Capítulo 3, os sistemas fuzzy foram ajustados por intermédio do modelo ANFIS. Este processo envolve inicialmente a definição dos parâmetros do sistema de inferência neuro-fuzzy adaptativo, a geração dos dados, a metodologia empregada para geração do sistema, o algoritmo de treinamento a ser utilizado e, finalmente, os parâmetros que determinam o critério de parada. Portanto, através do processo de treinamento, o ANFIS fornecerá o sistema fuzzy ajustado e com as regras já definidas, sendo então possível finalmente realizar as análises e validações do sistema por intermédio de simulações com os dados de testes.

Cabe aqui salientar que os dados de testes mostrados ao sistema fuzzy não fizeram parte do treinamento do sistema de inferência neuro-fuzzy adaptativo utilizado para o ajuste do mesmo. Desta forma, pode-se demonstrar a capacidade de generalização do sistema fuzzy abordado.

Na simulação do motor de indução foram geradas 6 curvas de torque de carga que simulam da partida ao regime permanente, considerando cada tensão. Deste modo, na primeira faixa de tensão (200-210 Volts), tem-se um total de 66 curvas. Sendo que 34 dessas foram utilizadas para o treinamento do sistema fuzzy, e as demais para teste de validação.

Como mencionado em seções anteriores, as simulações do motor de indução foram realizadas usando um motor de $1 \mathrm{cv}$ alimentado em $220 \mathrm{~V}$, pois tais 
motores são encontrados com freqüência em aplicações industriais, sendo que a metodologia empregada neste trabalho pode ser também aplicada em outras faixas de tensões e potências de máquinas.

\subsection{Resultados do Sistema Fuzzy na Identificação de Torque de Carga Linear}

Nesta seção serão apresentados os resultados obtidos pela generalização do sistema fuzzy desenvolvido considerando para as cargas com conjugado linear. Visando tal objetivo, apresentam-se figuras que mostram as curvas de torque estimado com as reais/simuladas. Será apresentada também uma tabela com os erros relativos médios para diversas tensões e conjugados de torque.

A Figura 5.1 mostra o resultado da generalização para uma carga linear com conjugado inicial em 0,2 $\mathrm{Nm}$ e, em regime permanente, em $2 \mathrm{Nm}$, submetido a uma tensão de 202 Volts. O torque de carga foi estimado com um erro relativo médio de $2,6 \%$, com desvio padrão de $3,9 \%$. O objetivo do valor desse perfil de tensão é simular uma subtensão no motor de indução visando testar o modelo proposto por esse trabalho. 


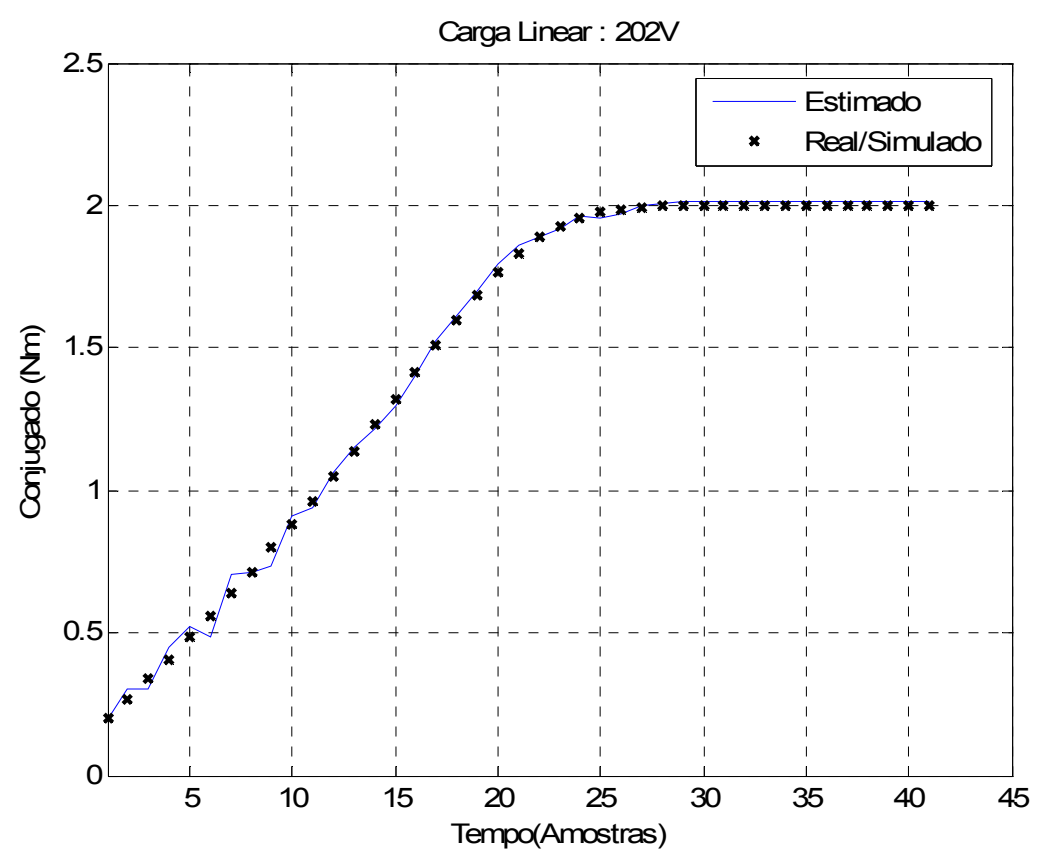

Figura 5.1 - MIT submetido a conjugado resistente linear alimentado com 202V.

A Figura 5.2 ilustra o resultado de simulação de uma carga linear aplicada ao MIT submetido a uma tensão de 220 Volts que, em regime permanente, atinge 6 $\mathrm{Nm}$. Esta estimativa obteve um erro relativo médio de $0,81 \%$ com um desvio padrão de $2,2 \%$.

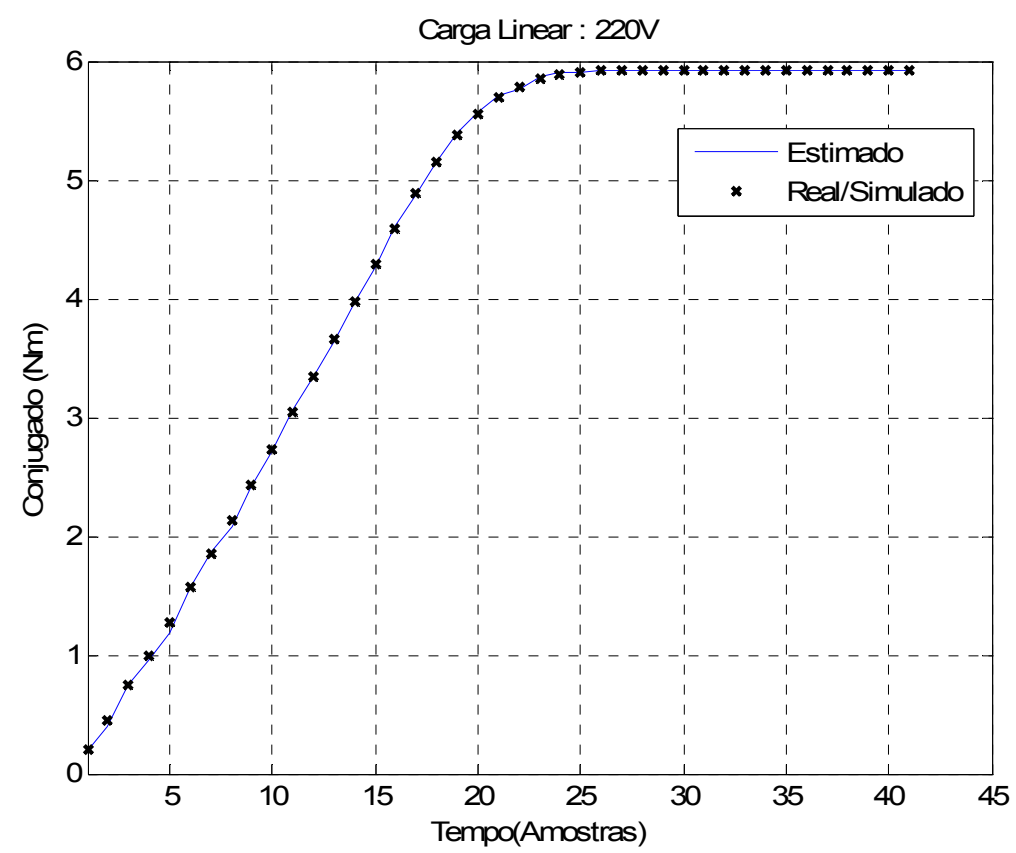

Figura 5.2 - MIT submetido a conjugado resistente linear alimentado com 220V. 
A Figura 5.3 ilustra os resultados de simulação de uma carga linear submetida a uma tensão de $238 \mathrm{~V}$, sendo que essa carga em regime permanente atinge um conjugado de $4 \mathrm{Nm}$. $\mathrm{O}$ torque de carga foi estimado com um erro relativo médio de $0,24 \%$ em relação ao torque desejado, tendo um desvio padrão de $0,29 \%$. O motor foi submetido a essa elevada tensão para simular uma sobretensão, sendo então possível analisar o comportamento do estimador proposto.

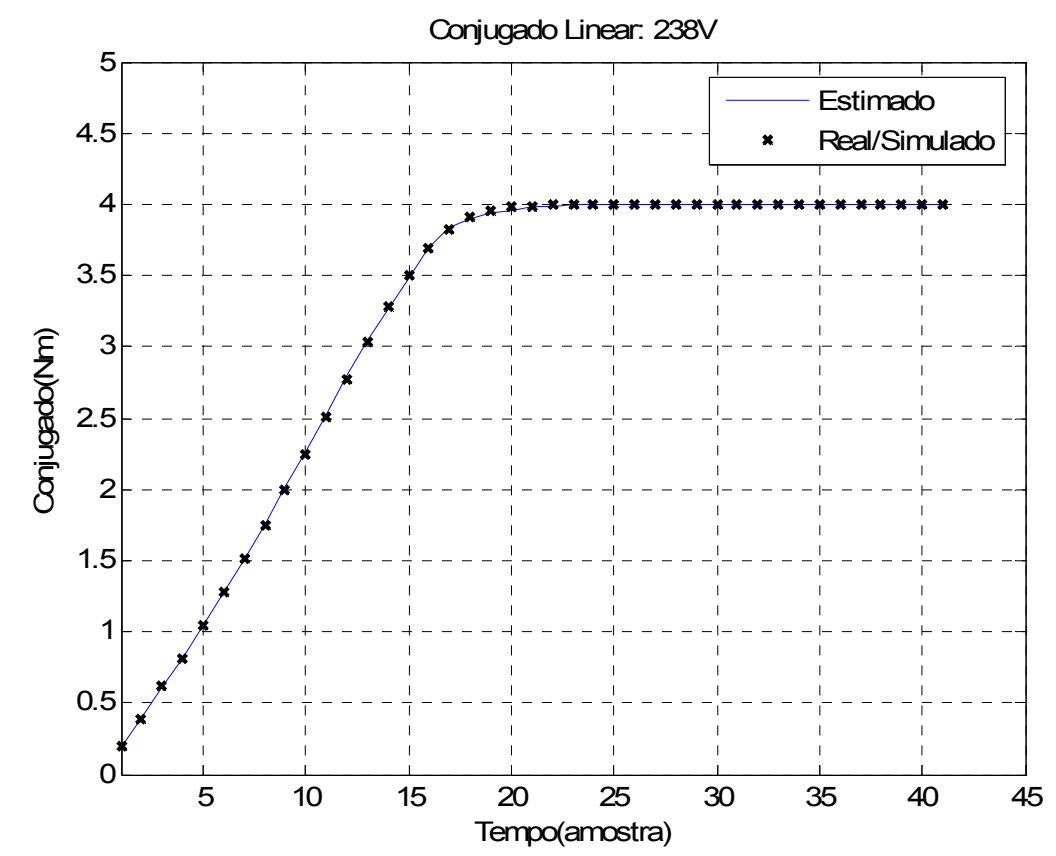

Figura 5.3 - MIT submetido a conjugado resistente linear alimentado com $238 \mathrm{~V}$.

A Figura 5.4 ilustra o comportamento do erro relativo ponto-a-ponto entre a curva estimada e a curva real/simulada, a qual foi ilustrada pela Figura 5.3. 


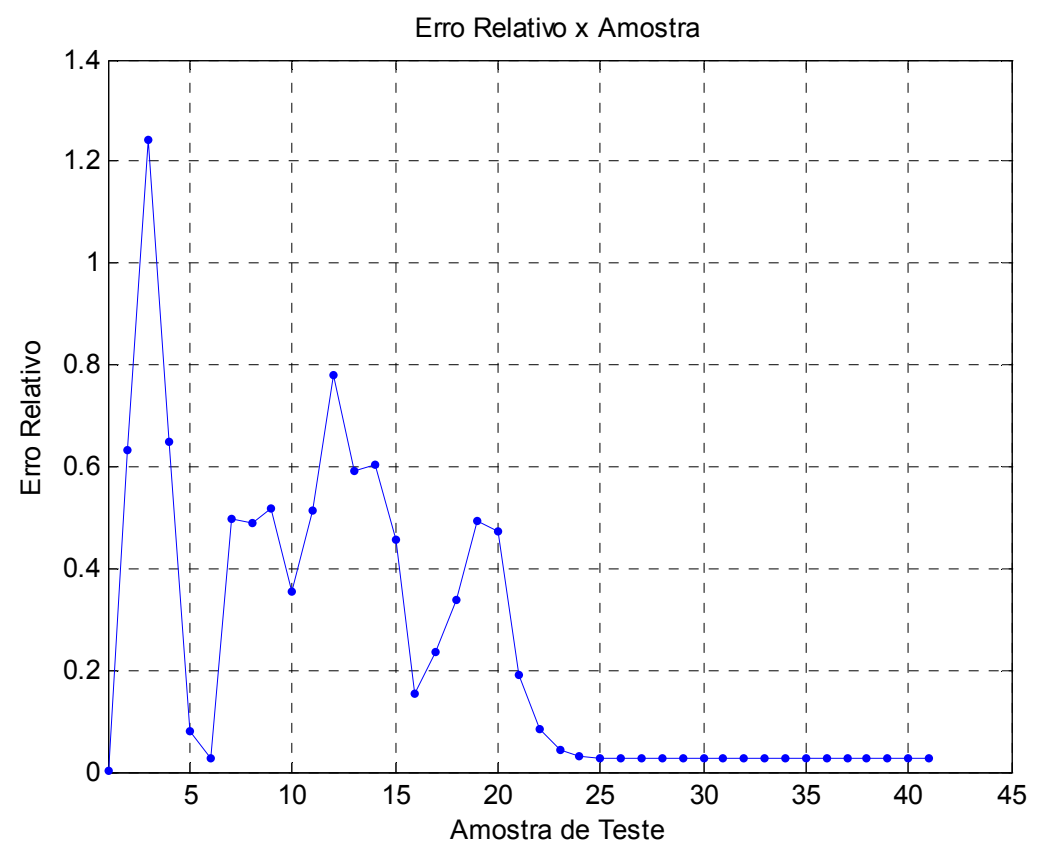

Figura 5.4 - Erro relativo ponto-a-ponto entre conjugado estimado e real/simulado.

Na TABELA 5.1 são apresentados os resultados para a estimativa do conjugado (saída do sistema), ilustrando alguns valores do erro relativo médio, desvio padrão, tensão e conjugado nominal para as simulações das cargas lineares.

TABELA 5.1 - Desempenho do estimador para conjugado linear.

\begin{tabular}{|c|c|c|c|}
\hline Tensão & $\begin{array}{c}\text { Conjugado } \\
(\mathrm{Nm})\end{array}$ & $\begin{array}{c}\text { Erro } \\
\text { Relativo } \\
\text { Médio } \\
(\%)\end{array}$ & $\begin{array}{c}\text { Desvio } \\
\text { Padrão } \\
(\%)\end{array}$ \\
\hline 201 & 2 & 2,50 & 4,30 \\
\hline 203 & 5 & 1,40 & 3,20 \\
\hline 205 & 2 & 3,40 & 7,30 \\
\hline 212 & 3 & 0,88 & 1,45 \\
\hline 215 & 4 & 0,69 & 1,04 \\
\hline 219 & 5 & 0,84 & 1,87 \\
\hline 224 & 6 & 0,40 & 0,74 \\
\hline 230 & 1 & 5,09 & 6,90 \\
\hline 235 & 1 & 1,68 & 1,82 \\
\hline
\end{tabular}




\subsection{Resultados do Sistema Fuzzy na Identificação de Torque de Carga Quadrática}

Nesta seção serão apresentados os resultados obtidos pela generalização do sistema fuzzy desenvolvido considerando as cargas com conjugado quadrático. Visando tal objetivo, apresentam-se figuras que mostram as curvas de torque estimado com as reais/simuladas. Será apresentada também uma tabela com os erros relativos médios para diversas tensões e conjugados de torque.

A Figura 5.5 mostra o resultado da generalização para uma carga quadrática com conjugado inicial em 0,2 $\mathrm{Nm}$ e, em regime permanente, em $1 \mathrm{Nm}$, submetido a uma tensão de 205 Volts. O torque de carga foi estimado com um erro relativo médio de $2,5 \%$ com desvio padrão de $3,1 \%$. O objetivo do valor desse perfil de tensão é simular uma subtensão no motor de indução para testar o modelo proposto por esse trabalho.

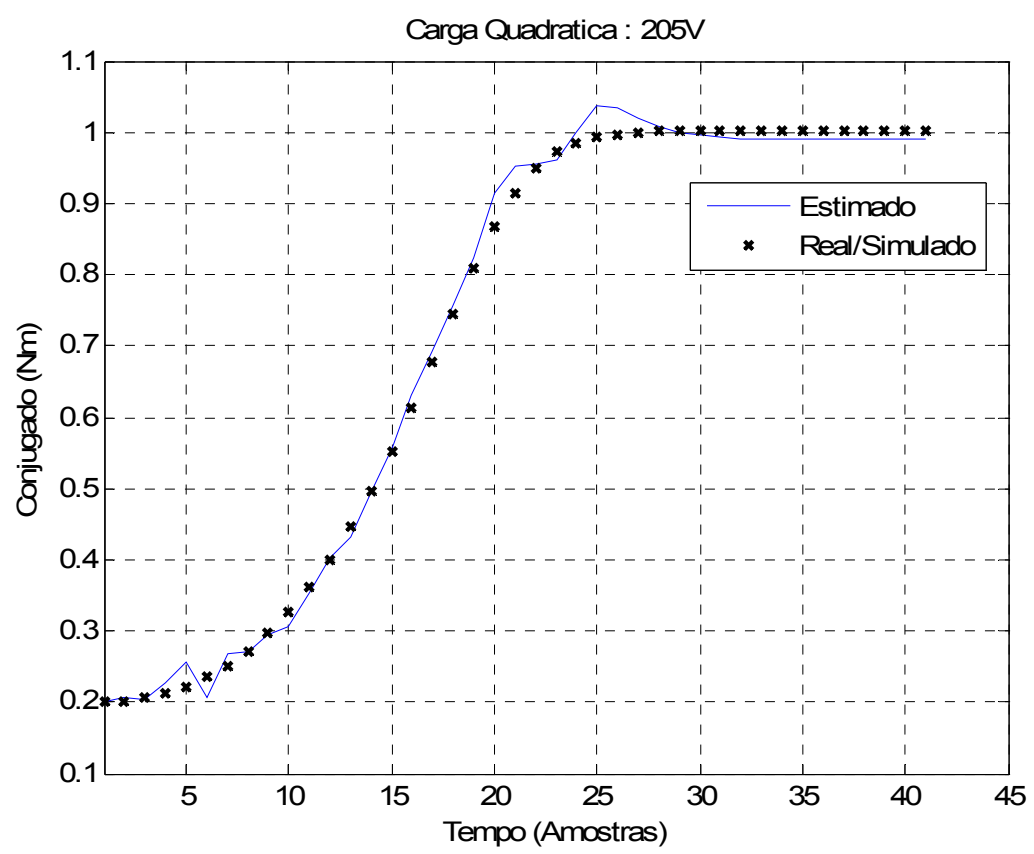

Figura 5.5 - MIT submetido a conjugado resistente quadrático alimentado com 205V. 
A Figura 5.6 ilustra o resultado de simulação de uma carga quadrática submetida a uma tensão de 220 Volts, que em regime permanente atinge $6 \mathrm{Nm}$. Esta estimativa obteve um erro relativo médio de $1,29 \%$ com desvio padrão de 2,93\%. A partir de tal simulação se pode realizar uma comparação dos resultados advindos do sistema fuzzy entre dois tipos de cargas submetidas ao mesmo motor com os mesmos parâmetros (Figura 5.2 e Figura 5.6).

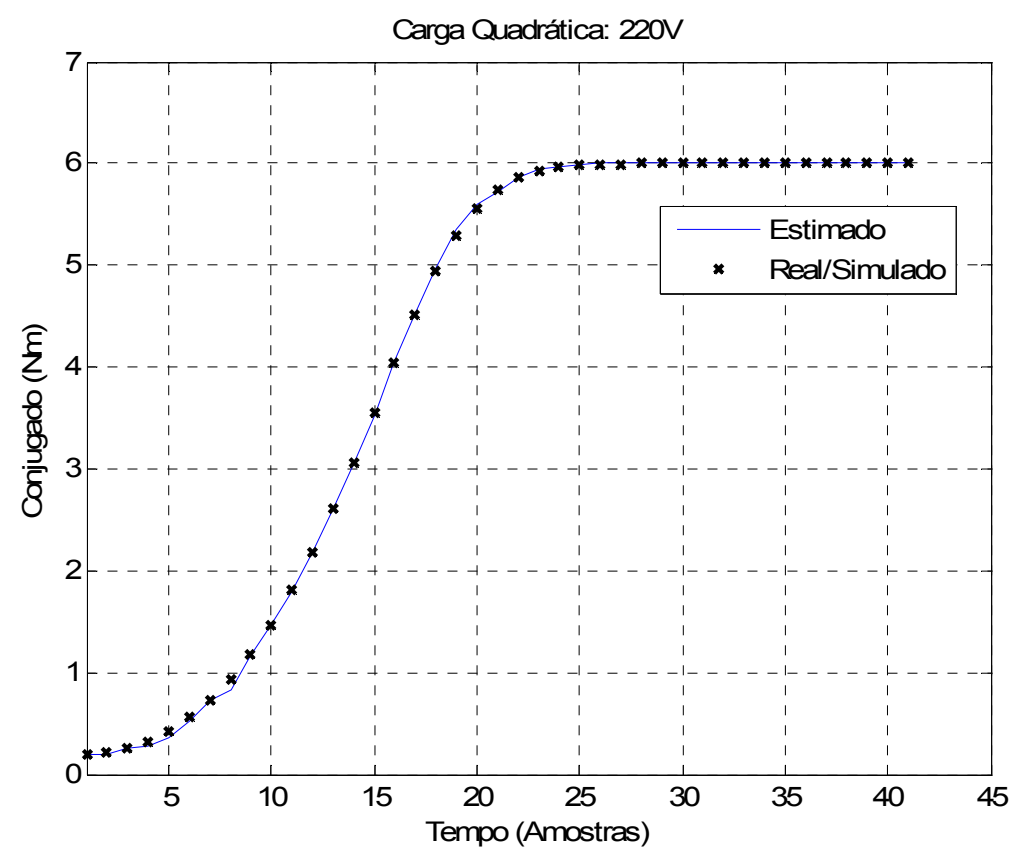

Figura 5.6 - MIT submetido a conjugado resistente quadrático alimentado com $220 \mathrm{~V}$.

A Figura 5.7 ilustra os resultados de simulação de uma carga quadrática submetida a uma tensão de $238 \mathrm{~V}$, sendo que a mesma em regime permanente atinge um conjugado de $4 \mathrm{Nm}$. O torque de carga foi estimado com um erro relativo médio de $0,25 \%$ em relação ao torque desejado, tendo um desvio padrão de $0,41 \%$. O motor foi submetido a essa elevada tensão para simular uma sobretensão, sendo então possível analisar o comportamento do estimador proposto. A partir de tal simulação se pode efetuar a comparação do sistema entre dois tipos de cargas 
submetidas ao mesmo motor com os mesmos parâmetros, sendo que o motor está submetido a uma sobretensão (Figura 5.3 e Figura 5.7).

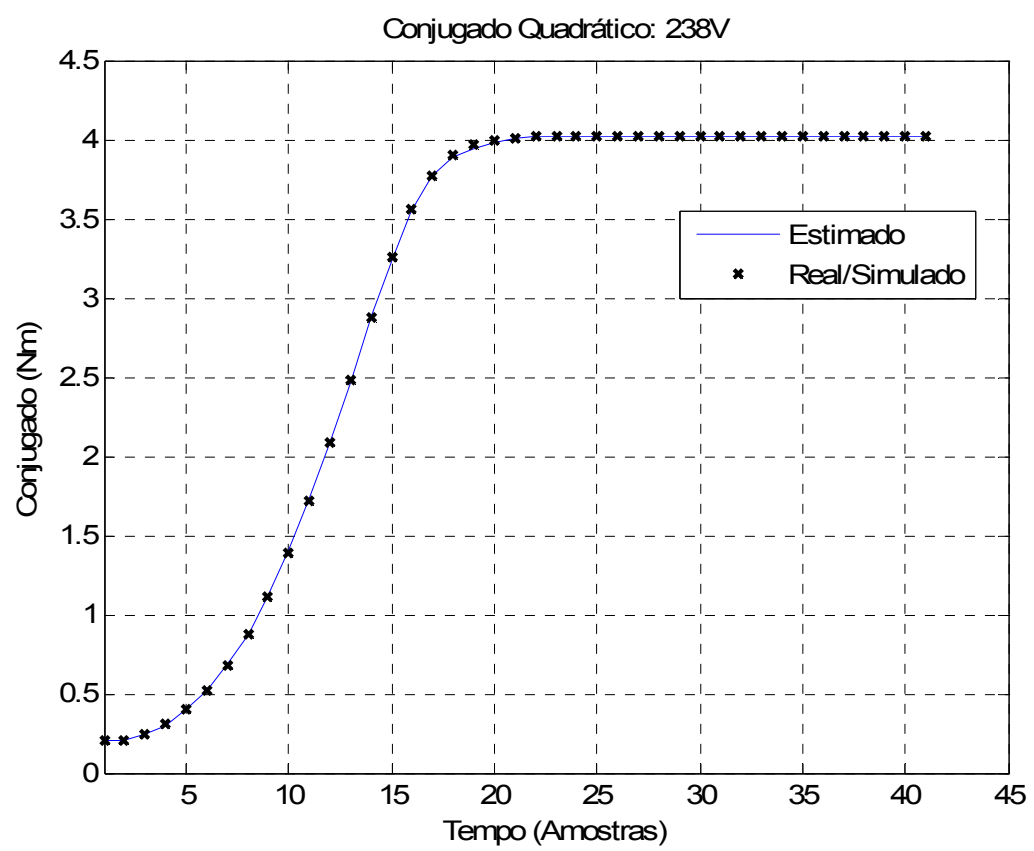

Figura 5.7 - MIT submetido a conjugado resistente quadrático alimentado com 238V.

A Figura 5.8 ilustra o comportamento do erro relativo ponto-a-ponto entre a curva estimada e a curva real/simulada, a qual foi ilustrada pela Figura 5.7.

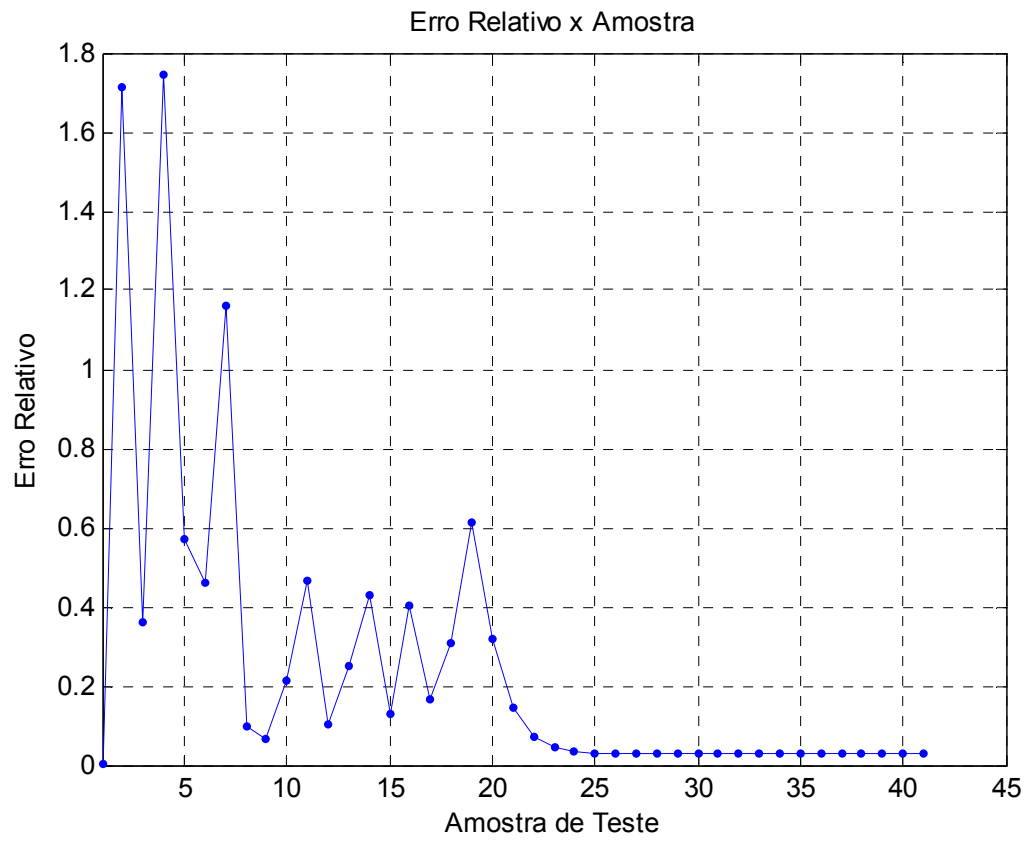

Figura 5.8 - Erro relativo ponto-a-ponto referente à Figura 5.7. 
Na TABELA 5.2 são apresentados alguns valores do erro relativo médio, desvio padrão, tensão e conjugado nominal para as simulações das cargas quadráticas. Os resultados apresentados pela mesma caracteriza a capacidade de generalização do sistema fuzzy empregado para a estimativa do torque.

TABELA 5.2 - Desempenho do estimador para conjugado quadrático.

\begin{tabular}{|c|c|c|c|}
\hline Tensão & $\begin{array}{c}\text { Conjugado } \\
(\mathrm{Nm})\end{array}$ & $\begin{array}{c}\text { Erro } \\
\text { Médio } \\
(\%)\end{array}$ & $\begin{array}{c}\text { Desvio } \\
\text { Padrão } \\
(\%)\end{array}$ \\
\hline 202 & 1 & 2,12 & 2,62 \\
\hline 206 & 2 & 1,47 & 2,01 \\
\hline 213 & 3 & 0,75 & 1,01 \\
\hline 218 & 4 & 0,52 & 0,81 \\
\hline 225 & 5 & 0,23 & 0,41 \\
\hline 228 & 6 & 0,56 & 1,09 \\
\hline 233 & 1 & 0,84 & 0,83 \\
\hline 236 & 2 & 0,59 & 0,85 \\
\hline 240 & 3 & 0,32 & 0,49 \\
\hline
\end{tabular}

\subsection{Resultados do Sistema Fuzzy na Identificação de Torque de Carga Inversa}

Nesta seção serão apresentados os resultados obtidos pela generalização do sistema fuzzy desenvolvido considerando as cargas com conjugado inverso. Visando tal objetivo, apresentam-se figuras que mostram as curvas de torque estimado com as reais/simuladas. Da mesma forma que foi apresentada para as outras cargas, aqui também será apresentada uma tabela com os erros relativos médios para diversas tensões e conjugados de torque da carga em questão.

A Figura 5.9 mostra o resultado da generalização para uma carga inversa com conjugado inicial em 7,5 $\mathrm{Nm}$ e, em regime permanente, em $5 \mathrm{Nm}$, submetido a uma tensão de 209 Volts. O torque de carga foi estimado com um erro relativo médio 
de $1,29 \%$ com desvio padrão de $5,29 \%$. O objetivo do valor dessa tensão é simular um subtensão no motor de indução para testar o modelo proposto por esse trabalho.

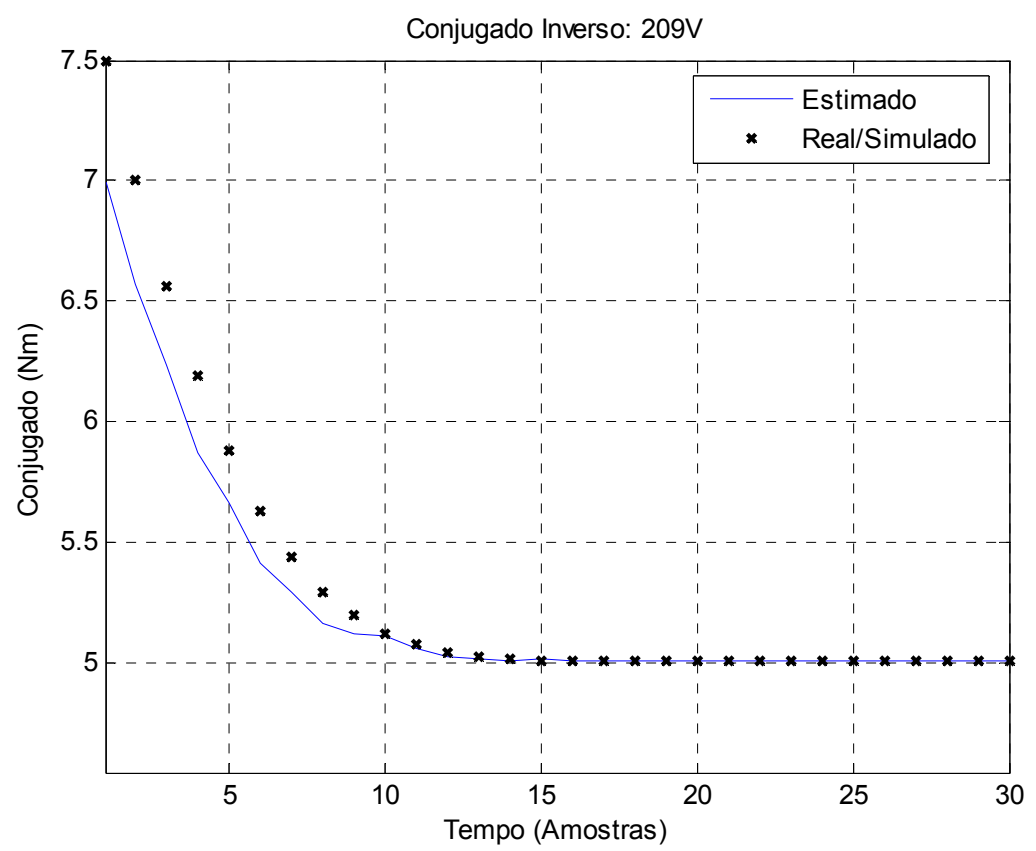

Figura 5.9 - MIT submetido a conjugado resistente inverso alimentado com $209 \mathrm{~V}$.

A Figura 5.10 ilustra o resultado de simulação de uma carga inversa submetida a uma tensão de 220 Volts, que em regime permanente atinge $6 \mathrm{Nm}$. Esta estimativa obteve um erro relativo médio de 1,27\% com um desvio padrão de 1,99\%. A partir de tal simulação, torna-se possível a comparação do sistema entre vários tipos de cargas submetidas ao mesmo motor com os mesmos parâmetros (Figura 5.2, Figura 5.6, Figura 5.10). 


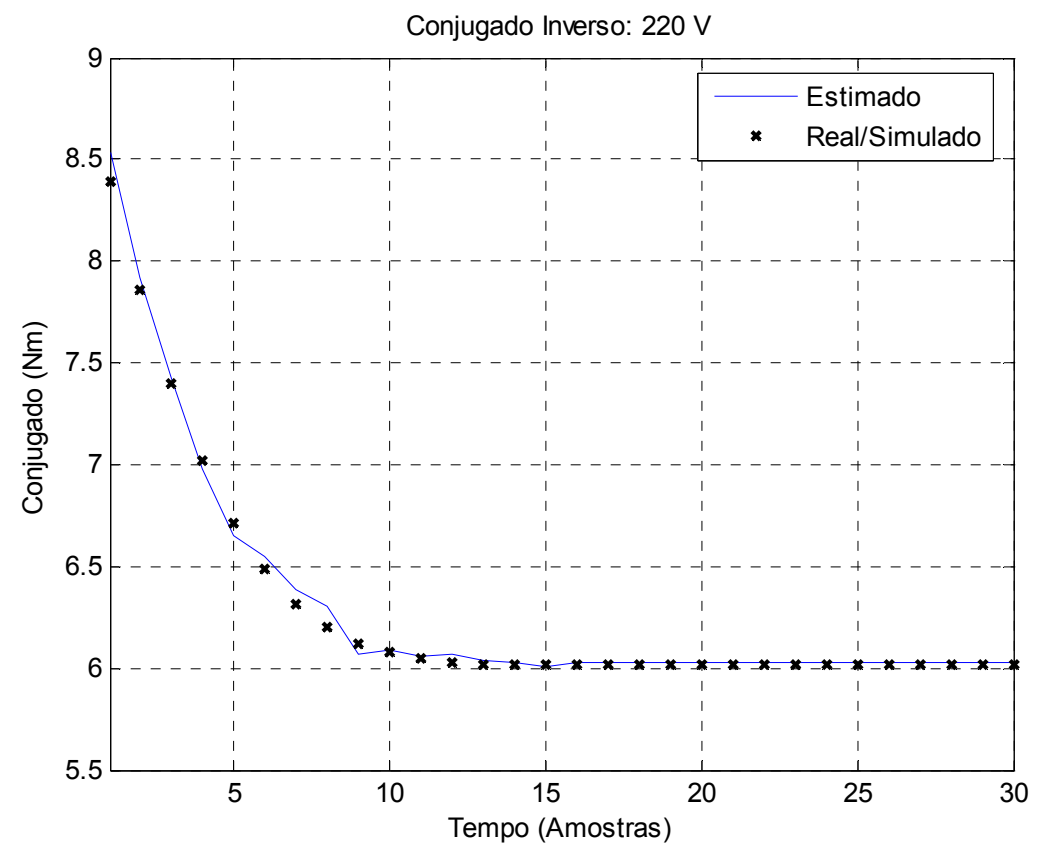

Figura 5.10 - MIT submetido a conjugado resistente inverso alimentado com $220 \mathrm{~V}$.

A Figura 5.11 ilustra os resultados de simulação de uma carga inversa submetida a uma tensão de $230 \mathrm{~V}$, sendo que a mesma em regime permanente atinge um conjugado de $3 \mathrm{Nm}$. $\mathrm{O}$ torque de carga foi estimado com um erro relativo médio de $2,17 \%$ em relação ao torque desejado, tendo um desvio padrão de $3,67 \%$. O motor foi submetido a essa elevada tensão para simular uma sobretensão, sendo então possível analisar o comportamento do estimador proposto. 


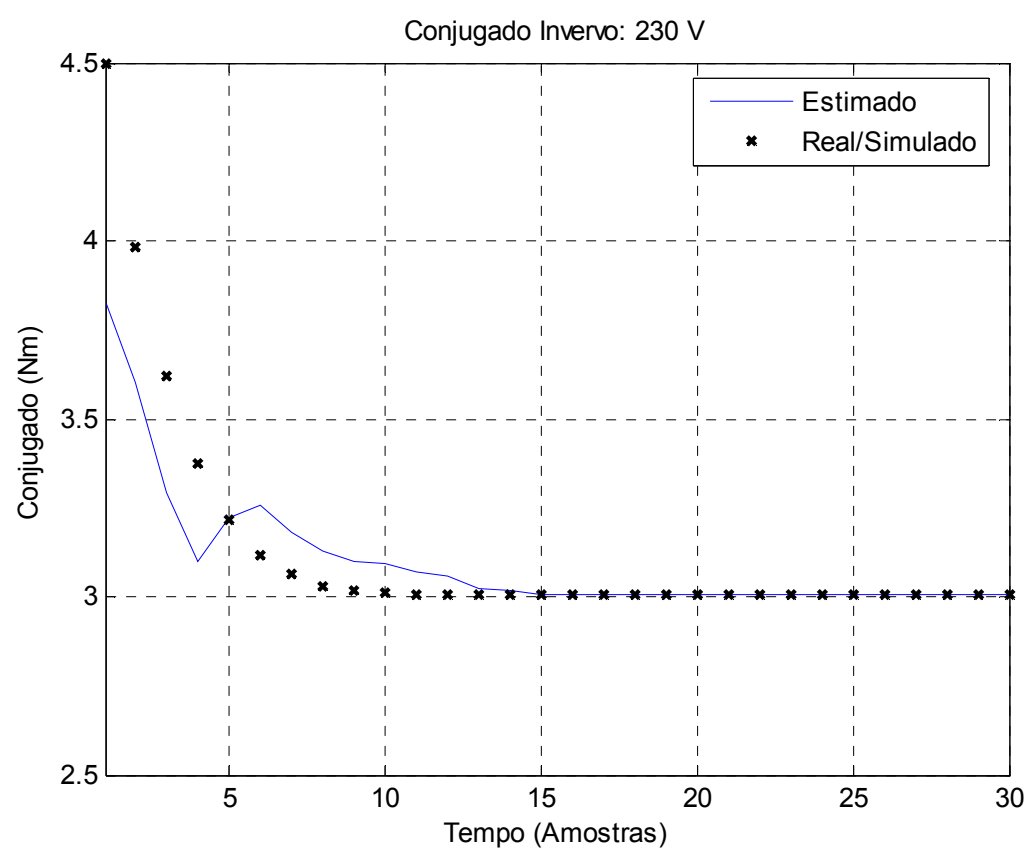

Figura 5.11 - MIT submetido a conjugado resistente inverso alimentado com $230 \mathrm{~V}$.

A Figura 5.12 ilustra o comportamento do erro relativo ponto-a-ponto entre a curva estimada e a curva real/simulada, a qual é ilustrada pela Figura 5.11.

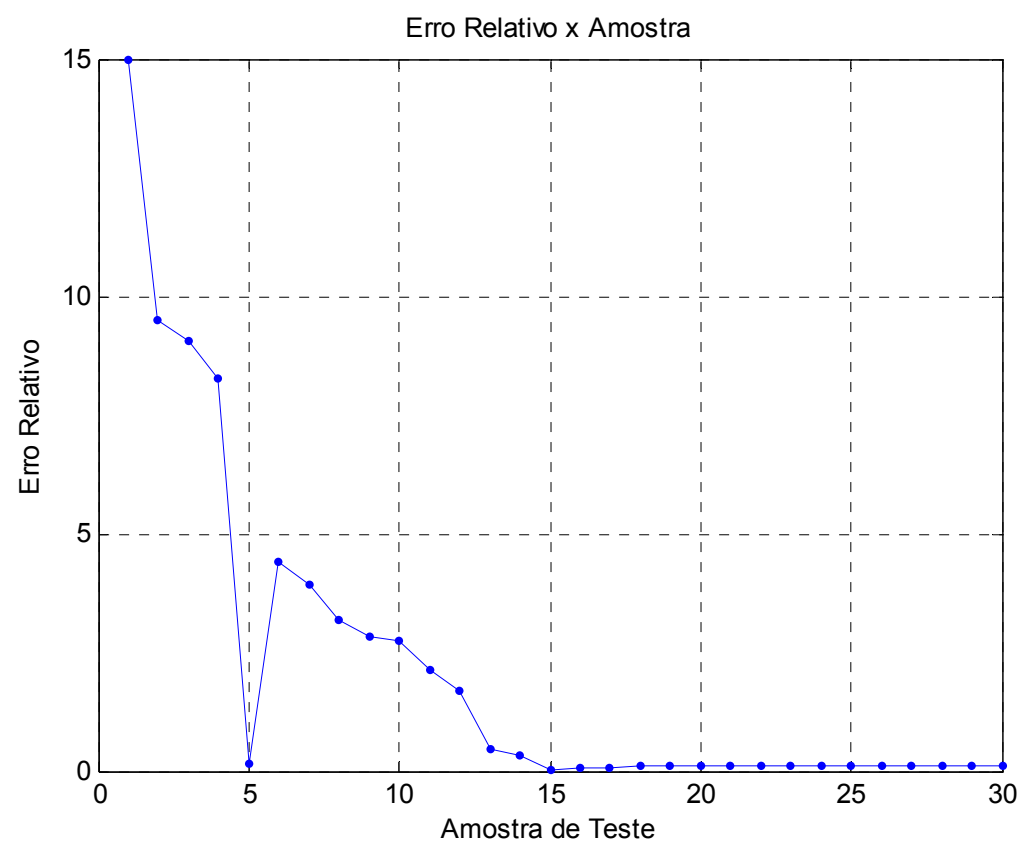

Figura 5.12 - Erro relativo ponto-a-ponto referente à Figura 5.11.

Na TABELA 5.3 são apresentados alguns dos resultados obtidos para a estimativa do conjugado de carga, ilustrando alguns valores do erro relativo médio, 
desvio padrão, tensão e conjugado nominal para as simulações das cargas inversas. No qual a tabela mostra os resultados para a carga considerando do momento da partida até o regime e, a segunda coluna da tabela ilustra o valor do conjugado da carga em regime.

TABELA 5.3 - Desempenho do estimador para conjugado inverso.

\begin{tabular}{|c|c|c|c|}
\hline Tensão & $\begin{array}{c}\text { Conjugado } \\
(\mathrm{Nm})\end{array}$ & $\begin{array}{c}\text { Erro } \\
\text { Médio } \\
(\%)\end{array}$ & $\begin{array}{c}\text { Desvio } \\
\text { Padrão } \\
(\%)\end{array}$ \\
\hline 200 & 2 & 2,28 & 3,15 \\
\hline 210 & 1 & 3,04 & 4,55 \\
\hline 213 & 3 & 1,25 & 2,36 \\
\hline 216 & 4 & 1,48 & 2,57 \\
\hline 220 & 1 & 1,43 & 1,52 \\
\hline 224 & 5 & 1,37 & 3,26 \\
\hline 229 & 6 & 1,49 & 3,20 \\
\hline 233 & 2 & 1,92 & 3,41 \\
\hline 236 & 3 & 1,54 & 3,09 \\
\hline 240 & 4 & 1,71 & 3,08 \\
\hline
\end{tabular}

\subsection{Comparação de Resultados Entre Estratégias Inteligentes}

Nesta seção serão apresentadas algumas tabelas comparando os resultados obtidos entre a estratégia fuzzy abordada por este trabalho e a estratégia abordada pelo trabalho [2], no qual utilizou redes neurais artificiais para a estimativa do conjugado de carga. Ambos os trabalhos utilizam as mesmas variáveis de entrada aos seus sistemas. Assim, na TABELA 5.4, apresenta-se os resultados calculados pela abordagem fuzzy desenvolvida aqui e aqueles obtidos pela abordagem neural proposto em [2], considerando a mesma faixa de tensão (220V) e mesmo conjugado para a carga linear. Os dados foram gerados pelo mesmo modelo 
matemático do motor de indução, onde são mostrados os resultados para os conjugados que variam entre $1 \mathrm{Nm}$ e $6 \mathrm{Nm}$.

TABELA 5.4 - Comparação de resultados entre sistemas inteligentes para a carga linear.

\begin{tabular}{|c|c|c|c|c|}
\hline \multirow{2}{*}{$\begin{array}{c}\text { Valor do } \\
\text { conjugado } \\
(\text { Nm) }\end{array}$} & \multicolumn{2}{|c|}{$\begin{array}{c}\text { Sistema Fuzzy } \\
\text { (abordado neste trabalho) }\end{array}$} & \multicolumn{2}{c|}{$\begin{array}{c}\text { Redes neurais artificiais } \\
\text { (abordado por [2]) }\end{array}$} \\
\cline { 2 - 5 } & $\begin{array}{c}\text { Erro Médio } \\
(\%)\end{array}$ & $\begin{array}{c}\text { Desvio Padrão } \\
(\%)\end{array}$ & $\begin{array}{c}\text { Erro Médio } \\
(\%)\end{array}$ & $\begin{array}{c}\text { Desvio padrão } \\
(\%)\end{array}$ \\
\hline 1 & 6,79 & 12.50 & 12,77 & 22,74 \\
\hline 2 & 3,12 & 5,95 & 6,44 & 18,48 \\
\hline 3 & 1,25 & 2,92 & 3,98 & 8,88 \\
\hline 4 & 0,69 & 1,12 & 6,91 & 7.56 \\
\hline 5 & 0,73 & 1,17 & 2,20 & 5,38 \\
\hline 6 & 0,81 & 2,22 & 3,18 & 8,21 \\
\hline
\end{tabular}

A TABELA 5.5 ilustra os resultados da comparação para as cargas quadráticas, respeitando as mesmas características citadas para a tabela anterior.

TABELA 5.5 - Comparação de resultados entre sistemas inteligentes para a carga quadrática.

\begin{tabular}{|c|c|c|c|c|}
\hline \multirow{2}{*}{$\begin{array}{c}\text { Valor do } \\
\text { conjugado } \\
(\text { Nm) }\end{array}$} & \multicolumn{2}{|c|}{$\begin{array}{c}\text { Sistema Fuzzy } \\
\text { (abordado neste trabalho) }\end{array}$} & \multicolumn{2}{c|}{$\begin{array}{c}\text { Redes neurais artificiais } \\
\text { (abordado por [2]) }\end{array}$} \\
\cline { 2 - 5 } & $\begin{array}{c}\text { Erro Médio } \\
(\%)\end{array}$ & $\begin{array}{c}\text { Desvio Padrão } \\
(\%)\end{array}$ & $\begin{array}{c}\text { Erro Médio } \\
(\%)\end{array}$ & $\begin{array}{c}\text { Desvio padrão } \\
(\%)\end{array}$ \\
\hline 1 & 2,46 & 3,01 & 9,17 & 13,07 \\
\hline 2 & 1,09 & 1,66 & 5,08 & 7,16 \\
\hline 3 & 0,83 & 1,46 & 5,80 & 10,31 \\
\hline 4 & 1,07 & 1,79 & 9,60 & 9,17 \\
\hline 5 & 1,08 & 2,41 & 4,69 & 6,95 \\
\hline 6 & 1,29 & 2,93 & 4,94 & 9,65 \\
\hline
\end{tabular}


Na TABELA 5.6 são apresentados os resultados da comparação para as cargas inversas, respeitando as mesmas características adotadas para as tabelas anteriores.

TABELA 5.6 - Comparação de resultados entre sistemas inteligentes para a carga inversa.

\begin{tabular}{|c|c|c|c|c|}
\hline \multirow{2}{*}{$\begin{array}{c}\text { Valor do } \\
\text { conjugado } \\
(\mathrm{Nm})\end{array}$} & \multicolumn{2}{|c|}{$\begin{array}{c}\text { Sistema Fuzzy } \\
\text { (abordado neste trabalho) }\end{array}$} & \multicolumn{2}{|c|}{$\begin{array}{r}\text { Redes neurais artificiais } \\
\text { (abordado por [2]) }\end{array}$} \\
\cline { 2 - 5 } & $\begin{array}{c}\text { Erro Médio } \\
(\%)\end{array}$ & $\begin{array}{c}\text { Desvio Padrão } \\
(\%)\end{array}$ & $\begin{array}{c}\text { Erro Médio } \\
(\%)\end{array}$ & $\begin{array}{c}\text { Desvio padrão } \\
(\%)\end{array}$ \\
\hline 1 & 1,43 & 1,52 & 3,14 & 3,27 \\
\hline 2 & 1,40 & 2,64 & 1,19 & 1,47 \\
\hline 3 & 1,96 & 3,69 & 0,81 & 1,11 \\
\hline 4 & 1,22 & 2,50 & 0,51 & 0,71 \\
\hline 5 & 1,40 & 2,46 & 0,39 & 0,45 \\
\hline 6 & 1,27 & 1,99 & 0,26 & 0,24 \\
\hline
\end{tabular}

De acordo com esses resultados ilustrados pelas tabelas anteriores, pode-se notar que o sistema de inferência fuzzy obteve melhores resultados em relação às redes neurais artificiais (RNA) para as cargas lineares e quadráticas. Entretanto, as RNAs obtiveram melhores resultados para a carga inversa.

É valido salientar que os valores de conjugados das tabelas apresentadas nessa seção ilustram o valor em regime para cada carga. Portanto, para cada carga são mostradas 6 curvas de torque em $\mathrm{Nm}$, como se pode observar na primeira coluna de cada tabela. 



\section{Conclusões Gerais e Trabalhos Futuros}

\subsection{Conclusões Gerais}

Este trabalho apresentou uma técnica baseada na utilização de sistemas de inferência fuzzy para estimativa de conjugado resistente aplicado nos motores de indução. Por intermédio desse modelo foi possível desenvolver uma estrutura computacional capaz de estimar o comportamento de conjugado de motores em processos industriais, a partir de sinais de tensão, corrente e velocidade.

O modelo proposto pode ser usado como uma alternativa aos métodos tradicionais para levantamento do comportamento de carga e, em processo de controle, onde há a necessidade de conhecimento do comportamento do conjugado aplicado ao eixo do motor.

Os resultados de simulação confirmaram que é possível estimar de forma bem satisfatória o conjugado exigido no eixo de um motor de indução trifásico usando um sistema de inferência fuzzy composto por 9 funções de pertinência em suas variáveis de entrada.

A metodologia proposta também apresentou, após o ajuste do sistema de inferência fuzzy, um menor esforço computacional do que a resolução de sistemas de equações diferenciais que definem o comportamento do motor, pois o relacionamento das entradas em relação à saída se resume a uma matriz formada a partir dos valores discretizados dos universos de discurso das respectivas entradas.

Sobre os resultados obtidos, torna-se de grande valia destacar o desempenho da metodologia abordada neste trabalho frente às redes neurais. De 
acordo com as tabelas ilustradas na Seção 5.5 se observou uma melhora na estimativa de torque de carga.

Em relação às ressalvas da técnica proposta, além das cargas aqui abordadas, pretendia-se analisar as cargas constantes, mas devido às suas características de comportamento, observou-se que a metodologia utilizada para as demais cargas não se aplica para esse tipo de carga em particular. Portanto, para a estimativa de torque de cargas constantes, deve-se investigar uma outra metodologia que consiga mapear adequadamente o comportamento das mesmas a partir de sinais de tensão, corrente e velocidade.

\subsection{Trabalhos Futuros}

Como trabalhos futuros, pode-se destacar o aperfeiçoamento do modelo proposto para outros tipos de cargas, incluindo na estrutura do mesmo eventuais ajustes advindos de testes práticos em laboratório.

Para trabalhos futuros podem-se considerar as variações térmicas, efeito pelicular e saturação da máquina, pois neste trabalho o modelo utilizado não levam em conta essas variáveis.

Ainda como trabalhos futuros, têm-se a implementação em hardware do sistema fuzzy desenvolvido, visando a confecção de um dispositivo compacto que possa ser utilizado para estimar em tempo real o torque de carga em motores de indução. 


\section{Referências Bibliográficas}

[1] EletrobRAS, "Ministerio de Minas e Energia, PROCEL - Programa de Conservaçao de energia elétrica ": http://www.eletrobras.com/elb/main.asp?ViewlD=\%7BDCF9673F-50BA-4F2D9BB7-DB4D6E31A44C\%7D\#, acessado em 30 de Janeiro de 2007.

[2] A. Goedtel, Estimativa de Conjugado de Carga Aplicado em Eixos de Motores de Indução Trifásico Através de Redes Neurais Artificiais. Mestrado em Engenharia Inustrial - Bauru: UNESP, 2003.

[3] Y. El-Ibiary, "An accurate low-cost method for determining electric' efficiency for the purpose of plant energy management," IEEE Transactions on Industry Applications, vol. 39, pp. 1205-1210, 2003.

[4] P. Vas, Artificial Intelligence Based Electrical Machines and Drives: Oxford University Press, 1999.

[5] I. Barbi, Teoria Fundamental do Motor de Indução: Editora da UFSC, 1985.

[6] B. K. Bose, Power Electronics and Variable Frequency Drives: Technology and Applications, 1996.

[7] A. E. Fitzgerald, Maquinas Elétricas: McGRAW - HILL do BRASIL LTDA, 1975.

[8] F. P. Speggiorin, Instrumentação Digital Aplicada ao Desenvolvimento de Controladores para Motores de Indução. Porto Alegre: UFRGS, 1998.

[9] C.-M. Ong, Dynamic Simulation of Electric Machinery Using Matlab/Simulink: Prentice Hall, 1997.

[10] J. Monteiro, J. Palma, and G. D. Marques, "Using Simplefied Observers in Torque of an Induction Machine Without Speed Sensor," $11^{\text {th }}$ IMEKO TC-4 Symposium - Trends in Electrical Measurement and Instrumentation and $6^{\text {th }}$ Euro Workshop on ADC Modelling and Testing, pp. 140-144, 2001.

[11] D. T. Vincent, Fundamentos de Máquinas Elétricas: Rio de Janeiro: PrenticeHall do Brasil, 1994.

[12] I. L. Kosov, Máquinas Elétricas e Transformadores: Porto Alegre: Globo, 1986.

[13] E. Avolio, Uma Contribuição Para o Estudo do Comportamento Térmico e Elétrico do Motor de Indução. Tese de Doutorado. Universidade Estual de Campinas (UNICAMPIFEEC), Brasil, 1992.

[14] P. C. Sen, Principles of Electric Machines and Power Electronics: New York: Wiley, 1989. 
[15] O. S. Lobosco and J. L. P. d. C. Dias, Seleção e Aplicação de Motores Elétricos: McGraw-Hill: Siemens, 1988.

[16] R. R. Yager and D. P.filev, Essentials of Fuzzy Modeling and Control. Canada: John Wiley \& Sons, Inc., 1994.

[17] L. C. Jain, "Guest editorial special section on fusion os neural nets, fuzzy systems and genetic algorithms in industrial applications," Industrial Electronics, IEEE Transactions on, vol. 46, pp. 1049-1050, 1999.

[18] B. Kosko, Fuzzy Engineering: Pretice-Hall, 1997.

[19] W. Pedrycz and F. Gomide, An Introduction to Fuzzy Sets: MIT Press, 1998.

[20] H. Ying, Fuzzy Control and Modeling: John Wiley, 2000.

[21] T. J. Ross, Fuzzy Logic with Engineering Applications: John Wiley, 2004.

[22] J.-S. R. Jang, C.-T.Sun, and E.Mizutani, Neuro-Fuzzy and Soft Computing: PRENTICE-HALL, 1997.

[23] M.Vasudevan, Dr.R.Arumugam, and S.Paramasivam, "Adaptive neuro-fuzzy inference system modeling of an induction motor," The Fifth International Conference on Power Electronics and Drive Systems, vol. 1, pp. 427-432, 2003.

[24] ZhixiongHou, QuntaiShen, and HeqingLi, "Nonlinear system identification based on ANFIS," in IEEE Int. Conf. Neural Networks \& Signal Processing, vol. 1, 2003, pp. 510-512.

[25] M. Vasudevan and R.Arumugam, "A robust torque control of induction motor for electric vehicle applications using ANFIS," TENCON IEEE Region 10 Conference, vol. 4, pp. 17-20, 2004.

[26] B.Kosko and L.X.Wang, "Fuzzy system are Universal approximators," IEEE Transactions on Computers, vol. 43, pp. 1329-1333, 1994.

[27] M.Sugeno and T.Yasukawa, "A Fuzzy-Logic-based approach to Qualitative Modeling," IEEE Transactions on Fuzzy Systems, vol. 1, pp. 7-31, 1993.

[28] F.Barreto, E.Galvan, A.Torralba, and L.G.Franquelo, "Novel Fuzzy-Logic Based Torque Estimator," The 25th Annual Conference of the IEEE, vol. 3, pp. 1259-1264, 1999.

[29] S.Mir, M.E.Elbuluk, and D.S.Zinger, "PI and Fuzzy Estimators for Tuning the Stator Resistance in Direct Torque Control of Induction Machines," IEEE Transactions on Power Electronics, vol. 13, pp. 279-287, 1998.

[30] B.K.Bose and N.R.Patel, "Quasi-Fuzzy Estimation of Stator Resistance of Induction Motor," IEEE Transactions on Power Electronics, vol. 13, pp. 401409, 1998.

[31] J. J. F. Cerqueira, A. Oliveira, A. S. Rebouças, and V. R. V. Rodeiro, "Metodologia para Estimação de Torque em Motores de Induçao Polifásicos," Congresso Brasileiro de Automática, pp. 2927-2932, 2006. 
[32] R.D.Lorenz, T.A.Lipo, and D.W.Novotny, "Motion Control With Induction Motors," Proceeding of the IEEE, vol. 82, pp. 1215-1240, 1994.

[33] K.Ohnishi, N.Matsui, and Y.Hori, "Estimation, Identification and Sensorless Control in Motion Control," Proceedings of the IEEE, vol. 82, pp. 1253-1265, 1994.

[34] M. Barut, S. Bogosyan, and M. Gokasan, "Speed sensorless direct torque control of IMs with rotor resistance entimation," Energy Conversion and Management, pp. 335-349, 2004.

[35] B.Grcar, P.Cafuta, G.Stumberger, and A.M.Stankovic, "New IM torque control with implicit rotor field tracking and efficiency maximization," The 8th IEEE International Workshop on Advanced Motion Control, pp. 59-64, 2004.

[36] J.Holtz and T.Thimm, "Identification of the machine parameters in a vectorcontrolled induction motor drive," IEEE Transactions on Industry Applications, vol. 27, pp. 1111-1118, 1991.

[37] S.A.Kalilah, "Improved torque and speed estimation in sensorless induction motor drive," 39th International Universities Power Engineering Conference, vol. 2, pp. 538-544, 2004.

[38] B. Lu, T. G. Habetler, and R. G. Harley, "A Survey of Efficiency-Estimation Methods for In-Service Induction Motors," IEEE Transactions on Industry Applications, vol. 42, pp. 924-933, 2006.

[39] J.Hsu and B.P.Scoggins, "Field test of motor efficiency and load changes through air-gap torque," IEEE Transactions on Energy Conversion, vol. 10, pp. 477-483, 1995.

[40] B.Lu, T.G.Habetler, and R.G.Harley, "A Survey of efficiency-estimation methods for in-service induction motors with considerations of condition monitoring requirements," IEEE International Conference on Electric Machines and Drives, pp. 1365-1372, 2006.

[41] M.-F. Tsai and Y.-Y. Tzou, "A Transputer-Based Adaptive Speed Controller for AC Induction Motor Drives with Load Torque Estimation," IEEE Transactions on Industry Applications, vol. 33, pp. 558-566, 1997.

[42] M.Ghanes, J. D. Leon, and A.Glumineau, "Validation of an interconnected high-gain observer for a sensorless induction motor against a low frequency benchmark: application to an experimental setup," IEE Proceedings Control Theory and Applications, vol. 152, pp. 371-378, 2005.

[43] ASSOCIAÇÃO BRASILEIRA DE NORMAS TÉCNICAS. NBR 7094: Máquinas Elétricas Girantes - Motores de Indução - Especificação. Rio de Janeiro, 1996. 



\section{Apêndice $A$}

\section{Toolbox Fuzzy Logic}

Esta dissertação utilizou o toolbox Fuzzy Logic do Matlab. Tal toolbox consiste de uma coleção de funções construídas sobre o ambiente do Matlab, permintindo assim uma maneira fácil de criar e editar sistemas de inferência fuzzy dentro do framework do Matlab, além da possibilidade de programas escritos em linguagem $\mathrm{C}$ executar funções construídas dentro do Matlab.

Para se utilizar um sistema de inferência fuzzy, este não necessita já estar modelado completamente. Mesmo possuindo somente um conjunto de dados quantitativos é possível criar um sistema de inferência fuzzy. Uma possível abordagem para criar tal sistema de inferência é denominada ANFIS (Adaptive Neuro-Fuzzy Inference System). O ANFIS será detalhado na Seção A.2.

O ambiente do Matlab, além de gerar um sistema fuzzy, se permite visualizar e, até mesmo, ajustar ("refinar") tal sistema. Tendo então esta necessidade, se pode utilizar o a ferramenta do Matlab conhecida como toolbox Fuzzy Logic. A Seção A.1 será responsável pela explanação deste toolbox.

É importante ressaltar que a compilação deste apêndice é toda baseado no guia de usuário (user's guide) do Matlab, sendo que o mesmo apresenta de forma bem didática todos os principais aspectos envolvidos com o toolbox Fuzzy Logic. 


\section{A.1 Toolbox Fuzzy Logic do Matlab}

O toolbox Fuzzy Logic do Matlab consiste de seis componentes. Além do editor ANFIS, o qual será detalhado na Seção A.2, possui ainda os editores: de regras (Rule Editor), o editor das funções de pertinência (Membership Function Editor) e o editor de Sistema de Inferência Fuzzy (FIS - Fuzzy Inference System). Acrescenta-se ainda neste toolbox os visualizadores de regras (Rule Viewer) e superfície (Surface Viewer). A Figura A.1 evidencia a visualização de um esquema mostrando os componentes constituintes do toolbox Fuzzy Logic do Matlab. Neste esquema, somente adiciona-se o editor ANFIS. A seguir será discutido, brevemente, cada um destes componentes.

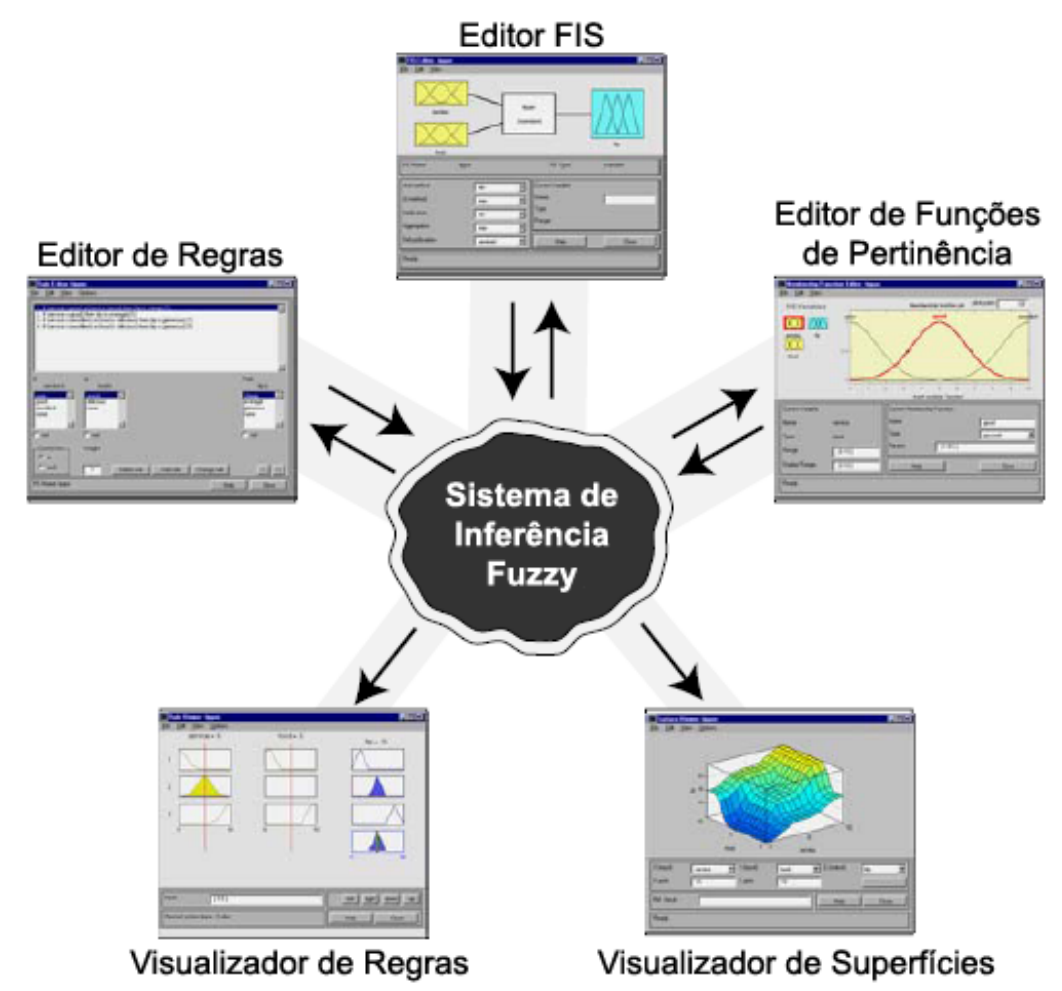

Figura A.1 - Esquema dos componentes constituintes do Toolbox Fuzzy Logic do Matlab. 
O primeiro componente a ser abordado é o editor FIS. É finalidade deste editor ilustrar as informações, de forma resumida, referente a um sitema de inferência fuzzy, por exemplo, um sistema fuzzy construído a partir da técnica ANFIS. Ou seja, o ANFIS ajusta as funções de pertinência e, também, cria as regras de tal sistema. Assim, por intermédio deste editor se consegue visualizar o sistema gerado a partir da técnica ANFIS. Para se obter a tela do editor FIS, basta digitar o comando "fuzzy" na janela de comandos no Matlab. Após a execução deste comando, torna-se possível visualizar a ilustração da Figura A.2, a qual consiste na sua tela inicial.

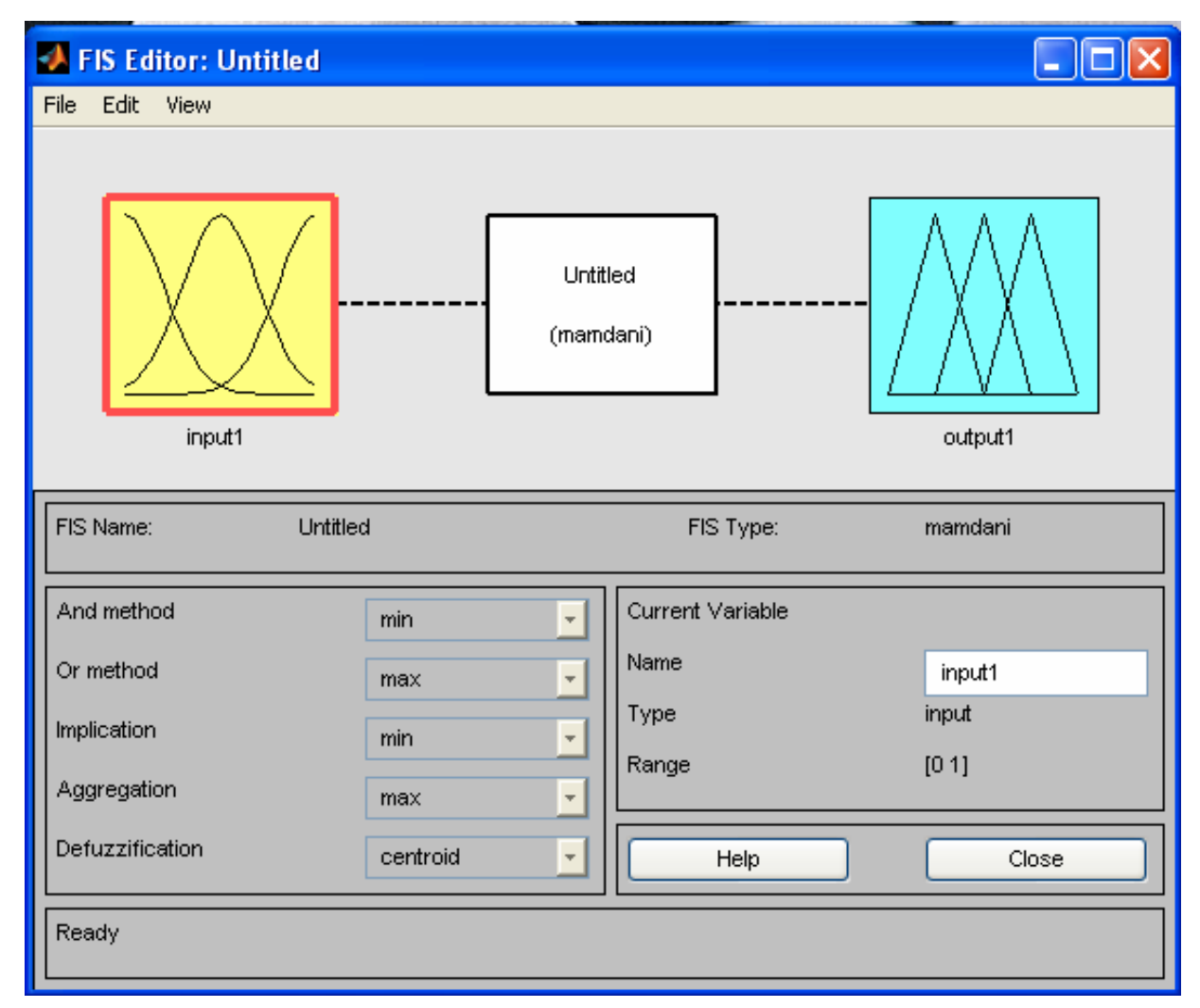

Figura A.2 - Tela inicial do editor FIS.

Para se obter a visualização de um sistema de inferência fuzzy, basta abrir o arquivo FIS referente ao mesmo. O arquivo FIS contém todas as informações de um 
sistema fuzzy, sendo que o editor FIS apenas mostra o conteúdo deste arquivo de uma maneira mais interativa.

Torna-se possível, através do editor de funções de pertinência, gerenciar os atributos das funções de pertinência do sitema fuzzy, ou seja, permite editar e visualizar todas suas características. A Figura A.3 exibe a tela inicial deste editor, mostrando uma das funções de pertinência usada na aplicação desta dissertação.

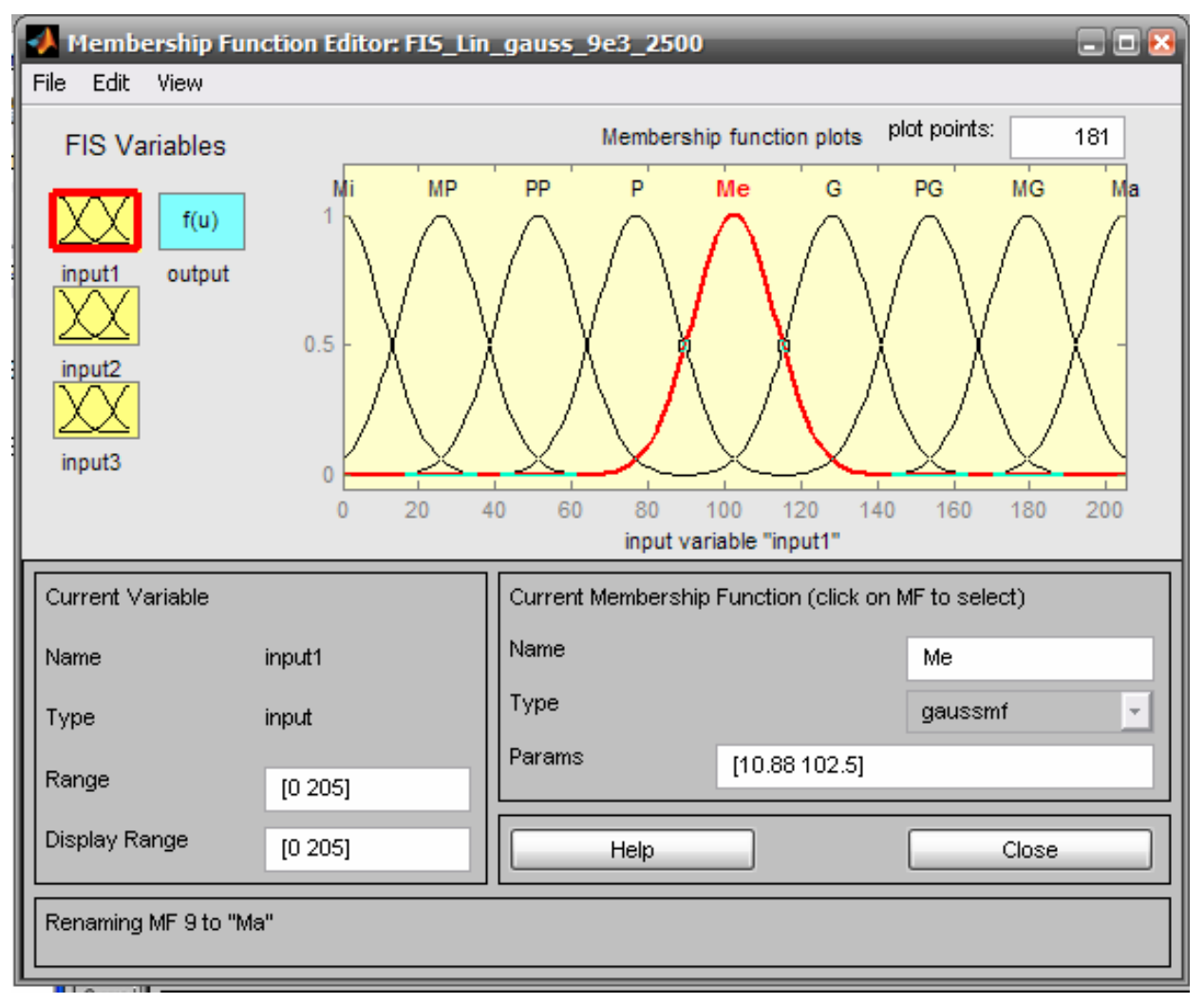

Figura A.3 - Tela inicial do editor das funções de pertinência.

Já o editor de regras tem como finalidade proporcionar um fácil ambiente para trabalhar com as regras do sistema fuzzy, permitindo construir, modificar, deletar e ignorar regras. Assim sendo, a Figura A.4 ilustra a tela do editor contendo as regras do sistema fuzzy proposto com três entradas. 


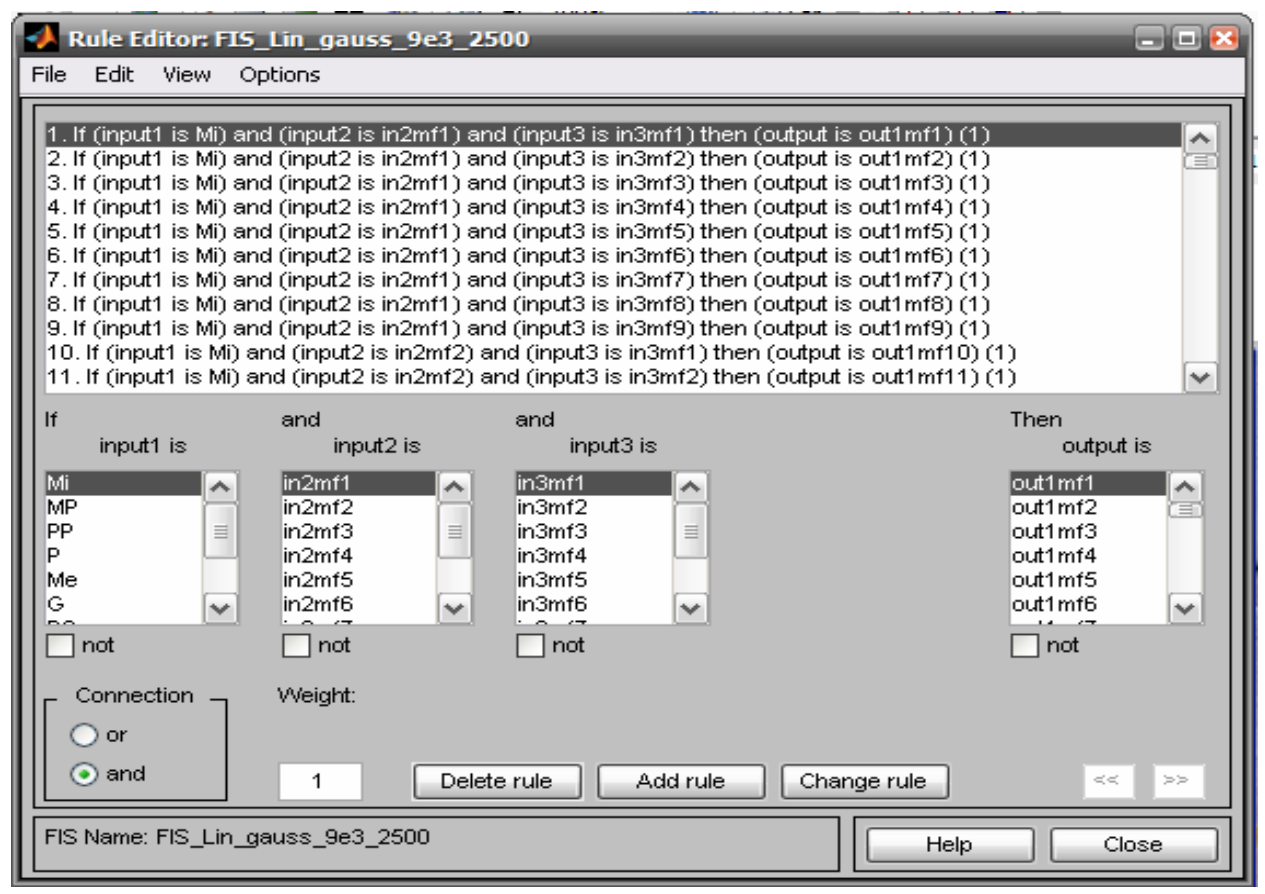

Figura A.4 - Editor de regras ilustrando regras de um sistema com três entradas.

Para visualizar as regras do sistema fuzzy, recorre-se ao componente do toolbox Fuzzy Logic conhecido como visualizador de regras. Assim sendo, a Figura A.5 permite visualizar as regras, as quais foram determinadas no editor de regras Fuzzy descrito anteriormente.

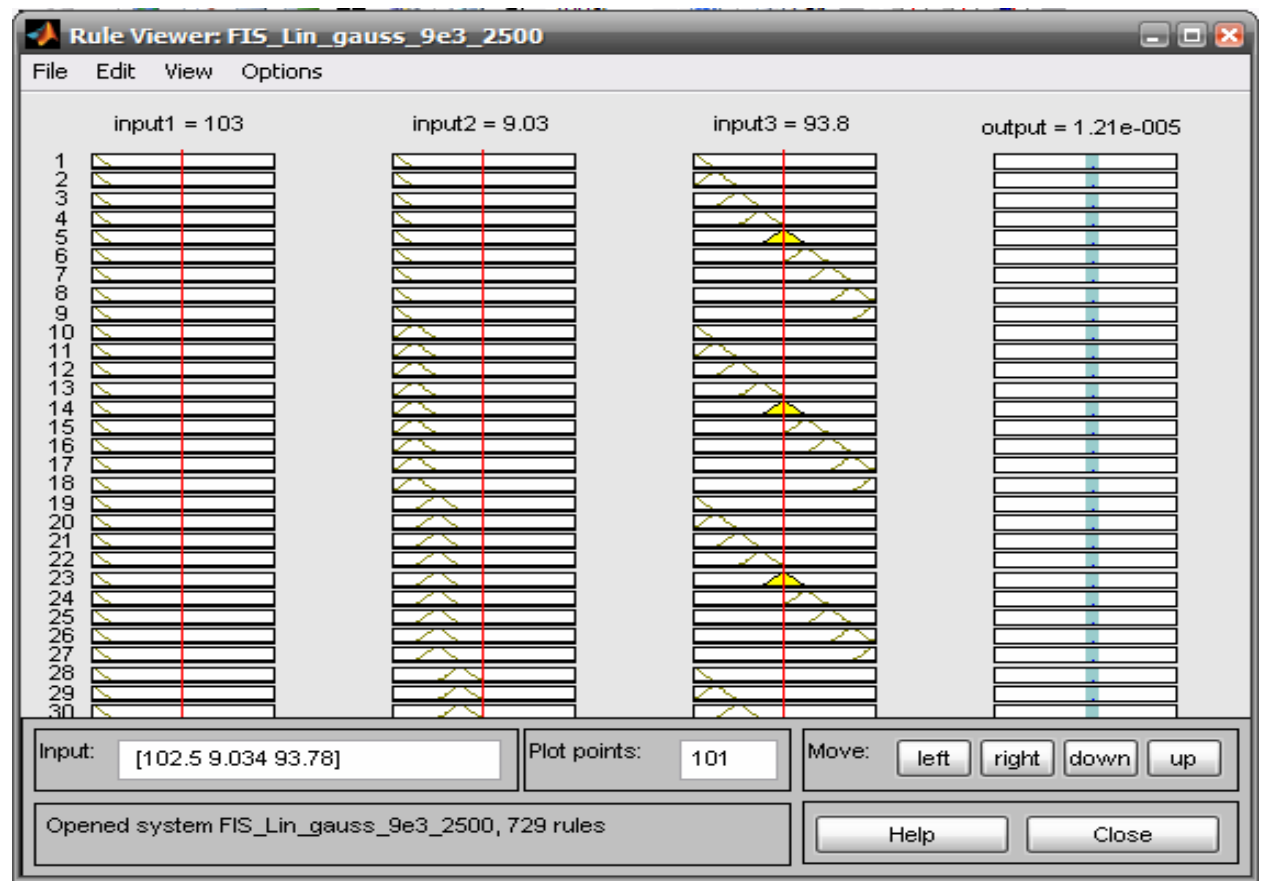

Figura A.5 - Visualização das regras de um sistema proposto com três entradas. 
Por fim, o toolbox Fuzzy Logic do Matlab possui o componente para visualizar as superfícies de saída do sistema. Este visualizador tem como objetivo criar uma curva tridimensional de saída visando representar o mapeamento das entradas do sistema fuzzy. Para os sistemas com mais de duas entradas e uma saída, como apresentado nesta dissertação, por exemplo, o visualizador consegue gerar uma superfície de saída tridimensional, pois os monitores dos computadores são incapazes de plotar uma superfície com cinco dimensões. Portanto, o visualizador permite que selecione duas das entradas e as demais serão consideradas como constante. Para ilustrar a tela desse visualizador, esta será apresentada juntamente com uma das superfícies de saída do sistema fuzzy usada nesta dissertação. Assim, a Figura A.6 evidencia o referido visualizador.

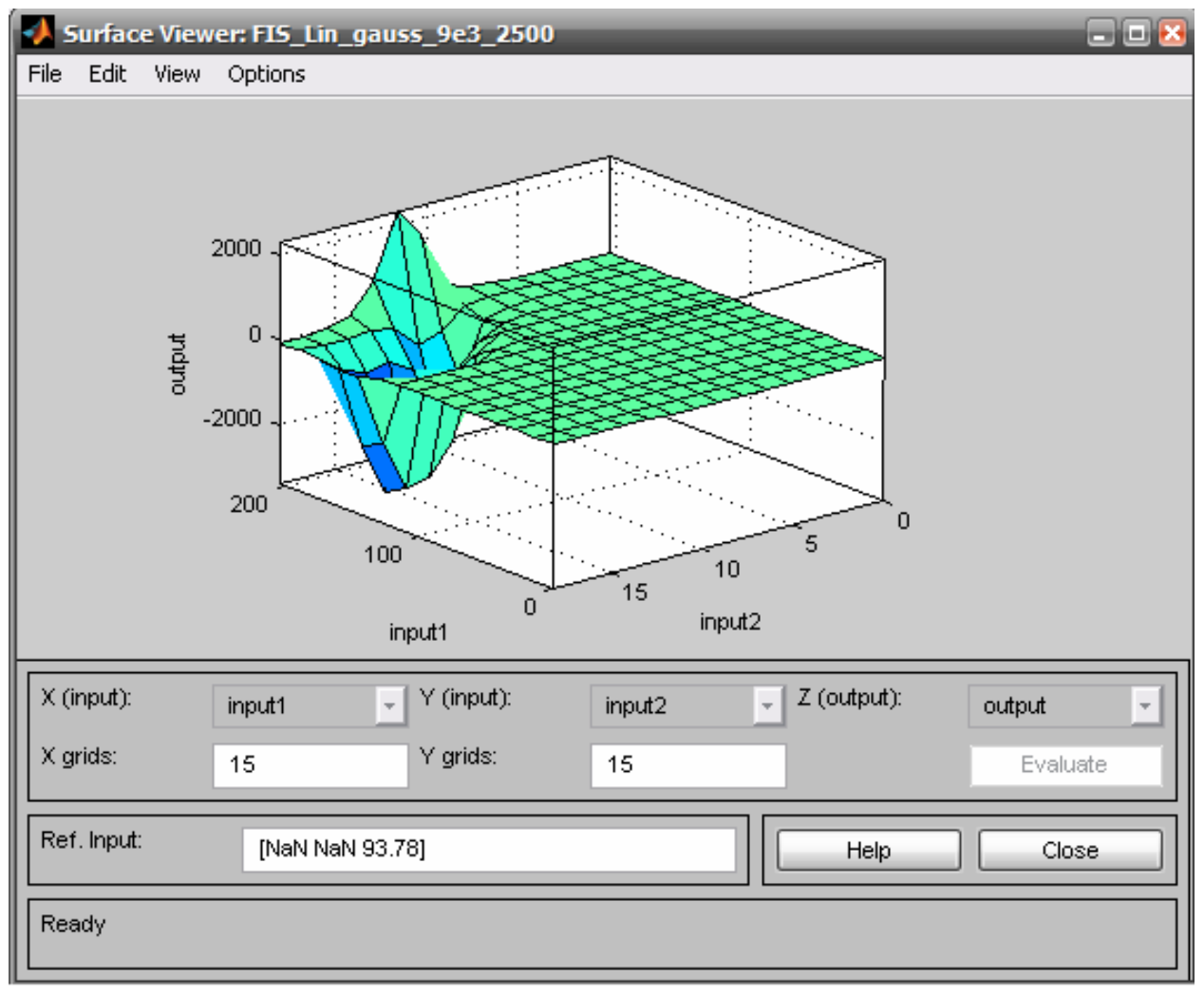

Figura A.6 - Visualizador de superfícies. 


\section{A.2 Técnica ANFIS}

Torna-se possível, mesmo contendo somente dados quantitativos, modelar um sistema de inferência fuzzy. O ANFIS consiste de uma das possíveis técnicas para tal procedimento, além de que é bem simples sua utilização. Assim sendo, investigar sua aplicabilidade evidencia uma tarefa extremamente relevante quando seus dados são disponibilizados da forma quantitativa e houver a necessidade de se gerar um sistema de inferência fuzzy.

Com um conjunto de dados quantitativos contendo as entradas e sua respectiva saída desejada, é possível obter um sistema de inferência fuzzy já ajustado com suas funções de pertinência e regras. Sendo assim, pode-se afirmar que as regras e as funções de pertinência foram geradas de forma automática.

Para se utilizar a técnica ANFIS no Matlab há duas maneiras: Primeira, através de uma interface gráfica conhecida como editor GUI (Ghaphical User Interface) e, a segunda, através de linha de comando. Ressalta-se que a primeira possibilidade é uma maneira interativa; porém, para se conseguir flexibilidade há também a necessidade de utilizar o ANFIS por linha de comando. Portanto, decidir qual das abordagens se deve utilizar dependerá, antes de tudo, da experiência e necessidade do usuário.

Nos próximos parágrafos será detalhará a abordagem do ANFIS por linha de comando, pois a utilização do mesmo via GUI já foi explanado na Seção 3.3.1.

Entende-se ANFIS por linha de comando a possibilidade de executar e parametrizar a sua estrutura fuzzy da mesma forma que o editor GUI permite. Contudo, tem-se aqui a flexibilidade de trabalhar diretamente com os comandos que são executados pelo editor. 
O primeiro comando, o genfis1, inicia o processo de treinamento gerando as funções de pertinência iniciais e cobrindo todo o espaço de busca. Este comando recebe como parâmetro de entrada três valores, sendo respectivamente: o arquivo com os dados quantitativos de entradas e sua respectiva saída, o número de funções de pertinência e, por último, o tipo de função de pertinência.

Já o comando anfis tem a finalidade de ajustar as funções de pertinência geradas inicialmente pelo comando genfis1. A quantidade de parâmetros recebidos são seis e são, respectivamente, os dados de entrada, a saída gerada pelo comando genfis1, as opções de treinamento (épocas, tolerância, etc), tratamento das mensagens durante e após o processo de treinamento (este parâmetro só existe por linha de comando) e, finalmente, o método (algoritmo) de treinamento que será utilizado. 


\section{Apêndice $B$}

Modelo do MIT usado para as simulações

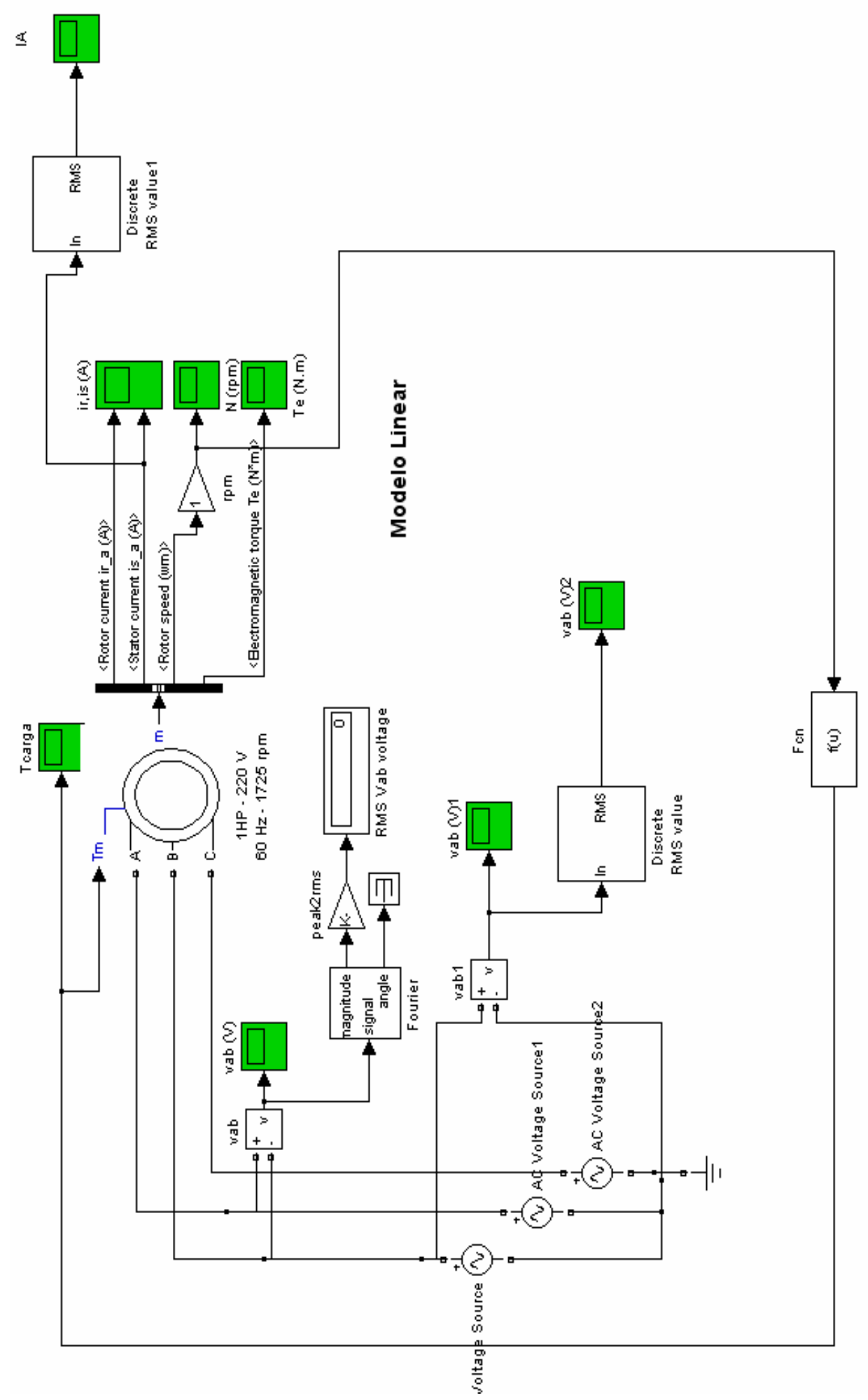

